\title{
Rad52 mediates class-switch DNA recombination to IgD
}

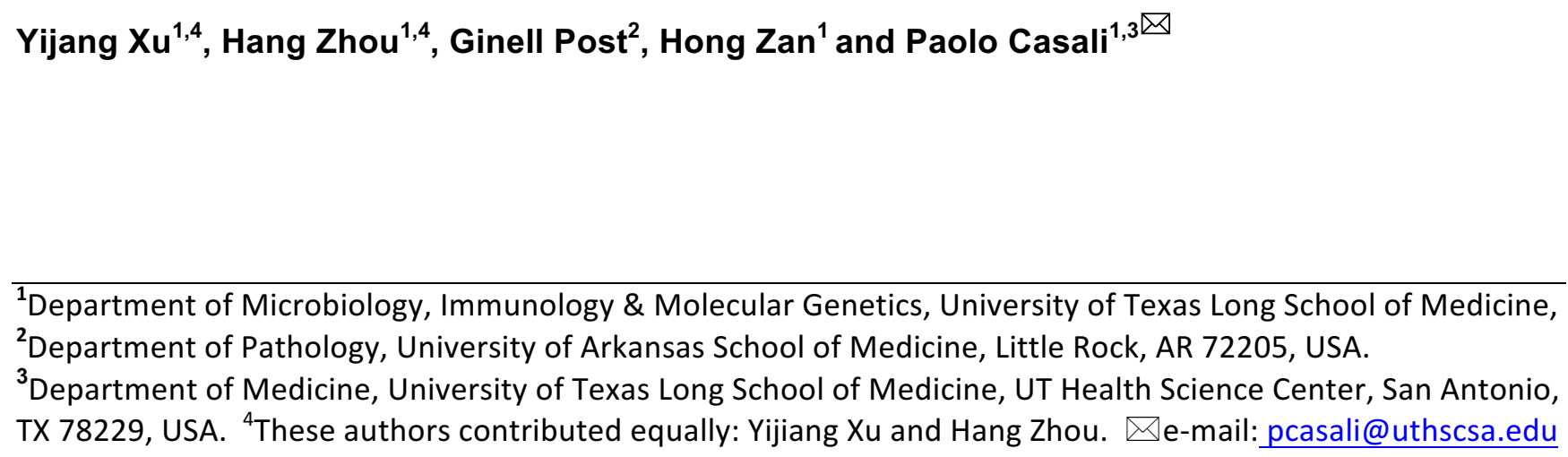


While the biology of IgD begins to be better understood, the mechanism of expression of this phylogenetically old and highly conserved Ig remains unknown. In B cells, IgD is expressed together with IgM as transmembrane receptor for antigen through alternative splicing of long primary $V_{H} D J_{H}-C \mu-s-m-C \delta-s-m$ RNAs, which also underpin secreted (s)IgD. IgD is also expressed through class switch DNA recombination (CSR), as initiated by AID-mediated double-strand DNA breaks (DSBs) in $S \mu$ and $\sigma \delta$, and resolution of such DSBs by a still unknown mechanism. This synapses $S \mu$ with $\sigma \delta$ region DSB resected ends leading to insertion of extensive S-S junction microhomologies, unlike Ku70/Ku86-dependent NHEJ which resolves DSB blunt ends in CSR to IgG, IgA and IgE with little or no microhomologies. Our previous demonstration of a novel role of Rad52 in a Ku70/Ku86-independent "short-range" microhomology-mediated synapsis of intra-S $\mu$ region DSBs led us to hypothesize that this homologous recombination DNA annealing factor is also involved in short-range microhomology-mediated alternative endjoining (A-EJ) recombination of $S \mu$ with $\sigma \delta$. We found that induction of IgD CSR by selected stimuli downregulated Zfp318 (the suppressor of $C \mu$-s- $m$ transcription termination), promoted Rad52 phosphorylation and Rad52 recruitment to $S \mu$ and $\sigma \delta$, leading to $S \mu-\sigma \delta$ recombination with extensive microhomologies, $V_{H} D J_{H}-C \delta$ s transcription and sustained IgD secretion. Rad52 ablation in mouse $\operatorname{Rad}^{2} 2^{-/-} \mathrm{B}$ cells aborted IgD CSR in vitro and in vivo and dampened the specific IgD antibody response to OVA. Further, Rad52 knockdown in human B cells virtually abrogated IgD CSR. Finally, Rad52 phosphorylation was associated with high levels of IgD CSR and anti-nuclear IgD autoantibodies in lupus-prone mice and lupus patients. Thus, Rad52 effects CSR to IgD through microhomology-mediated A-EJ and in concert with Zfp318 modulation. This is a previously unrecognized, critical and dedicated role of Rad52 in mammalian DNA repair that provides a mechanistic underpinning to CSR A-EJ. 
IgD has been an enigmatic antibody class for many years, despite being evolutionarily ancient and highly conserved across species $^{1-6}$. As primordial as $\operatorname{IgM}, \operatorname{IgD}$ appeared in cartilaginous fishes, amphibians and occurs in fishes, rodents, cattle and humans ${ }^{2,7}$. As an example, in Xenopus, the Ig $\delta$ exon cluster is in the same position, immediately $3^{\prime}$ of the Ig $\mu$ locus, as it exists in mammals ${ }^{7}$. In mice and humans, $\operatorname{IgD}$ is expressed primarily as a transmembrane IgD receptor together with IgM with identical antigen specificity on naïve mature B cells in the form of BCR. IgD also exists as a secreted antibody. In humans, circulating $\operatorname{IgD}$ occurs at concentrations up to more than two-thousand folds greater than $\operatorname{IgE}(10-250 \mu \mathrm{g} / \mathrm{ml}$ vs. $\sim 0.1 \mu \mathrm{g} / \mathrm{ml})$, the rarest peripheral blood Ig class. $\mathrm{IgD}$ are secreted by $\operatorname{IgM}^{-} \operatorname{IgD}^{+}$plasmablasts and plasma cells differentiated from B cells in lymphoepithelial organs in aerodigestive mucosae, including palatine and pharyngeal tonsils. $\operatorname{IgM}^{-} \operatorname{IgD}{ }^{+} \mathrm{B}$ cells and plasma cells can also be found in the lachrymal, salivary and mammary glands ${ }^{3}$. In addition to existing as free molecule, IgD can occurs on the surface of innate effector cells, including basophils, mast cells and monocytes ${ }^{1,8,9}$. IgD bound to these cells would enhance immune surveillance and exert proinflammatory and antimicrobial effects ${ }^{1,8,9}$. These include triggering basophils to secret IL-4, IL-5 and IL-13 upon antigen engagement or attenuating basophil or mast cell allergic degranulation induced by $\operatorname{IgE}$ co-engagement ${ }^{1}$. Thus, $\operatorname{IgD}$ would contribute to mucosal homeostasis by endowing effector cells with reactivity to microbial commensals and pathogens ${ }^{5,6}$.

Identifying the stimuli and molecular mechanisms that underpin $\operatorname{IgD}$ expression is important to understand the regulation of $\operatorname{IgD}$ secretion throughout the body. The immediately proximal location and unique integration of $\mathrm{C} \delta$ and $\mathrm{C} \mu$ gene loci in the same transcriptional unit allow these two Ig isotypes to be coordinately regulated in transcription $^{10,11}$. In naive mature $\mathrm{B}$ cells, (membrane) $\mathrm{mIgM}$ and $\mathrm{mIgD}$ are co-expressed by alternative splicing of long primary transcripts consisting of rearranged $\mathrm{V}_{\mathrm{H}} \mathrm{DJ}_{\mathrm{H}}$ exons and downstream $\mathrm{C} \mu$ and $\mathrm{C} \delta$ exons $\left(V_{H} D J_{H^{-}} C \mu-\right.$ $s-m-C \delta-s-m)$. Alternative splicing of the same long primary $V_{H} D J_{H^{-}} C \mu-s-m-C \delta-s-m$ transcripts also leads to expression of (secreted) $\mathrm{sIgM}$ and $\mathrm{sIgD}^{2,8}$. Transcription of long primary $V_{H} D J_{H^{-}} C \mu-s-m-C \delta-s-m$ RNA requires the zinc finger ZFP318 repressor of transcriptional termination, which obliterates the effect of the transcriptional termination sites (TTS) intercalated between the $\mathrm{C} \mu$ and $\mathrm{C} \delta$ exon clusters ${ }^{10,11}$ (Fig. 1a). IgD can also be expressed through class switch DNA recombination (CSR), by which $\operatorname{IgM}^{+} \operatorname{IgD}^{+} \mathrm{B}$ cells juxtapose $V_{H} D J_{H}$ DNA from the $\mathrm{C} \mu$ (IgM) to the $\mathrm{C} \delta(\mathrm{IgD})$ exons cluster, giving rise to $V_{H} D J_{H^{-}} C \delta m \mathrm{RNA}$ transcripts and $\operatorname{IgM}^{-} \operatorname{IgD}^{+} \mathrm{B}$ cells ${ }^{1,5,8,9,12}$ (Fig. 1b). In human and mouse nasopharyngeal and intestinal lymphoid tissues, a significant proportion of mucosal B cells class-switch to $\operatorname{IgM}^{-} \operatorname{IgD}^{+} \mathrm{B}$ cells, which subsequentially differentiate to plasmablasts and plasma cells $\mathrm{s}^{1,3,5,6}$. Generally, CSR to $\operatorname{IgD}(\mathrm{C} \delta)$ is a less frequent event than CSR to $\operatorname{IgG}(\mathrm{C} \gamma), \operatorname{IgA}(\mathrm{C} \alpha)$ or $\operatorname{IgE}(\mathrm{C} \varepsilon)$, perhaps a reflection among other factors of the peculiar structure of the pseudo-switch $\sigma \delta$ region lying immediately upstream of $\mathrm{C} \delta$ exons. Compared to the canonical $\mathrm{S} \mu, \mathrm{S} \gamma, \mathrm{S} \alpha$ and $\mathrm{S} \varepsilon$ regions lying 5' of the respective Ig $\mu, \operatorname{Ig} \gamma, \operatorname{Ig} \alpha$ and Ig $\varepsilon$ loci, $\sigma \delta$ is shorter and contain differing motifs of nucleotide (nt) repeats ${ }^{2,5,8,13,14}$. These would provide an unconventional substrate for AID-mediated insertion of DSBs, possibly more prone to end-resection and generation of single-strand overhangs for $\mathrm{S} \mu-\sigma \delta$ recombination, which leads to expression of post-recombination $V_{H} D J_{H^{-}} C \delta$ RNA transcripts ${ }^{2,8,13-15}$.

Unlike CSR to IgG, IgA and IgE, the mechanism of CSR to IgD remains unknown. Recombination involving $\mathrm{S} \mu \mathrm{DSB}$ ends with DSB ends in downstream $\mathrm{S} \mu, \mathrm{S} \gamma, \mathrm{S} \alpha$ or $\mathrm{S} \varepsilon$ region is effected by non-homologous end-joining 
(NHEJ), one of the two major DNA DSB repair pathways, the other being homologous recombination (HR) ${ }^{16,17}$. HR accurately repairs resected (staggered) DSB ends using a sister chromatid as a homologous single-strand template during cell cycle S-G2. It critically effects error-free DSB repair in somatic cells and helps orchestrate chromosome segregation in meiosis. In contrast to HR, NHEJ is a homology-independent error-prone process. It synapses blunt or virtually blunt DSB ends that lack substantial joining complementarity to form "direct" junctions, predominantly in G1 but also throughout the whole cell cycle ${ }^{16}$. NHEJ requires Ku70/Ku86 and in CSR mediates efficient long-range synapses of $\mathrm{S} \mu \mathrm{DSB}$ ends with $\mathrm{S} \gamma, \mathrm{S} \alpha$ and $\mathrm{S} \varepsilon \mathrm{DSB}$ ends, leading to $\operatorname{IgG}, \operatorname{IgA}$ and $\operatorname{IgE}{ }^{15}$. The finding, however, that reduction or deletion of $\mathrm{Ku} 70 / \mathrm{Ku} 86$ led to reduced but still substantial CSR to IgG1 and IgG3 supported the existence of an alternative CSR end-joining (A-EJ) pathway ${ }^{18-20}$. This, like HR, would join resected DSB ends, thereby giving rise to S-S junctions with microhomologies. Unlike HR, however, the A-EJ pathway juxtaposes DSB overhangs to be joined without using a homologous template as a guide. Rather, it utilizes differing extents of sequence complementarity (homology) between the upstream and downstream resected DSB overhangs to align the to-be DNA junctions ${ }^{21}$. As we have shown, HR factor Rad52 competes with $\mathrm{Ku}$ 70/Ku86 for binding to $\mathrm{S}$ region DSB ends and synapses DSB ends by A-EJ through microhomology-mediated end-joining $(\mathrm{MMEJ})^{20}$, as inferred from increased NHEJ-mediated IgG, IgA and IgE CSR events with even fewer

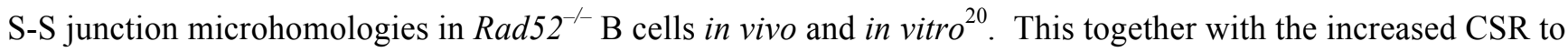
IgD in B cells lacking 53BP1, which protects S regions DSB ends from resection and facilitates long-range NHEJ to $\mathrm{IgG}$, IgA and $\mathrm{IgE}^{22-24}$, as well as other findings of ours showing reduced intra-S $\mu$ DSB short-range rejoining in $\operatorname{Rad}_{52} 2^{--} \mathrm{B}$ cells ${ }^{20}$ led us to hypothesize that by annealing to single-strand resected DSB ends, Rad52 mediates CSR to IgD through A-EJ involving short-range $\mathrm{S} \mu-\sigma \delta \mathrm{DSB}$ recombination.

To test the hypothesis that Rad52 synapses $\mathrm{S} \mu$ with $\sigma \delta$ DSB ends for IgD CSR, we first set up to define the stimuli that consistently induce CSR to IgD in mouse and human B cells. We then used such stimuli in mouse Rad52// B cells and RAD52 siRNA knockdown human B cells together with molecular genetic methods to determine the impact of Rad52 deficiency as well as Rad52 phosphorylation on $S \mu-\sigma \delta$ DNA recombination and IgD expression. We validated our findings by analyzing specific IgD antibody and total IgD titers in mouse blood, lungs and gut, as well as recombined $\mathrm{S} \mu-\sigma \delta$ DNA sequences in mouse spleen, mesenteric lymph nodes (MLNs) and Peyer's patches as well as human tonsil B cells. We adapted chromatin immunoprecipitation (ChIP) assays to analyze the recruitment of $\operatorname{Rad52/RAD52}$ to the $\sigma \delta$ region in mouse and human B cells induced to undergo CSR to IgD, in which we also analyzed regulation of $V_{H} D J_{H^{-}} C \delta$ transcription. We found that different stimuli induced IgD expression by alternative splicing of long $V_{H} D J_{H^{-}} C \mu-s-m-C \delta-s-m$ RNA transcripts or by $S \mu-\sigma \delta$ CSR. Further, we determined the expression of IgD by CSR to be related to Zfp318-mediated repression of the TTS integrated in $\mathrm{C} \mu-\mathrm{C} \delta$ loci. We also correlated $\mathrm{S} \mu-\sigma \delta \mathrm{CSR}$ with IgD secretion and plasma cell differentiation. Finally, we analyzed B cell Rad52 phosphorylation in lupus patients and lupus-prone mice and correlated it with CSR to IgD involving extensive microhomologies and somatic mutations in $\mathrm{S} \mu-\sigma \delta$ junctional sequences, as well as the occurrence of high levels of anti-nuclear antigen IgD autoantibodies. Our findings show that Rad52 mediates CSR to IgD through microhomology-mediated A-EJ and in concert with Zfp318 modulation. This is a previously unrecognized, critical and dedicated role of Rad52 in an essential DNA repair process in mammals. 
Rad52 mediates CSR to IgD

\section{Results}

Definition of stimuli that induce $S \mu-\sigma \delta$ CSR in mouse and human B cells. Toward testing our hypothesis that Rad52 mediates CSR to $\operatorname{IgD}$, we first determined the stimuli that induce $\operatorname{IgM}^{+} \operatorname{IgD}{ }^{+}$B cells to undergo $\mathrm{S} \mu-\sigma \delta$ recombination. In these $\mathrm{B}$ cells, $\mathrm{mIgD}$ and $\mathrm{sIgD}$ and $\operatorname{IgM}$ are expressed by alternative splicing of long primary $V_{H} D J_{H^{-}} C \mu-s-m-C \delta-s-m$ mRNAs - the $\mathrm{C} \delta$ locus is located immediately downstream of the $\mathrm{C} \mu$ locus in the same transcriptional unit, allowing these two loci be coordinately regulated at the transcriptional level ${ }^{1,2,4,6}$ (Fig. 1a). As CSR can be induced in a T-dependent or T-independent antibody fashion ${ }^{15,25}$, we used CD40 ligand CD154 (for mouse and human B cells), TLR4 ligand LPS (mouse B cells) and TLR9 ligand CpG (human B cells) in conjunction with differing cytokines and/or BCR-cross-linking to induced CSR to IgD. Recombined $S \mu-\sigma \delta, S \mu-$ $S \gamma 1, S \mu-S \gamma 3, S \mu-S \alpha$ and $S \mu-S \varepsilon$ DNAs were detected by specific nested PCRs followed by positive identification of amplified DNA by blotting and hybridization with specific DNA probes (Fig. 1 inset), complemented by sequencing of the junctional $\mathrm{S} \mu-\sigma \delta$ or $\mathrm{S} \mu-\mathrm{S}_{\mathrm{X}}$ DNA. Of all stimuli used, only LPS or CD154 plus IL-4 induced CSR to IgD in mouse B cells (Fig. 2a), and only CpG plus IL-2 and IL-21, or CD154 plus IL-4 or IL-15 and IL21 induced CSR to IgD in human B cells. IgD CSR was also detected in vivo in tonsil B cells (Fig. 2b). The effectiveness of the stimuli that did not induce CSR to $\operatorname{IgD}$ was verified by the respective induction of the expected $\mathrm{S} \mu-\mathrm{S} \gamma 1, \mathrm{~S} \mu-\mathrm{S} \gamma 3, \mathrm{~S} \mu-\mathrm{S} \alpha$ or $\mathrm{S} \mu-\mathrm{S} \varepsilon$ DNA recombination. (IgG1, IgG3, IgA or IgE) (Fig. 2a) - no CSR to IgD, IgG, $\operatorname{Ig} \mathrm{A}$ or $\operatorname{IgE}$ occurred in $\mathrm{Aicda}^{-/-} \mathrm{B}$ cells. In all cases, CSR was further confirmed by detection of postrecombination $I \mu-C \gamma 1, I \mu-C \gamma 3, I \mu-C \alpha$ and $I \mu-C \varepsilon$ transcripts at $72 \mathrm{~h}$ of culture - as post-recombination $I \mu-$ $\mathrm{C} \delta$ transcripts are indistinguishable from germline $\mid \mu-\mathrm{C} \delta s-\mathrm{m}$ RNA transcripts and consistent with high levels of the latter in naïve B cells, I $\mu-\mathrm{C} \delta$ amplification products were less abundant in class-switched IgD than naïve B cells (Figs. 1, 2c). Thus, only select stimuli induce CSR to IgD in mouse and human B cells.

\section{$S \mu-\sigma \delta$ junctions are enriched in microhomologies and abetted by somatic mutations in mouse and human}

B cells. The mechanisms effecting CSR S-S synapses can leave a S-S junctional signature ${ }^{20,26}$. As we previously showed, Rad52 mediates A-EJ of resected DSB ends by juxtaposing overhangs with nucleotide complementarities, thereby giving rise to $\mathrm{S} \mu$-Sx DNA junctions with microhomologies ${ }^{20}$. Next generation sequencing of more than 100,000 recombined $\mathrm{S} \mu$-Sx DNA junctions from mouse and human B cells in vitro and/or in vivo showed that $\mathrm{S} \mu-\sigma \delta$ junctions contained significantly more microhomologies $(p<0.01)$ than $\mathrm{S} \mu-\mathrm{S} \gamma 1$ or $\mathrm{S} \mu-\mathrm{S} \alpha \mathrm{DNA}$ junctions (representative frequencies and lengths of microhomologies in human and mouse B cells are depicted in Fig. 3a; representative human and mouse intra- $\sigma \delta$ and junctional $\mathrm{S} \mu-\mathrm{Sx}$ sequences are depicted in Fig. 4 and Extended Data Figs. 1,2), indicating that a $\mathrm{MMEJ}^{21}$ synaptic process underpinned $\mathrm{S} \mu-\sigma \delta$ junction formation. In both human and mouse B cells, the microhomologies in $\mathrm{S} \mu-\sigma \delta$ junctions were significantly more extensive than those in $\mathrm{S} \mu-$ $\mathrm{S} \gamma 1$ and, to a lesser extent, $\mathrm{S} \mu-\mathrm{S} \alpha$ junctions (Fig. 4, Extended Data Figs. 1,2). As one example, in human tonsil B cells, $100 \%$ of analyzed $S \mu-\sigma \delta$ junctions contained microhomologies, consisting of 2 to 13 nucleotides (mean $=6.30$ ), while only $21 \%$ of $S \mu-S \gamma 1$ junctions contained microhomologies, consisting of 1 to 6 nucleotides (mean $=0.72$ ) (Fig. 3a). Interestingly, there were a few common S-S sequences shared by recombined $\mathrm{S} \mu-\sigma \delta$ DNA junctions in human tonsil B cells and blood naïve B cells stimulated in vitro by CpG plus IL-2 and IL-21, suggesting that $\mathrm{S} \mu$ and $\sigma \delta \mathrm{DSB}$ hotspots underpin $\mathrm{S} \mu-\sigma \delta$ in DNA recombinations. A high frequency of 
microhomologies was also evident in the synaptic repair process of intra- $\sigma \delta$ DSBs, evocative of what we showed in intra-S $\mu \mathrm{DSBs}^{20}$. Consistent with the greatest occurrence of microhomologies in $\mathrm{S} \mu-\sigma \delta$ junctions, $\mathrm{S} \mu$ is better suited for complementary DNA single-strand annealing with $\sigma \delta$ than $\mathrm{S} \gamma 1$ or, to a lesser extent, $\mathrm{S} \alpha$ (mouse) or S $\alpha 1$ (human), based on various numbers and contexts of these DNA regions discrete motifs, such as $\left[\mathrm{G}_{\mathrm{n}}\right]$ AGCT repeats ( $\mathrm{S} \mu, \mathrm{S} \gamma$ and $\mathrm{S} \alpha$ ) or AGCTGAGCTG repeats ( $\mathrm{S} \mu$ and $\sigma \delta$ ), as revealed by Pustell Matrix dot-plot analysis (Fig. 3b). Finally, $\mathrm{S} \mu-\sigma \delta$ DNA junctions were associated with somatic point-mutations. These were more frequent in the $\sigma \delta$ area than $\mathrm{S} \mu$ area abetting the $\mathrm{S} \mu-\sigma \delta$ junction (e.g., $0.559 \times 10^{-2}$ vs. $0.973 \times 10^{-2}$ change/base in mouse spleen $\mathrm{B}$ cells in vivo and $1.251 \times 10^{-2}$ vs. $1.985 \times 10^{-2}$ change/base in mouse B cells stimulated by LPS plus IL-4 in vitro) (Fig. 3c). Thus, the high frequency of microhomologies in $S \mu-\sigma \delta$ junctions supports a role of $\operatorname{Rad} 52$ in mediating CSR to IgD.

$174 \operatorname{Rad} 52$ is critically required for $\mathbf{S} \boldsymbol{\mu}-\boldsymbol{\sigma} \boldsymbol{\delta}$ recombination. Having established that LPS or CD154 pus IL-4 induced $175 \mathrm{CSR}$ to IgD in mouse $\mathrm{B}$ cells, we used these stimuli and $\mathrm{Rad} 52^{-/} \mathrm{B}$ cells together with appropriate controls (LPS alone, LPS plus TGF- $\beta$ and RA, CD154 or CD154 plus TGF- $\beta$ and RA) and the same approach used in the experiments of Fig. 2 to investigate whether or not Rad52 was required for CSR to IgD. LPS plus IL-4 and $\mathrm{CD} 154$ plus IL-4 failed to induce $\mathrm{S} \mu-\sigma \delta$ recombination in $R a d 52^{-/-}$B cells, while either treatment efficiently induced $\mathrm{S} \mu-\mathrm{S} \gamma 1$ and $\mathrm{S} \mu-\mathrm{S} \varepsilon$ recombinations in the same $\operatorname{Rad} 52^{-/-} \mathrm{B}$ cells, and $\mathrm{S} \mu-\sigma \delta$ recombination in $\operatorname{Rad} 52^{+/+} \mathrm{B}$ cells (Fig. 5a) - in Rad52 $2^{--}$B cells, LPS and LPS or CD154 plus TGF- $\beta$ and RA induced CSR to IgG3 and IgA, respectively. As expected, CSR to $\operatorname{IgD}$ as well as $\operatorname{IgG}, \operatorname{IgA}$ and $\operatorname{IgE}$ was ablated in $\mathrm{Aicda}^{-/} \mathrm{B}$ cells. Finally, the failure of $\operatorname{Rad} 52^{-/}$B cells to undergo CSR to $\operatorname{IgD}$ was associated with significantly decreased secretion of $\operatorname{IgD}$ (Fig. 5b). Thus, $\operatorname{Rad} 52$ is critical for $\mathrm{S} \mu-\sigma \delta$ DNA recombination and seemingly important for IgD secretion.

Rad52 is required to mount a specific IgD antibody response. We determined the role of Rad52 in supporting a specific IgD antibody response by immunizing $\operatorname{Rad}_{52^{-/}}$and $\operatorname{Rad} 52^{+/+}$mice with OVA $(20 \mu \mathrm{g}$ in alum, i.p., 3 times). Rad52 $2^{--}$mice showed no $\mathrm{S} \mu-\sigma \delta$ recombination in spleen, mesenteric lymph nodes (MLNs) or Peyer's patch B cells (Fig. 6a). The lack of CSR to IgD was specific, as B cells in such mice showed $\mathrm{S} \mu-\mathrm{S} \gamma 1$ and $\mathrm{S} \mu-$ $\mathrm{S} \alpha$ DNA recombinations as B cells in $R a d 52^{+/+}$mice, which also underwent $\mathrm{S} \mu-\sigma \delta$ recombination. In $\operatorname{Rad} 52^{-/}$ mice, $\mathrm{S} \mu-\mathrm{S} \gamma 1$ and $\mathrm{S} \mu-\mathrm{S} \alpha \mathrm{DNA}$ junctions showed fewer and shorter microhomologies than in Rad $52^{+/+}$mice (Fig. 6b, Extended Data Figs. 2,3), a reflection of involvement of Rad52 in CSR to isotypes other than IgD ${ }^{20}$. Rad $^{2} 2^{-}$ mice showed significantly decreased total and/or OVA-specific IgD in circulating blood, bronchoalveolar lavage (BALF), feces (free or bound to fecal bacteria), and IgD-producing cells in MLNs and lamina propria, as compared to their $\operatorname{Rad} 52^{+/+}$counterparts (Fig. 6c-h). This contrasted with the normal or elevated total and OVA-specific $\operatorname{IgM}, \operatorname{IgG} 1$ and IgA levels in the same $\operatorname{Rad}_{52^{--}}$mice, as predicted based on our previous findings ${ }^{27}$. Thus, $\operatorname{Rad} 52$ is required to mount an efficient antigen-specific class-switched IgD response. analyzed $\mathrm{Rad52}, \mathrm{Ku} 70, \mathrm{Ku} 86$ and Aicda transcripts as well as respective Rad52, Ku70, Ku86 and AID proteins, including phosphorylated Rad52 (p-Rad52 has been shown to display enhanced ssDNA annealing activity ${ }^{28}$ ), in B cells induced to undergo CSR to IgD. Mouse B cells stimulated by LPS plus IL-4 and human B cells stimulated 
Rad52 mediates CSR to IgD

by CD154 plus IL-4 and IL-21 increased $K u 70 / K u 86$ and Ku70/Ku86 expression at $24-48 \mathrm{~h}$ concomitant with significantly greater expression of Aicda and AID, which was nearly undetectable at time 0 , while somewhat downregulating Rad52 and Rad52. Rad52 protein, however, was progressively phosphorylated within the same time range (Fig. 7a-c). Further supporting its role in CSR to IgD, Rad52 was recruited to $\mathrm{S} \mu, \sigma \delta$ (and $\mathrm{S} \gamma 1$ ) in $\mathrm{B}$ cells stimulated by LPS plus IL-4, which induced $\mathrm{S} \mu-\sigma \delta$ (and $\mathrm{S} \mu-\mathrm{S} \gamma 1$ ) DNA recombination, but not by stimuli that did not induce $S \mu-\sigma \delta$ recombination, i.e., LPS alone or LPS plus TGF- $\beta$ and RA, as shown by chromatin immunoprecipitation (ChIP) using an anti-Rad52 Ab - the specificity of the ChIP Rad52 recruitment assay being emphasized by the lack of chromatin immunoprecipitation in Rad52 ${ }^{-/}$B cells (Fig. 7d,e). Recruitment of Rad52 but not Ku70/Ku86 to $\sigma \delta$ in CSR to IgD, as induced by LPS plus IL-4, contrasted with that of Ku70/Ku86 to S $\gamma 3$ and $\mathrm{S} \alpha$ regions as induced in CSR to IgG3 and IgA (Fig. 7f), a possible reflection of the competition of these HR and NHEJ elements for binding to S region DSB ends ${ }^{20}$. Notably, LPS plus IL-4 induced recruitment of Rad52 but not $\mathrm{Ku} 70 / \mathrm{Ku} 86$ to $\sigma \delta$, while inducing mostly $\mathrm{Ku} 70 / \mathrm{Ku} 86$ recruitment to $\mathrm{C} \gamma 1$, consistent with the efficient LPS pus IL-4 induction of CSR to IgG1, mediated mainly by NHEJ ${ }^{20}$. Thus, Rad52 expression and, importantly, Rad52 phosphorylation are modulated by IgD CSR-inducing stimuli.

Stimuli that induce $S \mu-\sigma \delta$ DNA recombination downregulate ZFP318/Zfp318 and lead to IgD secretion. Next, we addressed the expression of $\mathrm{mIgD}$ and $\operatorname{sgD}$ and its regulation by stimuli inducing CSR to IgD. Resting B cells expressed $\mathrm{mIgD}$ and $\mathrm{mIgM}$, but little or no sIgD or sIgM, reflecting high levels of $V_{H} D J_{H^{-}} C \delta m$ and $V_{H} D J_{H^{-}}$ $C \mu m$ trancripts and low levels of $V_{H} D J_{H^{-}} C \delta s$ and $V_{H} D J_{H^{-}} C \mu s$ transcripts (Fig. 8a). Induction of CSR to IgD (by LPS or CD154 plus IL-4) resulted in loss of virtually all $\mathrm{mIgD}$, emergence of $V_{H} D J_{H^{-}} C \delta$ s transcripts together with $V_{H} D J_{H^{-}} C \mu s$ transcripts and significant IgD secretion (Fig. 8a-b). By contrast, application of IgD CSR noninducing stimuli (LPS plus TGF- $\beta$ and RA) to similar naive $\operatorname{IgM}^{+} \operatorname{IgD}{ }^{+} B$ cells resulted in partial loss of mIgD, no change in $V_{H} D J_{H^{-}} C \delta m$ transcripts and marginal IgD secretion (Fig. 8a-b). The changes in $V_{H} D J_{H^{-}} C \delta m, V_{H} D J_{H^{-}}$ $C \delta$ s transcripts, $\mathrm{mIgD}$ and $\mathrm{sgD}$ brough about by IgD CSR-inducing stimuli paralleled the downregulation of $Z f p 318$ transcripts and Zfp318 protein - Zfp318 represses the TTS that mediates alternative transcriptional $V_{H} D J_{H^{-}}$ $C \mu / V_{H} D J_{H-} C \delta$ termination, thereby allowing for long-range transcription throughout $V_{H} D J_{H-} C \mu-s-m-C \delta$-s-m DNA (Fig. 8c-e). Zfp318 downregulation was specific to IgD CSR, as it did not occur in response to IgA CSR-inducing stimuli (LPS plus TGF- $\beta$ and RA). ZFP318 downregulation concomitant with decreased $\mathrm{mIgD}$ expression and increased IgD secretion was reproduced in human B cells submitted to IgD CSR-inducing stimuli (CpG plus IL2 and IL-21) but not IgD CSR non-inducing stimuli (CpG plus IL-4 and IL-21) (Fig. 8,f). Similarly, ZFP318 transcripts and ZFP318 protein were downregulated in human B cells undergoing IgD CSR in vivo, as in tonsils (Fig. 8,g). Zfp318 downregulation was independent and likely preceding expression of AID or Rad52, as revealed

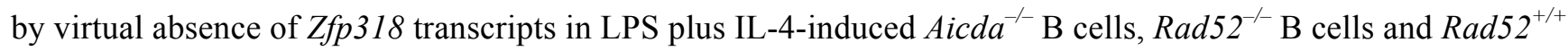
B cells, all of which lost mIgD expression as compared to similar B cells stimulated by IgA CSR-inducing stimuli (LPS plus TGF- $\beta$ and RA) (Fig. $8 \mathrm{~h}-\mathrm{j}$ ). Thus, the stimuli that specifically induce CSR to IgD downregulate ZFP318/Zfp318 independently of AID or Rad52 expression and prior to S $\mu-\sigma \delta$ DNA recombination.

RAD52 knockdown reduces $S \mu-\sigma \delta$ DNA recombination and IgD secretion in human B cells. The high frequency of microhomologies in $\mathrm{S} \mu-\sigma \delta$ junctions of human tonsil B cells in vivo and human B cells induced to 
Rad52 mediates CSR to IgD

undergo CSR to IgD in vitro (Figs. 3a,4,6b, Extended Data Figs. 1-5) suggested to us that RAD52 also mediates $\mathrm{S} \mu-\sigma \delta$ DNA recombination in human B cells. We purified naïve $\operatorname{IgM}^{+} \operatorname{IgD}^{+} \mathrm{B}$ cells from peripheral blood of 3 healthy subjects and knocked down using RAD52-specific siRNAs RAD52 transcripts and RAD52 protein by up to $75 \%$ and $95 \%$, respectively. In these B cells, $\mathrm{S} \mu-\sigma \delta$ recombination, as induced by CpG plus IL-2 and IL-21, was virtually abolished, while $A I C D A$ or AID expression and $\mathrm{S} \mu-\mathrm{S} \gamma 1$ recombination were not altered (Fig. 9a-c). The reduced $\mathrm{S} \mu-\sigma \delta$ DNA recombination in RAD52 knockdown human B cells was associated with decreased expression of $V_{H} D J_{H^{-}} C \delta$ s transcripts, without significant alteration of $V_{H} D J_{H^{-}} C \delta m$ transcripts (Fig. 9d). The critical role of RAD52 in human CSR to IgD was emphasized by RAD52 recruitment to $\mathrm{S} \mu$ and $\sigma \delta$ regions in human naïve B cells induced to undergo CSR to IgD (by CpG plus IL-2 and IL-21) in vitro, human tonsil (IgD ${ }^{+}$) B cells undergoing CSR to $\operatorname{IgD}$ in vivo, but not in unstimulated naïve $\operatorname{IgD}^{+} \operatorname{IgM}^{+}$B cells (Fig. 9e). Thus, $\operatorname{Rad} 52$ critically mediates CSR to IgD through $\mathrm{S} \mu-\sigma \delta$ recombination in human B cells.

S $\mu-\sigma \delta$ DNA recombination leads to IgD plasma cell differentiation. To determine whether the substantial IgD production we observed only upon induction of CSR to IgD (Figs. 5b,6c-h,8b,f) would be associated with plasma cell differentiation, we analyzed human $\operatorname{IgM}^{+} \operatorname{IgD}^{+} \mathrm{B}$ cells induced to undergo CSR to IgD by CpG plus IL-2 and IL-21. More than $13 \%$ of these $\mathrm{B}$ cells became $\operatorname{mgM}^{-}$intracellular $\operatorname{IgD}^{+}$compared to about half of their counterparts stimulated by CpG plus IL-4 and IL-21 and not switching to IgD (Fig. 10a). More than 90\% of the $\operatorname{IgM} \operatorname{IgD}^{+} \mathrm{B}$ cells emerging from $\mathrm{CpG}$ plus IL-2 and IL-21 simulation expressed BLIMP-1 and almost $60 \%$ were $\mathrm{CD} 27^{+} \mathrm{CD} 38^{+}$versus about $10 \%$ of the $\operatorname{IgM}^{-} \mathrm{IgD}^{+} \mathrm{B}$ cells from $\mathrm{CpG}$ plus IL-4 and IL-21 expressing BLIMP-1 and less than $12 \%$ being $\mathrm{CD} 27^{+} \mathrm{CD} 38^{+}$. Among mouse $\operatorname{IgM}^{+} \operatorname{IgD}^{+} \mathrm{B}$ cells induced to undergo CSR to IgD by LPS plus IL-4, about 25\% expressed intracellular IgD. All these B cells also expressed Blimp-1 and 70\% or more acquired CD138 (Fig. 10b). By contrast, among $\operatorname{IgM}^{+} \operatorname{IgD}^{+} \mathrm{B}$ cells induced to undergo CSR to IgA by LPS plus TGF- $\beta$ and RA, about 50\% expressed intracellular IgD but virtually none expressed Blimp-1 or acquired surface CD138. The relevance of IgD CSR to sustained IgD secretion was suggested by analysis of 3 human myelomas, two $\operatorname{IgD}$ and one IgA. Both IgD myelomas displayed $\mathrm{S} \mu-\sigma \delta$ DNA, but not $\mathrm{S} \mu-\mathrm{S} \alpha$ DNA recombination (Fig. 10c). Conversely, the IgA myeloma showed $\mathrm{S} \mu-\mathrm{S} \alpha$, but not $\mathrm{S} \mu-\sigma \delta$ DNA recombination. Thus, $\operatorname{IgD}^{+} \mathrm{B}$ cells emerging by CSR would are prone to differentiate into IgD-secreting plasmablasts/plasma cells for sustained IgD secretion. And such $\operatorname{IgD}^{+} \mathrm{B}$ cells may function as precursors of neoplastic $\operatorname{IgD}^{+}$transformants.

\section{B cell Rad52 phosphorylation, increased CSR to IgD and IgD autoantibodies in systemic autoimmunity.}

Serum IgD have been suggested to increase in patients with inflammatory autoimmune diseases, such as systemic lupus erythematosus (SLE) ${ }^{29}$ and rheumatoid arthritis ${ }^{30}$, and in hereditary autoinflammatory syndromes, most notably the hyper-IgD syndrome (HIDS) ${ }^{31-34}$. While in healthy humans, many B cells make IgD that react with components of the self ${ }^{35}$, we found patients with systemic lupus to display significantly higher levels of circulating IgD, including IgD specific for nuclear antigens, than their healthy subject controls (Fig. 11a,d). This possibly reflected the higher level of B cell Rad52 and/or p-Rad52 expression in such lupus patients (Fig. 11k). Similarly, we found lupus-prone MRL/Fas ${ }^{l p r / p r}$ mice to show far higher levels of IgD than their wildtype C57BL/6 counterparts in serum, feces and BALF as well as increased IgD-coated bacteria in feces, a reflection of high levels of $V_{H} D J_{H^{-}} C \delta s$ transcripts in bone marrow, spleen, MLNs and Peyer's patches B cells as well as increased 
274 numbers of $\operatorname{IgD}^{+}$B cells in lamina propria, MLNs and Peyer's patches (Fig. 11a-f). In MRL/Fas ${ }^{l p r / p r}$ mice, the 275 elevated IgD levels reflected increased IgD-producing cells and increased $\mathrm{S} \mu-\sigma \delta$ DNA recombination in bone 276 marrow, spleen, MLNs and Peyer's patches (Fig. 11g). Increased CSR to IgD in MRL/Fas ${ }^{l p r / p r}$ was associated 277 with high levels of p-Rad52 expression, greater frequency and length of microhomologies in $\mathrm{S} \mu-\sigma \delta$ as compared 278 to $\mathrm{S} \mu-\mathrm{S} \gamma 1$ and $\mathrm{S} \mu-\mathrm{S} \alpha$ junctional sequences, as well as with a high frequency of somatic point-mutations in areas 279 abetting S $\mu$-S $\delta$ DNA junctions (Fig. 11h-k and Extended Data Fig. 6). Thus, high levels of B cells expressing p280 Rad52 are associated with high levels of $\operatorname{IgD}$ and $\operatorname{IgD}$ autoantibodies to nuclear antigens in lupus patients and in 281 lupus-prone MRL/Fas ${ }^{l p r / p r}$ mice. In these mice, $\mathrm{S} \mu-\sigma \delta$ DNA recombination events involving high frequency of 282 junctional microhomologies occur in B cells of different body districts, giving rise to high levels of $\mathrm{IgD}$ 283 autoantibodies locally and systemically. 
Rad52 mediates CSR to IgD

\section{Discussion}

The mechanism of CSR to IgG, IgA and IgE are quite well understood, as mediated by $\mathrm{Ku} 70 / \mathrm{Ku} 86$-dependent NHEJ, although occurrence of a "residual" IgM to IgG CSR in B cells lacking Ku70/Ku86 expression has suggested the existence of a Ku70/Ku86-independent A-EJ synaptic mechanism ${ }^{18-20}$. Mice lacking 53BP1, in which NHEJ-dependent CSR to IgG, IgA and IgE was significantly decreased - 52BP1 protects resection of DSB ends, thereby skewing the synaptic process toward NHEJ - showed increased CSR to IgD and increased circulating IgD levels, suggesting that the short-range $\mathrm{S} \mu-\sigma \delta$ CSR was mediated by a 53BP1-independent synaptic process involving resected DSB ends and entailing a high frequency of $S \mu-\sigma \delta$ junctional microhomologies ${ }^{22,23}$. This together with our previous demonstration that $\operatorname{Rad} 52$ plays a central role in synapsing intra-S $\mu$ region resected DSB ends as well as $c-M y c / I g H$ locus translocations also involving resected DSB ends, both processes entailing significant junctional microhomologies, prompted us to hypothesize that Rad52 mediates the A-EJ process that synapses $\mathrm{S} \mu$ and $\sigma \delta \mathrm{DSB}$ with complementary overhangs in CSR to $\operatorname{IgD}^{20}$. Here, we demonstrated that Rad52 mediates CSR to IgD in mouse and human B cells (Extended Data Fig. 7), thereby unveiling a previously unknown, critical and dedicated role of this HR factor in mammalian DNA repair.

We have provided here unequivocal evidence that Rad52 is critical for CSR to IgD in vitro and in vivo, in mouse and human B cells. In mouse $R a d 52^{-/} \mathrm{B}$ cells, $\mathrm{S} \mu-\sigma \delta$ DNA recombination was ablated and IgD secretion greatly reduced. Similarly, in $R A D 52$ knockdown B cells from healthy subjects, $\mathrm{S} \mu-\sigma \delta$ DNA recombination was virtually abrogated and $\mathrm{IgD}$ secretion greatly decreased - as expected ${ }^{1,5}, \mathrm{~S} \mu-\sigma \delta$ DNA recombination could not occur in the absence of AID, which introduces DSBs in $\sigma \delta$ as it does in $\mathrm{S} \mu, \mathrm{S} \gamma, \mathrm{S} \alpha$ or $\mathrm{S} \varepsilon$. In mouse $\operatorname{Rad} 52^{-/} \mathrm{B}$ cells and human $R A D 52$ knockdown $\mathrm{B}$ cells, decreased post-recombination $V_{H} D J_{H^{-}} C \delta$ s transcripts resulted in reduced $\mathrm{IgD}$ secretion, which occurred in presence of unaltered transmembrane $V_{H} D J_{H^{-}} C \delta m$ transcript levels, at least within the first 72 hours from CSR induction. Interestingly, the stimuli that selectively induced CSR to $\operatorname{IgD}$ modulated the overall levels of Ku70/KU70, Ku86/KU86 and Rad52/RAD52 transcripts while significantly upregulating Aicda/AICDA in mouse and human B cells. This was concomitant with induction of AID and moderate decrease in Rad52 protein, which, in fact, was increasingly phosphorylated at Tyr104. Rad52 Tyr104 phosphorylation has been shown to boost Rad52-mediated DNA single-strand annealing and is possibly effected by c-ABL kinase ${ }^{28}$. Rad52 involvement in CSR to IgD was further emphasized by recruitment of this protein to $\sigma \delta$ region (in addition and necessarily to $\mathrm{S} \mu$ ) in vivo in human tonsil $\operatorname{IgD}^{+} \mathrm{B}$ cells, as well as in vitro, in mouse and human naïve $\mathrm{B}$ cells induced to undergo CSR to $\operatorname{IgD}$, but no or only marginally in similar B cells undergoing $\mathrm{CSR}$ to IgG3 or IgA. Instead, these $\mathrm{B}$ cells recruited $\mathrm{Ku} 70 / \mathrm{Ku} 86$ to $\mathrm{S} \gamma 3$ and $\mathrm{S} \alpha$, consistent with the major contribution of NHEJ to CSR to IgG3 and IgA.

Rad52 is a member of the eponymous epistasis group for DSB repair that shows strong evolutionary conservation $^{17,36}$. In Saccharomyces cerevisiae, $\operatorname{Rad} 52$ is a key element of the HR pathway, and its deletion or mutation impairs DNA DSB repair ${ }^{37,38}$. Indeed, yeast Rad52 is a recombination mediator and a facilitator of annealing of complementary DNA single-strands ${ }^{39,40}$. It functions as a cofactor of Rad51, which forms nucleoprotein filaments with single-strand DNA and promotes strand pairing, by overcoming the inhibitory effect of replication protein $\mathrm{A}(\mathrm{RPA})^{41}$. By contrast, Rad52 mutation or even deletion results in no obvious abnormalities 
in viability or functions in mammalian cells. As we have shown, $\operatorname{Rad} 52^{-/-}$mice displayed no significant alteration of immune system elements, including B cells ${ }^{20}$, possibly owing to the presence of mammalian gene paralogues, such as BRCA2 and RAD51, which by encoding functions related to Rad52, can compensate for the absence of this factor ${ }^{42}$. Human BRCA2 functions as a recombination mediator by facilitating RAD51 nucleoprotein filament formation $^{40,43-45}$. Nevertheless, human BRCA2 cannot facilitate annealing of RPA-coated DNA, a function that Rad52 carries out efficiently in the absence of BRCA $2^{46}$. This together with Rad52 involvement in DSB repair at stalled or collapsed replication forks points at a unique role of Rad52 in catalyzing single-strand annealing in homology-directed DNA repair in human cells ${ }^{47-49}$.

Our identification of Rad52 as essential in IgD CSR $\mathrm{S} \mu-\sigma \delta$ synapses provides, to the best of our knowledge, the first demonstration of a critical and dedicated role of this factor in mammalian DNA repair. The short-range Rad52-mediated $S \mu-\sigma \delta$ recombination of resected DSB ends adds to the other Rad52-mediated short-range DSB recombination we recently uncovered: intra-S $\mu$ region DSB recombination ${ }^{20}$. This, like $\mathrm{S} \mu-\sigma \delta$ synapsing, engages resected DSB ends and yields significant junctional nucleotide microhomologies ${ }^{20}$. In this function, as in CSR to IgD, Rad52 is not fungible in mouse or human B cells. Our identification of Rad52 as the critical element in $\mathrm{S} \mu-\sigma \delta$ synapsis also sheds light on the mechanistic nature of the CSR A-EJ DSB repair pathway (originally referred to as A-NHEJ ${ }^{19}$ ). As per our current findings, the CSR A-EJ pathway uses HR Rad52 to synapse upstream and downstream DSB overhangs by a MMEJ process but does not require a homologous template as a guide, as the HR pathway does. The DNA polymerase $\theta$ has been suggested to contribute to A-EJ ${ }^{21}$. Our previous findings, however, did not support a role of this polymerase in Rad52-mediated intra-S $\mu$ DSB recombination or $\mathrm{S} \mu-\mathrm{S} \gamma 1, \mathrm{~S} \mu-\mathrm{S} \gamma 3, \mathrm{~S} \mu-\mathrm{S} \gamma 2 \mathrm{a} / \mathrm{S} \gamma 2 \mathrm{c}$ and $\mathrm{S} \mu-\mathrm{S} \alpha$ recombination (CSR to IgG1, IgG3, IgG2a/IgG2c and $\operatorname{IgA})^{20}$. Finally, while (MMEJ) A-EJ functions as a back-up pathway in cells defective in NHEJ or HR, it also synapses DSB ends in cells that are competent for both NHEJ and $\mathrm{HR}^{50}$, as exemplified by microhomologies in $\mathrm{S}-\mathrm{S}$ junctions in a proportion of B cells that class-switched to $\mathrm{IgG}, \operatorname{IgA}$ and $\mathrm{IgE}$, as well as the disappearance of such microhomologies upon Rad52 ablation ${ }^{20}$.

As we showed here, Rad52 works in concert with Zfp318 to modulate IgD expression through an interplay of alternative RNA splicing and DNA recombination, the latter after AID intervention. Zfp318 represses the TTS intercalated between the $\mathrm{C} \mu$ and $\mathrm{C} \delta$ exons within the $\operatorname{Igh} \mu / \operatorname{Igh} \delta$ loci transcriptional complex unit ${ }^{10,11}$, thereby allowing for transcription of long primary $V_{H} D J_{H^{-}} C \mu-s-m-C \delta-s-m$ RNA. Zfp318, however, would also simultaneously allow for the continuous expression of primary $I \mu-C \mu-s-m-C \delta-s-m$ RNA transcripts. In fact, albeit possibly more abundant, hence their predominant detection in our specific PCR assays, $I \mu-C \delta$ transcripts - in secretory or membrane form - are identical in sequence to their post-recombination $I \mu-C \delta$ counterparts (Fig. 1a,b). During B cell development, Zfp318 expression closely parallels mIgD expression ${ }^{10,11}$. Indeed, consistent with its repression of the TTS intercalated between the $C \mu$ and $C \delta$ exons complex, the Zfp318 protein is expressed during the transition from immature $\operatorname{IgM}^{+} \operatorname{IgD}^{-}$to mature $\operatorname{IgM}^{+} \operatorname{IgD}^{\text {hi }} \mathrm{B}$ cell ${ }^{10,11}$. As we showed here, naïve mature $\mathrm{B}$ cells which express high levels of $\mathrm{mIgD}$ also express high levels of Zfp 318 transcripts and Zfp318 protein. In these B cells, stimuli that induced $\mathrm{S} \mu-\sigma \delta$ DNA recombination, yielding primary $V_{H} D J_{H^{-}} C \delta-s-m$ RNA transcripts, also 
mediated TTS repression is a prerequisite for $\mathrm{S} \mu-\sigma \delta$ DNA recombination to unfold. Conversely, as we also showed here, naïve mature $\operatorname{IgM}^{+} \operatorname{IgD}{ }^{+} \mathrm{B}$ cells submitted to stimuli that induced CSR to isotypes other than $\operatorname{IgD}$, such as IgA (by LPS plus IL-4 and RA), further upregulated Zfp318 transcripts and Zfp318 protein, concomitant with no $\mathrm{S} \mu-\sigma \delta$ recombination, thereby allowing for massive expression of $\mathrm{mIgD}$ rather than $\operatorname{sgD}$.

The role of Zfp318 as gene transcription regulator is highly specific for $\operatorname{IgD}$, as genome-wide transcriptome analysis of B cell Zfp318-deficient (Vav-Cre dependent deletion) mice identified Sva as the only other gene altered in expression ${ }^{11}$ - interestingly, $S v a$ is also involved in alternative splicing, albeit outside the $\operatorname{IgH}$ locus ${ }^{51}$. Zfp318 would be under the control of 5'AMP-activated protein kinase (Ampk). This is phosphorylated by Lbk $1^{52}$, whose signaling triggers the B cell GC reaction. Indeed, Lbk1's failure to activate Ampk or Ampk loss specifically muted Zfp318 expression and IgD transcription ${ }^{52}$. In contrast, activation of Ampk by phenformin impaired GC formation $^{52}$, likely by heightening Zfp318 expression, possibly in addition to other mechanisms. This would result in increased expression of primary $V_{H} D J_{H^{-}} C \mu-s-m-C \delta-s-m$ RNA transcripts but not $\mathrm{S} \mu-\sigma \delta$ DNA recombination, suggesting that CSR to IgD is one of the multiple and complex events inherent to GC formation. This is triggered by naturally occurring generally microbial stimuli, as in tonsil GCs and GCs or other secondary lymphoid formations in aerodigestive mucosae ${ }^{1,5,6}$. Consistent with the contention that Ampk mediates the regulation of Zfp318 as well as the contrasting impact of IgD CSR-inducing (LPS plus IL-4) and non-inducing stimuli (LPS plus TGF- $\beta$ and RA) on expression of Zfp318, stimulation of both human and mouse cells by LPS has been shown to result in dephosphorylation/inactivation of Ampk, while similar cell stimulation by TGF- $\beta$ resulted in rapid phosphorylation/activation of this protein kinase ${ }^{53}$.

In our experiments, stimuli that induced CSR to IgD (e.g., LPS plus IL-4 in mouse B cells, and CD154 plus IL-2 and IL-21 in human B cells) also downregulated Zfp318 expression which, in turn, reduced $V_{H} D J_{H^{-}} C \delta m$ transcript level and $\mathrm{mIgD}$, while greatly increasing $V_{H} D J_{H^{-}} C \delta s$ transcripts and sIgD. This argues for CSR to IgD to be critical for significant IgD secretion. Indeed, stimuli that induced $\mathrm{S} \mu-\sigma \delta$ recombination and $\operatorname{IgD}$ secretion also induced plasmablast/plasma cell differentiation, as shown by Blimp- 1 and $\mathrm{C} 38^{+} \mathrm{CD} 27^{+}$expression in human B cells, and Blimp-1 and CD $138^{+}$in mouse B cells. A similar outcome was not produced by stimuli that did not induce $\mathrm{S} \mu-\sigma \delta$ recombination and $\mathrm{IgD}$ secretion in mouse or human B cells. Thus, while alternative splicing of long primary $V_{H} D J_{H^{-}} C \mu-s-m-C \delta-s-m$ RNA transcripts in B cells that have not undergo CSR would make some contribution to the overall level of IgD production in vivo, CSR to IgD is likely required for substantial and sustained IgD production, as secreted by plasmablasts/plasma cells or by neoplastic transformants, such as IgD myeloma cells. The limited IgD amounts detected in supernatants of mouse or human B cells primed by stimuli that induced high levels of $\mathrm{mIgD}$ but not $\mathrm{S} \mu-\sigma \delta$ synaptic recombination would result from translation of alternative spliced long primary $V_{H} D J_{H^{-}} C \mu-s-m-C \delta-s-m$ RNA transcripts as well as some "shedding" of mIgD.

Bacteria and viruses have been suggested to play an important role in driving CSR to IgD, generally through stimulation of TLRs in gut and respiratory lymphoid tissues, and mesenteric lymph nodes, possibly leading to emergence of plasmablasts and plasma cells secreting $\operatorname{IgD}{ }^{1,3-5,51,54-56}$. Circulating $\operatorname{IgD}$ are increased in patients 
isotype $^{1,3,5,56}$. Our findings support the notion that both T-dependent (CD154) and T-independent (TLR ligands) stimuli induce $S \mu-\sigma \delta$ DNA recombination, in combination with various cytokines ${ }^{1,4-6}$. Interestingly, although we previously showed that BCR-signaling synergizes with TLR-signaling for induction of AID and CSR to IgG and Ig $\mathrm{A}^{25}$, BCR signaling did not synergize with TLR7 or TLR9 signaling to induce CSR to IgD, as shown by the lack of $\mathrm{S} \mu-\sigma \delta$ DNA recombination in B cells stimulated by $\mathrm{CpG}$ or R848 plus IL-4 and anti-Ig $\delta \mathrm{Ab}$. In the in vivo Tdependent antibody response to OVA, ablation of CSR to $\operatorname{IgD}\left(\mathrm{Rad}_{52^{-/}}\right.$mice) resulted in reduced levels of total and specific $\mathrm{IgD}$ in circulating blood and BALF, decreased total and/or bacteria-bound $\operatorname{IgD}$ in feces as well as decreased numbers of $\operatorname{IgD}^{+} \mathrm{B}$ cells lamina propria and MLNs, a privileged site of $\operatorname{IgD} \mathrm{CSR}^{12}$. As predicted by our previous findings ${ }^{20}$, the overall decreased IgD levels in $\mathrm{Rad}_{52^{-/}}$mice were associated with increased $\operatorname{IgG} 1$ and IgA as well as greatly decreased frequency and lengths of microhomologies in $\mathrm{S} \mu$-S $\gamma 1$ and $\mathrm{S} \mu$-S $\alpha$ junctions. This reflected the lack of Rad52 contribution to the synaptic process underpinning such junctions as well as the lack of Rad52 competition with $\mathrm{Ku} 70 / \mathrm{Ku} 86^{20}$, which resulted solely in $\mathrm{Ku} 70 / \mathrm{Ku} 86$-mediated NHEJ, a process that limits microhomologies to $0-3 \mathrm{nt}^{16}$.

Information on the contribution of $\operatorname{IgD}$ to autoimmunity is scant and contradictory. Self-antigen-binding and mostly polyreactive IgD occur in healthy subjects, much like $\operatorname{IgM}$ or even $\operatorname{IgG}$ and $\operatorname{IgA}$ do ${ }^{35,57-60}$. High levels of IgD have been reported in rheumatoid arthritis patients and thought to possibly be implicated in the pathogenesis of the disease ${ }^{30}$. $\mathrm{mIgD}$ expression, however, has been speculated to exert an inhibitory effect on $\mathrm{B}$ cell autoreactivity, as suggested by elevated autoantibody production, increased deposition of immune complexes in kidneys and severe nephritis in lupus-prone C56BL/6lpr mice with deletion of the Ig $\delta$ locus ${ }^{61,62}$. Our findings showed total and self-reactive IgD (dsDNA, histone, RNP/Sm or RNA and ANAs) to be elevated in the circulation of lupus patients and lupus-prone MRL/Fas ${ }^{l p r / p r}$ mice. The latter displayed higher levels of IgD in serum, BALF and feces, than their wildtype C57BL/6 counterparts. Such high IgD levels reflected CSR recombinations that included $S \mu-\sigma \delta$ junctions with extensive microhomologies and high frequency of somatic mutations in the DNA areas abetting $\mathrm{S} \mu-\sigma \delta$ junctions. Such IgD CSR occurred in different districts, such as bone marrow, spleen, MLNs and Peyer's patches, and were reflected in the $\operatorname{IgD}^{+} \mathrm{B}$ cells in those districts. This together with the $\mathrm{B}$ cell high levels of p-Rad52 and the low levels Zfp318 indicated that in murine and likely human lupus, IgD autoantibodies stem from extensive B cell $\mathrm{S} \mu-\sigma \delta$ recombination rather than alternative splicing of primary $V_{H} D J_{H-} C \mu-s-m-C \delta-s-$ $m$ RNA transcripts. Our findings do not suggest a "protective" role of $\mathrm{IgD}$ in autoimmunity ${ }^{61,62}$, while supporting a role of CSR to IgD in systemic lupus autoantibody responses.

Collectively, our data outline a critical and dedicated role of Rad52 in mediating the synapsis of $S \mu$ with $\sigma \delta$ DSB resected ends. They also provide the first demonstration of Rad52 as a critical element in the poorly understood contribution of A-EJ to the resolution of DSBs in nonmalignant cells. In malignant B cells, Rad52 is involved in DNA recombination events that give rise to DNA deletions and translocations. As we previously showed, Rad52 ablation reduced the frequency of $c-M y c / I g H$ translocations in mouse $p 53^{-/-} \mathrm{B}$ cells by more than $70 \%$, with the residual translocations containing limited microhomologies ${ }^{20}$. Whether Rad52 intervention extends to other modalities of A-EJ in neoplastic and non-neoplastic lymphoid mammalian cells remains to be determined. 
that this highly conserved HR element is critical for CSR to IgD in both mouse and human B cells. This together with the further reduction of the physiologically moderate microhomologies in $S \mu-S \gamma 1, S \mu-S \gamma 3, S \mu-S \alpha$ and $S \mu-$

433 S $\varepsilon$ junctions in Rad52 $2^{-/}$B cells (current data and refs. ${ }^{18-20}$ ) solidifies the role of Rad52 as critical mediator of the 434 A-EJ backup pathway underpinning the residual CSR to IgG, IgA and IgE in the absence of Ku70/Ku86 proteins ${ }^{20}$. 435 Our findings also showed how stimuli that induce $\mathrm{S} \mu-\sigma \delta$ recombination coordinate Rad52 function, as enabled 436 by phosphorylation, with downregulation of Zfp318, unique repressor of the TTS intercalated between the C $\mu$ and $437 \mathrm{C} \delta$ loci, whose activity allows transcription throughout $V_{H} D J_{H}-S \mu-C \mu-s-m-\sigma \delta-C \delta-s-m$ and $I \mu-C \mu-s-m-\sigma \delta-C \delta-s-m$. 438 Further, they indicate that CSR to $\operatorname{IgD}$ is required for sustained $\operatorname{IgD}$ secretion and possibly a prerequisite for $\operatorname{IgD}$ 439 plasma cell differentiation. They also add new and significant information to a potential role of CSR to IgD, as 440 promoted by Rad52 phosphorylation, in systemic autoimmunity. Finally, they provide important new molecular 441 information to approach the virtually unexplored mechanistic underpinning of hyper-IgD syndrome, a relatively 442 rare but a severe autoinflammatory disease associated with mevalonate kinase deficiency (due to $M V K$ recessive 443 mutations) and exorbitant levels of $\operatorname{IgD}^{31,32,63}$.

\section{Acknowledgements}

446 We thank Dr. Patrick M. Sung for reviewing this manuscript. We also would like to thank Amanda Fisher, Dr. 447 Justin B. Moroney, Dr. Helia N. Sanchez and Dr. Huoqun Gan for their help in some experiments. This work was 448 supported by NIH grants R01 AI 079705, T32 AI138944, R01 AI 105813 and the Lupus Research Alliance Target 449 Identification in Lupus Grant 641363 to P.C.

450 Author contributions

451 Y. Xu and H. Zhou performed experiments; G. Post provided myeloma samples; H. Zan designed and performed 452 experiments, analyzed data, supervised the work and wrote the manuscript; P. Casali planned the study, designed 453 the experiments, analyzed the data, supervised the work and wrote the manuscript. 
Rad52 mediates CSR to IgD

454

455

456

457

458

459

460

461

462

463

464

465

466

467

468

469

470

471

472

473

474

475

476

477

478

479

480

481

482

483

484

485

486

487

488

489

\section{Methods}

Mice. Rad52 $2^{-/}$mice were generated by replacing exon 3 of the Rad52 gene with positive selection marker neomycin, as driven by the phosphoglycerate kinase (PGK) promoter, and an upstream mouse sequence functioning as a transcription terminator (Dr. Albert Pastink, Leiden University, Leiden, The Netherlands) ${ }^{36}$. Rad $52^{-/-}$mice were backcrossed to C57/BL6 mice for more than six generations. No full length or truncated Rad52 protein was produced from the disrupted allele ${ }^{36}$. Rad $52^{-/-}$mice were viable and fertile, and showed no gross abnormalities. Aicda ${ }^{-/-}$mice (C57BL/6 background) ${ }^{64}$ were obtained from Dr. Tasuku Honjo (Kyoto University, Kyoto, Japan). C57BL/6 and MRL/Fas ${ }^{l p r / p r}$ mice were purchased from Jackson Laboratory (Bar Harbor, Maine). All mice were housed in pathogen-free conditions. Both male and female mice aged 8-12 weeks were used for the experiments. The Institutional Animal Care and Use Committees (IACUC) of the University of Texas Health Science Center at San Antonio approved all animal protocols.

Mouse $B$ cells and CSR induction in vitro. Naïve $\operatorname{IgM}^{+} \operatorname{IgD}{ }^{+} B$ cells were isolated from spleens of 8-12-weekold C57BL/6, Rad52 $2^{-/}$or Aicda ${ }^{-/-}$mice as described ${ }^{25}$. B cells were resuspended in RPMI 1640 medium with 10\% FBS (FBS-RPMI), $50 \mathrm{mM} \beta$-mercaptoethanol and 1x antibiotic-antimycotic mixture (15240-062; Invitrogen) and stimulated with LPS (4 $\mu \mathrm{g} / \mathrm{ml})$ from Escherichia coli (055:B5; Sigma-Aldrich), CD154 (1 U/ml; obtained from membrane fragments of baculovirus-infected Sf21 insect cells $\left.{ }^{25}\right)$, CpG ODN 1826 (1.0 $\mu$ M; Eurofins Genomics) or R848 (1.0 $\mu \mathrm{M}$; Medkoo) plus nil, IL-4 (5.0 ng/ml; R\&D Systems) and/or TGF- $\beta$ (2.0 ng/ml; R\&D Systems) and retinoic acid (RA, $10 \mathrm{nM}$ ) or anti-BCR Ab (anti- $\delta$ mAb-dextran, $30 \mathrm{ng} / \mathrm{ml}$; Fina Biosolutions). Mouse B cells were cultured in FBS-RPMI at $37^{\circ} \mathrm{C}$ in 48 -well plates for 24, 48, 72 and $96 \mathrm{~h}$.

Human $B$ cells and CSR induction in vitro. Naïve $\operatorname{IgM}^{+} \operatorname{IgD}{ }^{+} B$ cells were purified by negative selection using the EasySep ${ }^{\mathrm{TM}}$ human naive B cell enrichment kit (19254; StemCell Technologies) from healthy subject PBMCs, following manufacturer's instructions. Tonsillar $\operatorname{IgD}^{+} \mathrm{B}$ cells were isolated from human tonsil cells by positive selection using biotin-anti-human IgD mAb (clone IA6-2; 348212, Biolegend) and MagniSort ${ }^{\mathrm{TM}}$ Streptavidin Positive Selection Beads (MSPB-6003-74, Thermo Fisher Scientific). Naïve B cells were stimulated with CD154 (10 U/ml) or CpG ODN 2395 (1.0 $\mu \mathrm{M}$; Eurofins Genomics) plus nil, IL-2 (20 ng/ml; BioLegend), IL-4 (20 ng/ml; R\&D Systems), IL-15 and/or IL-21 (50 ng/ml; R\&D Systems). Human B cells were cultured in FBS-RPMI at $37^{\circ} \mathrm{C}$ in 48 -well plates for $24,48,72,96$ and $120 \mathrm{~h}$.

Flow cytometry. For surface staining, mononuclear cells were reacted with VF-anti-CD19 mAb (75-0193-0100, Tonbo), PE-anti-IgM mAb (clone RMM1, 406507, BioLegend), and FITC anti-mouse IgD mAb (clone 11-26c.2a, 405704, BioLegend) and 7-AAD. For intracellular staining, cells were stained with anti-CD19 mAb (Clone 1D3; Tonbo) and fixable viability dye eFluor ${ }^{\circledR} 450$ (FVD 450 , eBiosciences) followed by incubation with the BD Cytofix/Cytoperm buffer at $4^{\circ} \mathrm{C}$ for $20 \mathrm{~min}$. After washing twice with the BD Perm/Wash buffer, cells were resuspended in HBSS with $1 \% \mathrm{BSA}$ and stored overnight at $4^{\circ} \mathrm{C}$. Cells were then stained with anti-Zfp318 $\mathrm{Ab}$ (AAS23325C, Antibody Verify; labeled with FITC using iLink ${ }^{\mathrm{TM}}$ Antibody Labeling Kits, ABP Biosciences). FACS analysis was performed on single cell suspensions. In all flow cytometry experiments, cells were appropriately gated on forward and side scattering to exclude dead cells and debris. Cell analyses were performed 
Rad52 mediates CSR to IgD

490

491

492

493

494

495

496

497

498

499

500

501

502

503

504

505

506

507

508

509

510

511

512

513

514

515

516

517

518

519

520

521

522

523

524

525

using a LSR-II flow cytometer (BD Biosciences), and data were analyzed using FlowJo software (TreeStar). All experiments were performed in triplicates.

Fluorescence microscopy. Fluorescence microscopy of tissues. To analyze IgM and IgD-producing cells in the lamina propria and PPs, the intestine was folded into a "Swiss-roll", fixed with PFA (4\%), and embedded in paraffin. Ten $\mu \mathrm{m}$ sections were cut and heated at $80{ }^{\circ} \mathrm{C}$ to adhere to the slide, washed four times in xylene for 2 min, dehydrated two times with $100 \%$ ethanol for $1 \mathrm{~min}$, two times with $95 \%$ ethanol for 1 min and washed two times in water for $1 \mathrm{~min}$. Antigens were unmasked using $2 \mathrm{mM}$ EDTA in $100{ }^{\circ} \mathrm{C}$ for $40 \mathrm{mins}$ followed by a cooling step at $25^{\circ} \mathrm{C}$ on the bench top, 3 times washing with 1x TBS and blocking using 10\% BSA for 15 min. Slides were again washed 3 times with 1x TBS and stained with FITC-anti-IgD mAb (clone 11-26c.2a; 405713, BioLegend), PE goat-anti-mouse-IgM mAb (406507, BioLegend) for $2 \mathrm{~h}$ in a dark moist chamber. After washing 3 times with Triton X-100 (0.1\%) in TBS, slides were air dried, and cover slips were mounted with ProLong ${ }^{\circledR}$ Gold Antifade Reagent with DAPI (Invitrogen). Fluorescence images were captured using a 10x objective lens with a Zeiss Axio Imager Z1 fluorescence microscope. To analyze IgD-producing cells in MLNs, $10 \mu \mathrm{m}$ MLN sections were prepared by cryostat and loaded onto positively charged slides, fixed in cold acetone and stained with FITC-anti-IgD mAb (405704, BioLegend), or PE goat-anti-mouse-IgM mAb (406507, BioLegend), respectively, for $1 \mathrm{~h}$ at $25^{\circ} \mathrm{C}$ in a moist chamber. Cover slips were then mounted using ProLong ${ }^{\circledR}$ Gold Antifade Reagent using DAPI (Thermo Fisher), before examination with a fluorescence microscope.

Fluorescence microscopy of B cells. B cells were suspended at $10^{5}$ cells $/ 100 \mu \mathrm{l}$ in FCS-RPMI. Pre-labeled slides were then placed into Cytofunnels and ran with $50 \mu \mathrm{l}$ of FCS-RPMI in order to wet the Cytofunnel paper. Cells were then placed again into the Cytofunnel and spun at 800 RPM for 3 min using a Cytospin ${ }^{\mathrm{TM}} 4$ Cytocentrifuge (Thermo Fisher). For intracellular visualization of IgM, IgD, CD138 and Blimp-1 proteins, cells were fixed with methanol for $15 \mathrm{~min}$ and washed 3 times in PBS-Tween 20. Cells were then blocked in 10\% BSA for $15 \mathrm{~min}$ and stained with 1:20 APC-anti-mouse IgD Ab (clone 11-26c.2a; 405713, BioLegend), FITC-antimouse IgM mAb (11-5790-81, Thermo Fisher), overnight in a dark moist chamber.

Detection of free and bacterial-bound antibodies. Titers of serum, BALF or fecal total IgD, IgM, IgG1 and IgA and OVA-binding IgD, IgM, IgG1 and IgA were measured using specific ELISAs, as we described ${ }^{20,25,65,66}$. Total $\mathrm{IgD}$ in in vitro culture supernatants of stimulated human and mouse B cells or in serum, BALF or feces were measured by dot blotting with serially two-fold diluted samples.

Bacteria-bound $\operatorname{IgD}$ and $\operatorname{IgA}$ were detected in feces by flow cytometry, as we described ${ }^{27}$. Feces $(10 \mathrm{mg})$ were suspended in $100 \mu \mathrm{l}$ x PBS (filtered through $0.2 \mu \mathrm{m}$ filter), homogenized and centrifuged at $400 \times \mathrm{g}$ for 5 min to remove large particles. The supernatant was then centrifuged at $8000 \mathrm{~g}$ for $10 \mathrm{~min}$ to remove non-bound antibodies (in supernatant). The bacterial pellet was suspended in $1 \mathrm{ml}$ of PBS with $1 \%(\mathrm{w} / \mathrm{v})$ BSA. After fixation with $7.2 \%$ formaldehyde for $10 \mathrm{~min}$ at room temperature, bacteria were washed with PBS, and stained with FITCanti-IgD mAb (clone 11-26c.2a; 405713, BioLegend) or FITC-anti-IgA mAb (C10-3, BD Biosciences) on ice for 30 min, washed with PBS, and further resuspended in $1 \times$ PBS containing $0.2 \mu \mathrm{g} \mathrm{ml}^{-1}$ DAPI for flow cytometry analysis. All events that stained with DAPI were considered as bacteria. 
S-S region DNA recombinations and S region somatic mutations. Genomic DNA was prepared from human or mouse B cells using QIAmp DNA Mini Kit (Qiagen), or from paraffin-embedded human IgD or IgA myeloma tissue sections (obtained from the University of Arkansas for Medical Science) using Quick-DNA ${ }^{\mathrm{TM}}$ FFPE Kit (Zymo Research). Recombined $\mathrm{S} \mu-\sigma \delta, \mathrm{S} \mu-\mathrm{S} \gamma 1, \mathrm{~S} \mu-\mathrm{S} \alpha$ and $\mathrm{S} \mu-\mathrm{S} \varepsilon$ DNA were amplified by two sequential rounds of specific PCR using Phusion ${ }^{\mathrm{TM}}$ high-fidelity DNA polymerase (Thermo Scientific ${ }^{\mathrm{TM}}$ ) and nested oligonucleotide primers $^{67}$ (Supplementary Table 1). The first and second rounds of PCR were performed at $98{ }^{\circ} \mathrm{C}$ for $30 \mathrm{sec}$, $58{ }^{\circ} \mathrm{C}$ for $45 \mathrm{sec}, 72{ }^{\circ} \mathrm{C}$ for 4 min $(30$ cycles). Amplified DNA was fractionated through $1.0 \%$ agarose, blotted onto Hybond- $\mathrm{N}^{+}$membranes (GE Healthcare) and hybridized to biotin-labeled $\mathrm{S} \mu$ and $\sigma \delta, \mathrm{S} \gamma 1$, $\mathrm{S} \alpha$ or $\mathrm{S} \varepsilon$ specific probes. Detection was performed using the Chemiluminescent Nucleic Acid Detection Module (Thermo Fisher Scientific) according to the manufacturer's instructions. For sequence analysis of the recombined DNA, PCR products were purified using a QIAquick PCR purification kit (Qiagen). The amplified library was tagged with barcodes for sample multiplexing, and PCR was enriched and annealed to the required Illumina clustering adapters. High-throughput 300-base pair (bp) paired-end sequencing was performed by the UTHSCSA Genome Sequencing Facility using the Illumina MiSeq platform. S-S junctions and somatic mutations in the S regions were analyzed by sequence alignment as performed by comparing PCR products sequences with germline S $\mu$ and $\sigma \delta, \quad S \gamma 1$ or $S \alpha$ sequences using National Center for Biotechnology Information BLAST (www.ncbi.nih.gov/BLAST).

RT-PCR and quantitative RT-PCR (qRT-PCR). For quantification of mRNA, germline $\mathrm{I}_{\mathrm{H}}-\mathrm{C}_{\mathrm{H}}$, postrecombination $\mathrm{I} \mu-\mathrm{C}_{\mathrm{H}}$ and mature $\mathrm{V}_{\mathrm{H}} \mathrm{DJ}_{\mathrm{H}}-\mathrm{C}_{\mathrm{H}}$ transcripts, RNA was extracted from 0.2-5.0 x $10^{6}$ cells using either Trizol $^{\circledR}$ Reagent (Invitrogen) or RNeasy Plus Mini Kit (Qiagen). Residual DNA was removed from the extracted RNA with gDNA eliminator columns (Qiagen). cDNA was synthesized from total RNA with the SuperScript ${ }^{\mathrm{TM}}$ IV First-Strand Synthesis System (Thermo Fisher) using oligo-dT primer. Transcript expression was measured by qRT-PCR with the appropriate primers (Supplemental Table 1) using a Bio-Rad MyiQ ${ }^{\text {TM }}$ Real-Time PCR Detection System (Bio-Rad Laboratories) to measure SYBR Green (IQ ${ }^{\text {TM }}$ SYBR ${ }^{\circledR}$ Green Supermix, Bio-Rad Laboratories) incorporation with the following protocol: $95^{\circ} \mathrm{C}$ for $15 \mathrm{sec}, 40 \mathrm{cycles}$ of $94^{\circ} \mathrm{C}$ for $10 \mathrm{sec}, 60^{\circ} \mathrm{C}$ for $30 \mathrm{sec}, 72^{\circ} \mathrm{C}$ for $30 \mathrm{sec}$. Data acquisition was performed during $72^{\circ} \mathrm{C}$ extension step. Melting curve analysis was performed from $72^{\circ} \mathrm{C}-95^{\circ} \mathrm{C}$. Mature $V_{H} D J_{H^{-}} C \mu m, V_{H} D J_{H^{-}} C \mu s, V_{H} D J_{H^{-}} C \delta m$ and $V_{H} D J_{H^{-}} C \delta s$ transcripts were analyzed by semi-quantitative PCR using serially two-fold diluted cDNA.

554 Western blotting. B cells were lysed in Laemmli buffer. Cell extracts containing equal amounts of protein (50$100 \mu \mathrm{g})$ were fractionated through SDS-PAGE $(6 \%)$. The fractionated proteins were transferred onto polyvinylidene difluoride membranes (Bio-Rad) overnight $(30 \mathrm{~V} / 90 \mathrm{~mA})$ at $4{ }^{\circ} \mathrm{C}$. After blocking and overnight incubation at $4{ }^{\circ} \mathrm{C}$ with anti-AID antibody (H-80, Santa Cruz), anti-Ku70 antibody (A0883, Abclonal), anti-Ku86 antibody (A5862, Abclonal), anti-Rad52 antibody (H-300, Santa Cruz Biotechnology), anti-phospho-Rad52 antibody (Y408472, Applied Biological Materials Inc.) or anti- $\beta$-Actin mAb (2F1-1, BioLegend), the membranes were incubated with horseradish peroxidase (HRP)-conjugated secondary antibodies. After washing with TBS- 
Rad52 mediates CSR to IgD

562 (PerkinElmer Life and Analytical Sciences).

563 ChIP and qPCR. ChIP assays were performed as previously described ${ }^{68-70}$. Human or mouse B cells $\left(1.0 \times 10^{7}\right)$ were treated with formaldehyde $(1 \% \mathrm{v} / \mathrm{v})$ for $10 \mathrm{~min}$ at $25^{\circ} \mathrm{C}$ to crosslink chromatin, washed once in cold PBS with protease inhibitors (Roche) and resuspended in lysis buffer (20 mM Tris-HCl, $200 \mathrm{mM} \mathrm{NaCl}, 2 \mathrm{mM}$ EDTA, $0.1 \% \mathrm{w} / \mathrm{v}$ SDS and protease inhibitors, $\mathrm{pH} \mathrm{8.0).} \mathrm{Chromatin} \mathrm{was} \mathrm{fragmented} \mathrm{by} \mathrm{sonication} \mathrm{(DNA} \mathrm{fragments} \mathrm{of}$ about 200 to 1,000 bp in length), pre-cleared with protein A agarose beads (Pierce) and incubated with agarose conjugated anti-Rad52 mAb (clone F-7; sc-365341 AC, Santa Cruz Biotechnology) at $4^{\circ} \mathrm{C}$ overnight. Immune complexes were washed and eluted (50 mM Tris-HCl, 0.5\% SDS, $200 \mathrm{mM} \mathrm{NaCl}, 100 \mu \mathrm{g} / \mathrm{ml}$ proteinase K, $\mathrm{pH}$ 8.0), followed by incubation at $65^{\circ} \mathrm{C}$ for $4 \mathrm{~h}$. DNA was purified using a QIAquick PCR purification kit (Qiagen). The $\mathrm{S} \mu$ or $\sigma \delta$ region DNA was amplified from immunoprecipitated chromatin by qPCR using appropriate primers (Supplemental Table 1). Data were normalized to input chromatin DNA and depicted as relative abundance of each amplicon.

$\boldsymbol{R A D 5 2}$ knockdown in human B cells. The human RAD52-specific siRNA oligo duplex (TT320001, Locus ID 5893) and non-effective Trilencer-27 Flurescent-labeled transfection control siRNA duplex (SR30002) were obtained from Origene Technologies. The siRNA duplexes were used to transfect purified human naïve B cells using the Human B Cell Nucleofector ${ }^{\mathrm{TM}}$ Kit (VPA-1001, LONZA). Transfected B cells were then stimulated with CpG ODN 2395 plus IL-2 and IL-21 for 96 h before genomic DNA extraction for analysis of S $\mu-\sigma \delta$ and $\mathrm{S} \mu-\mathrm{S} \gamma 1$ DNA recombination. Expression of RAD52 and AICDA transcripts were analyzed by qRT-PCR using specific primers $24 \mathrm{~h}$ after transfection. Expression of RAD52, phosphorylated-RAD52, AID and $\beta$-ACTIN proteins were analyzed by immune-blotting $24 \mathrm{~h}$ after transfection.

High-throughput mRNA-Seq. RNA was isolated from cells using the Directzol RNA Microprep Kit (Zymogen Research), according to manufacturer's instructions and as previously described ${ }^{66}$. RNA integrity was verified using an Agilent Bioanalyzer 2100 (Agilent). Next generation RNA-Seq for mRNA and non-coding RNA was performed by the Genome Sequencing Facility at University of Texas Health Science Center San Antonio Greehey Children's Cancer Research Institute. High-quality RNA was processed using an Illumina TruSeq RNA sample prep kit v2 or TruSeq Small RNA Sample Prep kit following the manufacturer's instructions (Illumina). Clusters were generated using TruSeq Single-Read Cluster Gen. Kit v3-cBot-HS on an Illumina cBot Cluster Generation Station. After quality control procedures, individual mRNA-Seq or small RNA-Seq libraries were then pooled based on their respective 6-bp index portion of the TruSeq adapters and sequenced at $50 \mathrm{bp} / \mathrm{sequence}$ using an Illumina HiSeq 3000 sequencer. Resulting reads were checked by assurance (QA) pipeline and initial genome alignment (Alignment). After the sequencing run, demultiplexing with CASAVA was employed to generate the Fastq file for each sample. All sequencing reads were aligned with their reference genome (UCSC mouse genome build mm9) using TopHat2 default settings, and the Bam files from alignment were processed using HTSeq-count to obtain the counts per gene in all samples. Quality control statistical analysis of outliers, intergroup variability and distribution levels, were performed for statistical validation of the experimental data.

597 Statistical analysis. Statistical analysis was performed using Excel (Microsoft) or Prism ${ }^{\circledR}$ GraphPad software. 
$598 P$-values were determined by paired and unpaired Student's $t$-tests; and $P$-values $<0.05$ were considered 599 significant.

600 IRB for use of human tissues and peripheral blood as well as IACUC for use of mice. For the use of DNA 601 procured from formalin fixed paraffin embedded tissues obtained from the University of Arkansas for Medical 602 Science, the study was reviewed by the University of Arkansas for Medical Sciences Institutional Review Board 603 (IRB) which determined that this project is not human subject research as defined in 45 CFR 46.102. Human B 604 cells were purified from PBMCs of healthy subject buffy coats obtained from South Texas Blood and Tissue 605 Center, San Antonio, Texas, under the Healthy Volunteer Blood Donor Program and lupus patients B cells were 606 purified PBMCs obtained under the Long School of Medicine IRB HSC 20140234H Class switching, somatic 607 hypermutation and plasma cell differentiation in B cells. Mouse and mouse B cell studies were performed under 608 the Long School of Medicine IACUC 20200019AR Somatic hypermutation, class switch DNA recombination and 609 plasma cell differentiation in antibody and autoantibody responses. 
$610 \quad$ Figure legends

611 Fig. 1 | Expression of cell surface and secreted $\lg D$ and $\lg M$, as well as $\operatorname{l} \mu-C \delta$ transcripts by alternative 612 splicing, alternative transcription termination and CSR. a, Schematics of alternative splicing and alternative 613 transcription termination for expression of membrane and secreted IgM and IgD, as well as germline $I \mu$-C $\mu$ and $614 I \mu-C \delta$ transcripts in B cells. In the presence of Zfp318, which represses the transcription termination sites (TTS) 615 of the $C_{\mu}$ gene, mature $B$ cells constitutively transcribe long primary $V_{H} D J_{H}-C \mu-C \delta s-m$ transcripts initiated by the $616 V_{H}$ promoter. These long primary transcripts undergo alternative splicing which removes intronic regions, leading 617 to dual expression of mature $V_{H} D J_{H^{-}} C \mu s$ and $V_{H} D J_{H^{-}} C \delta m$ transcripts encoding IgM and IgD. In the absence of 618 Zfp318, transcription stops at $\mathrm{C} \mu \mathrm{TTS}$, resulting in a shorter primary transcript, which does not contain C $\delta$ exons, 619 and lead to expression of a mature $V_{H} D J_{H}-C \mu-S-m$ transcript only. Mature B cells also transcribe $I \mu, C \mu$, and $C \delta$ regions under control of the $1 \mu$ promoter. When Zfp318 is present, unswitched mature $B$ cells constitutively transcribe long primary $I \mu-C \mu-s-m-C \delta-s-m$ transcripts, which undergo alternative splicing to removes intronic regions, leading to dual expression of germline $I \mu-C \mu$ and $I \mu-C \delta$ transcripts. In the absence of Zfp318, I $\mu$ promoter-initiated transcription stops at $\mathrm{C} \mu$ TTS, and only germline $\mathrm{I}_{\mu}-\mathrm{C} \mu$ transcripts are expressed. $\mathbf{b}$, Expression of membrane and secreted $\lg \mathrm{D}$, and $I \mu-C \delta$ transcripts by CSR. Schematic representation of CSR from IgM to $\operatorname{lgD}$. The $S \mu$ region recombines with the $\sigma \delta$ region and loops out the intervening DNA, which forms a switch circle. The recombined DNA is transcribed leading to expression of $V_{H} D J_{H^{-}} C \delta-S-m$ and $I \mu-C \delta$ transcripts, initiated by the $V_{H}$ and $I \mu$ promoters, respectively. In this case, $I \mu-C \delta$ transcripts are generated as post-recombination transcripts. Graphics depict portion of the $I g H$ locus and the resulting primary and mature transcripts. The inset depicts a schematic representation of the detection of $S \mu-\sigma \delta$ junctional DNA (CSR to IgD) by nested PCR amplification followed by Southern-blotting using specific $S_{\mu}$ and $\sigma \delta$ probes (Southern-blotting of amplified recombined $S_{\mu-\sigma \delta}$ DNA from human naïve and germinal center B cells). In many cases the amplified $S_{\mu-\sigma \delta} D N A$ was sequenced for further analysis of junctional sequence well as dentification and census of mutations. $\mathrm{iE} \mu, \operatorname{lgH}$ intronic enhancer; $1 \mu$, intervening $\mu$ exon; $\mu \mathrm{m}$, exon encoding the transmembrane region of IgM; $\delta \mathrm{m}$, exon encoding the secretory piece of $\operatorname{IgM} ; \sigma \delta$, noncanonical switch-like region $5^{\prime}$ to $\mathrm{C} \delta$; $\delta \mathbf{s}$, exon encoding the secretory region of $\mathrm{IgD} ; \mathrm{C} \delta \mathrm{m}$, exon encoding the transmembrane region of $\mathrm{lgD}$. Dotted gray lines show splicing configurations of primary transcripts to yield secreted and transmembrane forms of $\lg M$ and $\lg D$.

637 Fig. 2 | Identification of stimuli inducing CSR to IgD and $\mathbf{S} \mu-\sigma \delta$ junctions in mouse and human B cells. a, 638 Wildtype C57BL/6 and $\mathrm{Aicda}^{-/}$mouse naïve B cells were stimulated with nil, LPS, LPS plus IL-4, LPS plus TGF$639 \beta$ and RA, CD154, CD154 plus IL-4, CD154 plus TGF- $\beta$ and RA, CpG, CpG plus IL-4, CpG plus TGF- $\beta$ and RA, 640 R848, R848 plus IL-4, R848 plus TGF- $\beta$ and RA, or CpG plus IL-4, or R848 plus IL-4 in the presence of anti-BCR. 641 Recombined $S_{\mu}-\sigma \delta$, as well as $S_{\mu}-S_{\gamma} 1, S_{\mu}-S_{\gamma} 3, S_{\mu}-S_{\alpha}$ and $S_{\mu}-S_{\alpha}$ DNA were analyzed 72 or 96 h post-stimulation 642 by nested long-range PCR using forward $I \mu$ and reverse $C \delta$ primers, or forward $I \mu$ and reverse $S \gamma 1, S \gamma 3, S \alpha$ or $S \varepsilon$ 643 primers, respectively, followed by Southern-blotting using a specific $S \mu, \sigma \delta, S \gamma 1, S \gamma 3$, S $\alpha$ or $S \varepsilon$ probe, as indicated. $644 \mathrm{~b}$, Recombined $\mathrm{S} \mu-\sigma \delta$ DNA in human tonsil $\lg \mathrm{D}^{+} \mathrm{B}$ cells, blood naive $\mathrm{B}$ cells, or blood naive $\mathrm{B}$ cells stimulated with 645 CD145 or CpG plus IL-2 and IL-21, IL-4 and IL-21, or IL-2, IL-4 and IL-21 or IL-15 and II-21, were analyzed 96 or $646120 \mathrm{~h}$ post-stimulation by nested long-range PCR using forward $\mathrm{l} \mu$ and reverse $C \delta$ primers, followed by Southern- 
blotting using specific human $S_{\mu}$ or $\sigma \delta$ probe. Data are one representative of 3 independent experiments yielding comparable results. c, Germline/post-recombination $I \mu-C \delta$ transcripts, post-recombination $I \mu-C \gamma 1$, I $\mid \mu-C \alpha$ and $I \mu-$ $\mathrm{C}_{\varepsilon}$ transcripts in wildtype C57BL/6 B cells stimulated with nil, LPS plus IL-4, or LPS plus TGF- $\beta$ and RA, analyzed $72 \mathrm{~h}$ post-stimulation by qRT-PCR and normalized to $\beta$-Actin expression. Each dot represents data obtained with B cells from an individual mouse ( $n=3$ per group). Data are mean \pm SEM.

Fig. 3 | Mouse and human $S_{\mu}-\sigma \delta$ DNA recombination junctions contain microhomologies and somatic

mutations. a, Amplified junctional DNAs of intra- $\sigma \delta$ deletions, as well as $S \mu-\sigma \delta, S \mu-S \gamma 1$ and $S \mu-S \alpha 1$ recombination from OVA-immunized C57BL/6 mouse spleen B cells, C57BL/6 mouse naïve $B$ cells stimulated with LPS plus IL-4 and cultured for $96 \mathrm{~h}$, as well as human tonsil B cells or human peripheral blood naïve B cells stimulated with CpG plus IL-2 and IL-21 and cultured for 96 or $120 \mathrm{~h}$ were sequenced by MiSeq. The length and numbers of nucleotide overlaps (microhomologies) in intra- $\sigma \delta$ deletions, $S \mu-\sigma \delta, S_{\mu-S} 1$ and $S \mu-S \alpha 1$ junctional DNAs are shown by violin plots. Each dot represents a unique junctional sequence ( $n=45$ per group). b, Mouse and human $S \mu$ and $\sigma \delta$ regions consist of repetitive motifs, which are better suited substrates for Rad52-mediated MMEJ than those in $S \mu$ and $S \gamma 1$ or $S \mu$ and $S \alpha$. As such, they can facilitate the formation of microhomologies. Repetitive sequence elements in mouse and human $S \mu, \sigma \delta, S_{\gamma} 1$ and $S \alpha$ that can potentially form microhomologies were identified by Pustell Matrix dot plot using MacVector software and are depicted by small dots. Intensity of dots depicts frequency and degree of complementarity of respective sequences. c, Somatic point-mutations in $S_{\mu}$ and $\sigma \delta$ regions abetting recombined $S \mu-\sigma \delta$ DNA junctions in IgD class-switched mouse and human $B$ cells in vitro and in vivo. Mutations were identified in a 48 to $506 \mathrm{nt}$ stretch of $S \mu$ or $\sigma \delta$ regions in unique $S \mu-\sigma \delta$ DNA recombination sequences. Each dot represents an individual sequence. Sequence data were pooled from 3 individuals in each group. In pie charts, the size of slices denotes the proportion of sequences with the same number of mutations and the grey hue denotes the number of point-mutations per sequence; below the pie charts is the overall mutation frequency (change/base). ${ }^{* *} p<0.01,{ }^{* * *} p<0.001$, ns: not significant (unpaired $t$ test). Amplified intra- $\sigma \delta$ deletional, $S_{\mu-\sigma \delta}, S_{\mu}-S_{\gamma} 1$ and $S_{\mu-S} \alpha 1$ junctional DNAs from human tonsil B cells were sequenced using MiSeq system. Thirty-two intra- $\sigma \delta, S_{\mu-} \sigma \delta, S_{\mu-S} 1$ or $S_{\mu-S \alpha 1}$ junction sequences are shown in each column. Each sequence is compared with the corresponding germline $S_{\mu}$ (above, blue) and $\sigma \delta, S_{\gamma} 1$ or $S_{\alpha} 1$ (below, red) sequences. Microhomologies (bold) were determined by identifying the longest region at the $S_{\mu}-\sigma \delta$, $S_{\mu}-S_{\gamma} 1$ or $S_{\mu-S \alpha 1}$ junction of perfect uninterrupted donor/acceptor identity or the longest overlap region at the S-S junction with no more than one mismatch on either side of the breakpoint.

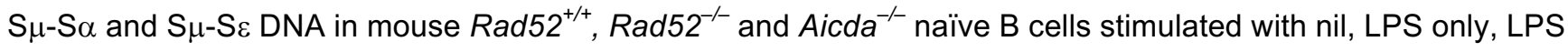
plus IL-4, LPS plus TGF- $\beta$ and RA, CD154 only, CD154 plus IL-4, or CD154 plus TGF- $\beta$ and RA, as well as $\mathrm{S}_{\mu-}$ $\mathrm{S} \gamma 3$ in $\operatorname{Rad}_{52}^{+/+}$, Rad52 ${ }^{-/}$and $\mathrm{Aicda}^{-/} \mathrm{B}$ cells stimulated with LPS only, were analyzed $96 \mathrm{~h}$ post stimulation by nested long-range PCR using forward $I \mu$ and reverse $C \delta, S \gamma 1, S \gamma 3, S \alpha$ or $S \varepsilon$ primers, respectively, followed by 
independent experiments yielding comparable results. b, IgD titers in culture $(96 \mathrm{~h})$ fluid of $\operatorname{Rad}^{2} 2^{+/+}$and $\operatorname{Rad}^{-} 2^{-}$ ${ }^{-}$B cells stimulated with LPS plus IL-4, as measured by dot-blotting (two-fold serial diluted culture fluid) using a rat anti-mouse $\operatorname{lgD} \mathrm{mAb}$. Data are one representative of 5 independent experiments yielding comparable results. mesenteric lymph nodes (MLN) and Peyer's patches B cells, as analyzed by nested long-range PCR using forward $I \mu$ and reverse $C \delta, S \gamma 1$ or $S \alpha$ primers, followed by Southern-blotting using specific $S \mu, \sigma \delta, S \gamma 1$ or $S \alpha$ probe, as indicated. Data are one representative of 3 independent experiments yielding comparable results. $\mathbf{b}, S \mu-\sigma \delta, S \mu-$ $S_{\gamma} 1$ and $S \mu-S \alpha$ junctional DNAs were amplified by nested PCR and sequenced using by MiSeq. The length and numbers of nucleotide overlaps (microhomologies) in $S \mu-\sigma \delta, S \mu-S \gamma 1$ and $S \mu-S \alpha$ junctional DNAs are shown by violin plots. Each symbol represents a unique sequence ( $n=45$ per group). c-f, Titers of total $\operatorname{lgD}$ in serum, $\mathrm{BALF}$ and feces, as analyzed by dot-blotting using rat anti-mouse $\lg \mathrm{D} \mathrm{mAb}$. Titers of total $\lg \mathrm{M}, \lg \mathrm{D}, \lg \mathrm{g} 1$ and $\lg \mathrm{A}$ as well as OVA-binding $\operatorname{lgM}, \lg D, \lg G 1$ and $\lg A$ as analyzed by specific ELISAs. Each dot represents data from one individual mouse ( $n=5-8$ per group, pooled from two experiments). ${ }^{*} p<0.05,{ }^{* *} p<0.01,{ }^{* * *} p<0.001$, ns: not significant (unpaired $t$ test). g, Bacteria-bound $\lg D$ and $\lg A$ in feces as analyzed by flow cytometry. $\mathbf{h}, \lg M, \lg D$ and IgA positive cells in mesenteric lymph nodes (MLNs) and lamina propria as visualized by fluorescence microscopy. Data in $\mathbf{g}, \mathbf{h}$ are representative of 3 independent experiments.

Fig. 7 | Rad52 is phosphorylated and recruited to $S_{\mu}$ and $\sigma \delta$ in B cells induced to undergo IgD CSR. a, C57BL/6 mouse naïve B cells were stimulated with LPS plus IL-4 and cultured for 0, 24, 48, 72 and 96 h. Rad52, Ku70, Ku86 and Aicda transcripts were analyzed by real-time qRT-PCR, normalized to $\beta$-Actin expression and depicted as relative to the expression in unstimulated $B$ cells (set as 1.0). Data are mean \pm SEM of 3 independent experiments. b, Expression of Rad52, phosphorylated Rad52 (p-Rad52), AID, Ku70, Ku86, and $\beta$-Actin proteins in mouse B cells stimulated with LPS plus IL-4 (as in a), as analyzed by specific immunoblotting. Data are one representative of 3 independent experiments yielding comparable results. c, Human peripheral blood naive B cells were stimulated with CD154 plus IL-4 and IL-21 and cultured for 0, 24, 48, 72 and $96 \mathrm{~h}$. RAD52, KU70, KU86 and $A I C D A$ transcripts were analyzed by real-time qRT-PCR, normalized to $\beta$-ACTIN expression and depicted as relative to the expression in unstimulated $B$ cells (set as 1.0). Data are mean \pm SEM of 3 independent experiments. d, Recruitment of Rad52 to $\sigma \delta$ region DNA, as analyzed by ChIP-qPCR assays in mouse $\operatorname{Rad}^{+/+}$and $\operatorname{Rad}^{-1} \mathrm{~B}$ cells stimulated with LPS plus IL-4 and cultured for $72 \mathrm{~h}$. Data are expressed as percent of pre-IP input for each sample (mean \pm SEM). e,f, C57BL/6 mouse B cells were stimulated with nil, LPS, LPS plus IL-4 or LPS plus TGF$\beta$ and RA and cultured for $72 \mathrm{~h}$. Recruitment of Rad52 (e) and Ku70/Ku86 (f) to $S_{\mu}, \sigma \delta, S_{\gamma} 1, S_{\gamma} 3$ and $S \alpha$ region DNA, as analyzed by ChIP-qPCR assays. Data are mean \pm SEM of 3 independent experiments. expression of $\lg \mathrm{M}$ and $\lg D$ were analyzed $96 \mathrm{~h}$ post stimulation by flow cytometry. Expression of $V_{H} D J_{H}-C \delta-m$, 
RT-PCR using serial two-fold dilution of cDNA templates. Data are representative of 3 independent experiments. b, IgD in supernatant from cultures ( $96 \mathrm{~h}$ ) of C57BL/6 mouse naïve B cell stimulated with nil, LPS plus IL-4, LPS plus TGF- $\beta$ and RA, or CD154 plus IL-4, as analyzed by dot-blotting using rat anti-mouse IgD mAb. Data are representative of 5 independent experiments. c, Expression of Zfp318 transcripts in mouse naïve B cells stimulated with nil, LPS plus IL-4, or LPS plus TGF- $\beta$ and RA, as analyzed $72 \mathrm{~h}$ post-stimulation by qRT-PCR and normalized to $\beta$-Actin expression and depicted relative to the average expression in unstimulated $\mathrm{B}$ cells (set as 1). Data are mean \pm SEM of 3 independent experiments. d, Expression of Zfp318 transcripts in mouse naïve $B$ cells stimulated with LPS plus IL-4, as analyzed $96 \mathrm{~h}$ post-stimulation by mRNA-Seq. Data are mean \pm SEM of 4 independent experiments. e, Zfp318 protein level in mouse naïve B cells stimulated with nil, LPS plus IL-4, or LPS plus TGF- $\beta$ and RA, as analyzed $96 \mathrm{~h}$ post-stimulation by intracellular staining with rabbit anti-Zfp318 Ab in flow cytometry. Bars on the right panel represent the MFI (mean \pm SEM) from 3 independent experiments. f, Human blood naïve B cells stimulated with nil, CpG plus IL-2 and IL-21 or CpG plus IL-4 and IL-21. Human $V_{H} D J_{H^{-}} C \delta-m$, $V_{H} D J_{H^{-}} C \delta-S, V_{H} D J_{H^{-}} C \mu-m$ and $V_{H} D J_{H^{-}}-C \mu-s$ transcript levels were measured $72 \mathrm{~h}$ post-stimulation by semiquantitative RT-PCR with serial two-fold dilution of CDNA templates - data are representative of 3 independent experiments (left panels). Expression of ZFP318 transcripts as analyzed $72 \mathrm{~h}$ post-stimulation by qRT-PCR and normalized to HPRT expression ( $f$ middle panel) - data are mean \pm SEM of 3 independent experiments. Secreted $\lg \mathrm{D}$ in supernatants of the human B cell cultures, as analyzed $120 \mathrm{~h}$ post stimulation by specific ELISA (f right panel) - data are mean \pm SEM of 4 independent experiments. g, Expression of $V_{H} D J_{H^{-}} C \delta-m, V_{H} D J_{H^{-}} C \delta-s, V_{H} D J_{H^{-}}$ $C \mu-m$ and $V_{H} D J_{H}-C \mu-s$ transcripts in human total $\lg D^{+}$tonsil B cells, as analyzed by semi-quantitative RT-PCR involving serial two-fold dilution of cDNA templates (left panel) - data are representative of 3 independent experiments. Expression of ZFP318 protein in human tonsil $\operatorname{lgM}^{+} \lg D^{+} B$ cells and $\lg M^{-} \lg D^{+} B$ cells, as analyzed by intracellular staining with anti-Zfp318 Ab in flow cytometry (middle panel) - data are representative of 4 independent experiments (mean \pm SEM, right panel). $h$, Surface expression of IgM and IgD in mouse naïve Rad52 $^{+/+}$, Rad52 ${ }^{-/}$and Aicda ${ }^{-/}$B cells stimulated with LPS plus IL-4, or LPS plus TGF- $\beta$ and RA, as analyzed 96 h post-stimulation by flow cytometry. Data are representative of 3 independent experiments. i, Expression of

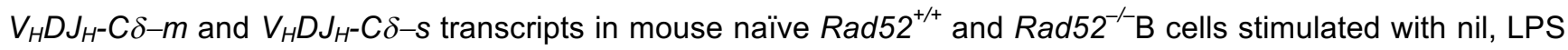
plus IL-4 or LPS plus TGF- $\beta$ and RA, as analyzed $72 \mathrm{~h}$ post-stimulation by semi-quantitative RT-PCR using serial two-fold dilution of cDNA templates. Data are representative of 3 independent experiments. j, Rad52 or AID deficiency does not alter Zfp318 expression. Expression of Zfp318 transcripts in mouse naïve Rad52 ${ }^{+/+}$, Rad52 ${ }^{-}$and Aicda $^{-/}$B cells stimulated with nil, LPS plus IL-4, or LPS plus TGF- $\beta$ and RA, as analyzed $72 \mathrm{~h}$ poststimulation by qRT-PCR and normalized to $\beta$-Actin expression, as depicted relative to expression in unstimulated $B$ cells (set as 1). Data are mean \pm SEM of 3 independent experiments.

Fig. 9 | RAD52 is required for $S \mu-\sigma \delta$ DNA recombination in human $B$ cells. a, Human blood naïve $\lg M^{+} \lg D^{+} B$ cells were transfected with specific RAD52 siRNA or scrambled (Scra) siRNA and stimulated by CpG plus IL-2 and IL-21. Recombined $S \mu-\sigma \delta$ and $S \mu-S \gamma 1$ DNA in the transfected B cells $120 \mathrm{~h}$ after siRNA transfection, as well as $S \mu-\sigma \delta$ DNA in tonsil $\lg M^{-} \lg D^{+}$and blood naive $\lg \mathrm{M}^{+} \lg D^{+} B$ cells were analyzed by nested long-range PCR using 
from 3 independent experiments. b, Expression of RAD52 and $A / C D A$ transcripts was analyzed $48 \mathrm{~h}$ after siRNA transfection by qRT-PCR and normalized to HPRT expression. Data are mean \pm SEM of 3 independent experiments. c, Expression of RAD52 and AID proteins were analyzed $72 \mathrm{~h}$ after siRNA transfection by specific immunoblotting. Data are representative of 3 independent experiments. $\mathbf{d}$, Expression of $V_{H} D J_{H^{-}} C \delta m$ and $V_{H} D J_{H^{-}}$ $C \delta s$ transcripts as analyzed by semi-quantitative RT-PCR with of serial two-fold dilution of cDNA templates. Data are representative of 3 independent experiments. e, RAD52 is recruited to $\sigma \delta$ region DNA in human B cells undergoing CSR to IgD. Recruitment of RAD52 to $S \mu$ and $\sigma \delta$ region DNA in human blood $B$ cells stimulated for $120 \mathrm{~h}$ with CpG plus IL-2 and IL-21, as analyzed by specific ChIP-qPCR. Data are mean \pm SEM of 3 or 4 independent experiments.

Fig. 10 | B cells undergoing CSR to IgD differentiate to IgD-producing plasmablasts/plasma cells. a, Human B cells stimulated with CpG plus IL-2 and IL-21, which induce IgD CSR, or CpG plus IL-4 and IL-21, which do not induce $\operatorname{lgD} C S R$. Proportions of $\mathrm{CD}^{138^{+}} \operatorname{lgD}^{+} \operatorname{lgM}{ }^{-}$plasmablasts/plasma cells among intracellular slgM $^{-} \operatorname{lgD}^{+} \mathrm{B}$ cells and Blimp1 expression in intracellular $\lg ^{+}$slgM $^{-}$cells, as analyzed $120 \mathrm{~h}$ post stimulation by flow cytometry. b, mouse $\mathrm{Rad}_{52}{ }^{+/+}$and $\mathrm{Rad}_{52} 2^{-/} \mathrm{B}$ cells stimulated with LPS plus IL-4, which induce IgD CSR. Proportions of sCD $138^{+}$plasmablasts/plasma cells among intracellular $\operatorname{lgD}^{+}$slgM $^{-}$cells and Blimp1 expression in intracellular $\lg ^{+}$slgM $^{-}$cells, as analyzed $96 \mathrm{~h}$ post stimulation by flow cytometry. Data in $\mathbf{a}$ and $\mathbf{b}$ are representative of 3 independent experiments. c, Recombined $S_{\mu-\sigma \delta}$ and $S_{\mu}-S_{\alpha}$ DNA in two $\lg D^{+}$myelomas and one $\lg A^{+}$myeloma as analyzed by nested long-range PCR followed by Southern-blotting using indicated probes.

Fig. 11 | p-Rad52 expression, CSR to IgD and anti-nuclear antigen IgD autoantibodies in lupus mice and patients. a, Concentrations of total, and dsDNA-, RNA-, histone- or RNP/Sm-binding IgD in healthy human subjects and SLE patients, as analyzed by specific ELISAs. Data are mean \pm SEM of 6 to 10 healthy subjects or SLE patients. b, Concentrations of total IgD in serum, feces and BALF as analyzed by dot-blotting, and concentrations of dsDNA- or histone-binding IgD autoantibodies in serum of C57BL/6 and MRL/Fas ${ }^{\text {Ipr/pr }}$ mice as analyzed by specific ELISAs. Data are mean \pm SEM of 3 to 9 mice. c, IgD concentrations in the serum, BALF and feces of C57BL/6 and MRL/Fas ${ }^{\text {Ipr/pr }}$ mice, as analyzed by dot-blotting. Shown are dot-blots from one C57BL/6 and one MRL/Fas ${ }^{\text {Ipr/pr }}$ mouse, representative of 3 to $9 \mathrm{C} 57 \mathrm{BL} / 6$ and MRL/Fas ${ }^{\text {Ipr/pr }}$ mice. Expression of $V_{H} D J_{H^{-}}$ $C \delta m, V_{H} D J_{H^{-}} C \delta s, V_{H} D J_{H^{-}} C \mu m$ and $V_{H} D J_{H^{-}} C \mu s$ transcripts in bone marrow (BM), spleen and mesenteric lymph nodes (MLNs) as analyzed semi-quantitative RT-PCR in serial two-fold dilutions of cDNA templates. Shown are RT-PCR data from one C57BL/6 and one MRL/Fas ${ }^{\text {Ipr/pr }}$ mouse, representative of 3 C57BL/6 and 3 MRL/Fas ${ }^{\text {Ipr/pr }}$ mice. d, ANAs as visualized by indirect immunofluorescence on HEp-2 cells that were incubated with sera from a human healthy subject and a SLE patient or C57BL/6 and MRL/Fas ${ }^{I / / p r}$ mice and revealed using FITC-labeled rat $\mathrm{mAb}$ to mouse $\operatorname{lgD}$. e, Bacteria-bound $\lg \mathrm{D}$ and $\lg \mathrm{A}$ in feces of C57BL/6 and MRL/Fas ${ }^{\text {Ir/l/pr }}$ mice, as analyzed by flow cytometry. $f, \operatorname{lgD}^{+} \mathrm{B}$ cells in lamina propria, MLNs and Peyer's patches of C57BL/6 and MRL/Fas ${ }^{\text {Ipr/pr }}$ mice, as visualized by fluorescent microscopy. $\mathbf{g}$, Recombined $\mathrm{S} \mu-\sigma \delta, \mathrm{S}_{\mu}-\mathrm{S}_{\gamma} 1$, and $\mathrm{S} \mu-\mathrm{S}_{\alpha}$ DNA in bone marrow, spleen, MLNs and Peyer's patches B cells from C57BL/6 and MRL/Fas ${ }^{\text {Ipr/pr }}$ mice were analyzed by nested long-range PCR using forward $I \mu$ and reverse $C \delta, S_{\gamma} 1$ or $S \alpha$ primers, followed by Southern-blotting using indicated probes. 
immunized MRL/Fas ${ }^{I p r / p r}$ mice, as amplified by nested PCR and sequenced by MiSeq. The length and numbers

794 of nucleotide overlaps (microhomologies) in $S \mu-\sigma \delta, S \mu-S \gamma 1$ and $S \mu-S \alpha$ junctional DNAs are shown by violin plots.

795 Each dot represents a unique sequence ( $n=45$ per group). i, Somatic point-mutations in $S \mu$ and $\sigma \delta$ regions 796 abetting recombined $S \mu-\sigma \delta$ DNA junctions in IgD class-switched spleen B cells from 3 MRL/Fas ${ }^{\text {Ipr/lpr }}$ mice. 797 Mutations were identified in a 48 to 506 nt stretch of $S \mu$ or $\sigma \delta$ regions in unique $S \mu-\sigma \delta$ DNA recombination 798 sequences. Each dot represents an individual sequence. In pie charts, the size of slices denotes the proportion 799 of sequences with the same number of mutations and the grey hue denotes the number of point-mutations per 800 sequence; below the pie charts is the overall mutation frequency (change/base). ${ }^{* *} p<0.05,{ }^{* *} p<0.01$, $801{ }^{* * *} p<0.001$, ns: not significant (unpaired $t$ test). j, Expression of Zfp318 and Aicda transcripts in MLNs from non802 immunized $\mathrm{C} 57 \mathrm{BL} / 6$ and $\mathrm{MRL} / \mathrm{Fas}^{\text {Ipr/pr }}$ mice as analyzed by specific qRT-PCR. Data are mean \pm SEM of 3 803 C57BL/6 and 3 MRL/Fas ${ }^{\text {Ipr/pr }}$ mice. k, Expression of phosphorylated Rad52 (p-Rad52), Rad52 and $\beta$-Actin 804 proteins in peripheral blood B cells from healthy human subjects and SLE patients as well as B cells from non805 immunized C57BL/6 and MRL/Fas ${ }^{\text {Ipr/pr }}$ mice, as analyzed by specific Western blotting using rabbit anti-p-Rad52 806 Ab (Y408472, Applied Biological Materials Inc.) or anti-B-Actin mAb (2F1-1, BioLegend). P-Rd52 (Y104) Ab 807 detected endogenous levels of Rad52 protein only when phosphorylated at tyrosine 104. 
Rad52 mediates CSR to IgD

\section{References}

1. Chen, K., Xu, W., Wilson, M., He, B., Miller, N.W., Bengten, E., Edholm, E.S., Santini, P.A., Rath, P., Chiu, A., Cattalini, M., Litzman, J., J, B.B., Huang, B., Meini, A., Riesbeck, K., Cunningham-Rundles, C., Plebani, A. \& Cerutti, A. Immunoglobulin D enhances immune surveillance by activating antimicrobial, proinflammatory and B cellstimulating programs in basophils. Nat Immunol 10, 889-898 (2009).

2. Chen, K. \& Cerutti, A. New insights into the enigma of immunoglobulin D. Immunol Rev 237, 160-179 (2010).

3. Cerutti, A., Chen, K. \& Chorny, A. Immunoglobulin responses at the mucosal interface. Annu Rev Immunol 29, 273-293 (2011).

4. Chen, K. \& Cerutti, A. The function and regulation of immunoglobulin D. Curr Opin Immunol 23, 345-352 (2011).

5. Choi, J.H., Wang, K.W., Zhang, D., Zhan, X., Wang, T., Bu, C.H., Behrendt, C.L., Zeng, M., Wang, Y., Misawa, T., Li, X., Tang, M., Zhan, X., Scott, L., Hildebrand, S., Murray, A.R., Moresco, E.M., Hooper, L.V. \& Beutler, B. IgD class switching is initiated by microbiota and limited to mucosa-associated lymphoid tissue in mice. Proc Natl Acad Sci U S $A$ 114, E1196-E1204 (2017).

6. Chen, K., Magri, G., Grasset, E.K. \& Cerutti, A. Rethinking mucosal antibody responses: IgM, IgG and IgD join IgA. Nat Rev Immunol 20, 427-441 (2020).

7. Ohta, Y. \& Flajnik, M. IgD, like IgM, is a primordial immunoglobulin class perpetuated in most jawed vertebrates. Proc Natl Acad Sci U S A 103, 10723-10728 (2006).

8. Gutzeit, C., Chen, K. \& Cerutti, A. The enigmatic function of IgD: some answers at last. Eur J Immunol 48, 1101-1113 (2018).

9. Shan, M., Carrillo, J., Yeste, A., Gutzeit, C., Segura-Garzon, D., Walland, A.C., Pybus, M., Grasset, E.K., Yeiser, J.R., Matthews, D.B., van de Veen, W., Comerma, L., He, B., Boonpiyathad, T., Lee, H., Blanco, J., Osborne, L.C., Siracusa, M.C., Akdis, M., Artis, D., Mehandru, S., Sampson, H.A., Berin, M.C., Chen, K. \& Cerutti, A. Secreted IgD Amplifies Humoral T Helper 2 Cell Responses by Binding Basophils via Galectin-9 and CD44. Immunity 49, 709-724 (2018).

10. Enders, A., Short, A., Miosge, L.A., Bergmann, H., Sontani, Y., Bertram, E.M., Whittle, B., Balakishnan, B., Yoshida, K., Sjollema, G., Field, M.A., Andrews, T.D., Hagiwara, H. \& Goodnow, C.C. Zinc-finger protein ZFP318 is essential for expression of IgD, the alternatively spliced Igh product made by mature B lymphocytes. Proc Natl Acad Sci U S A 111, 4513-4518 (2014).

11. Pioli, P.D., Debnath, I., Weis, J.J. \& Weis, J.H. Zfp318 regulates IgD expression by abrogating transcription termination within the Ighm/Ighd locus. J Immunol 193, 2546-2553 (2014).

12. Rouaud, P., Saintamand, A., Saad, F., Carrion, C., Lecardeur, S., Cogne, M. \& Denizot, Y. Elucidation of the enigmatic IgD class-switch recombination via germline deletion of the IgH 3' regulatory region. J Exp Med 211, 975-985 (2014).

13. Kluin, P.M., Kayano, H., Zani, V.J., Kluin-Nelemans, H.C., Tucker, P.W., Satterwhite, E. \& Dyer, M.J. IgD class switching: identification of a novel recombination site in neoplastic and normal B cells. Eur J Immunol 25, 3504-3508 (1995).

14. Arpin, C., de Bouteiller, O., Razanajaona, D., Fugier-Vivier, I., Briere, F., Banchereau, J., Lebecque, S. \& Liu, Y.J. The normal counterpart of IgD myeloma cells in germinal center displays extensively mutated IgVH gene, Cm-Cd switch, and lambda light chain expression. J Exp Med 187, 1169-1178 (1998).

15. Xu, Z., Zan, H., Pone, E.J., Mai, T. \& Casali, P. Immunoglobulin class-switch DNA recombination: induction, targeting and beyond. Nat Rev Immunol 12, 517-531 (2012).

16. Pannunzio, N.R., Watanabe, G. \& Lieber, M.R. Nonhomologous DNA end-joining for repair of DNA double-strand breaks. J Biol Chem 293, 10512-10523 (2018).

17. Wright, W.D., Shah, S.S. \& Heyer, W.D. Homologous recombination and the repair of DNA double-strand breaks. $J$ Biol Chem 293, 10524-10535 (2018).

18. Yan, C.T., Boboila, C., Souza, E.K., Franco, S., Hickernell, T.R., Murphy, M., Gumaste, S., Geyer, M., Zarrin, A.A., Manis, J.P., Rajewsky, K. \& Alt, F.W. IgH class switching and translocations use a robust non-classical end-joining pathway. Nature 449, 478-482 (2007).

19. Boboila, C., Yan, C., Wesemann, D.R., Jankovic, M., Wang, J.H., Manis, J., Nussenzweig, A., Nussenzweig, M. \& Alt, F.W. Alternative end-joining catalyzes class switch recombination in the absence of both Ku70 and DNA ligase 4 . $J$ Exp Med 207, 417-427 (2010).

20. Zan, H., Tat, C., Qiu, Z., Taylor, J.R., Guerrero, J.A., Shen, T. \& Casali, P. Rad52 competes with Ku70/Ku86 for binding to S-region DSB ends to modulate antibody class-switch DNA recombination. Nat Commun 8, 14244 (2017).

21. Sallmyr, A. \& Tomkinson, A.E. Repair of DNA double-strand breaks by mammalian alternative end-joining pathways. J Biol Chem 293, 10536-10546 (2018). 
bioRxiv preprint doi: https://doi.org/10.1101/2021.06.28.450246; this version posted July 14, 2021. The copyright holder for this preprint (which was not certified by peer review) is the author/funder. All rights reserved. No reuse allowed without permission.

Rad52 mediates CSR to IgD

22. Bothmer, A., Robbiani, D.F., Feldhahn, N., Gazumyan, A., Nussenzweig, A. \& Nussenzweig, M.C. 53 BP1 regulates DNA resection and the choice between classical and alternative end joining during class switch recombination. $J$ Exp Med 207, 855-865 (2010).

23. Bothmer, A., Robbiani, D.F., Di Virgilio, M., Bunting, S.F., Klein, I.A., Feldhahn, N., Barlow, J., Chen, H.T., Bosque, D., Callen, E., Nussenzweig, A. \& Nussenzweig, M.C. Regulation of DNA end joining, resection, and immunoglobulin class switch recombination by 53BP1. Mol Cell 42, 319-329 (2011).

24. Marini, F., Rawal, C.C., Liberi, G. \& Pellicioli, A. Regulation of DNA Double Strand Breaks Processing: Focus on Barriers. Front Mol Biosci 6, 55 (2019).

25. Pone, E.J., Zhang, J., Mai, T., White, C.A., Li, G., Sakakura, J.K., Patel, P.J., Al-Qahtani, A., Zan, H., Xu, Z. \& Casali, P. BCR-signalling synergizes with TLR-signalling for induction of AID and immunoglobulin class-switching through the non-canonical NF-kappaB pathway. Nat Commun 3, 767 (2012).

26. Wu, X., Tsai, C.Y., Patam, M.B., Zan, H., Chen, J.P., Lipkin, S.M. \& Casali, P. A role for the MutL mismatch repair Mlh3 protein in immunoglobulin class switch DNA recombination and somatic hypermutation. J Immunol 176, 54265437 (2006).

27. Sanchez, H.N., Moroney, J.B., Gan, H., Shen, T., Im, J.L., Li, T., Taylor, J.R., Zan, H. \& Casali, P. B cell-intrinsic epigenetic modulation of antibody responses by dietary fiber-derived short-chain fatty acids. Nat Commun 11, 60 (2020).

28. Honda, M., Okuno, Y., Yoo, J., Ha, T. \& Spies, M. Tyrosine phosphorylation enhances RAD52-mediated annealing by modulating its DNA binding. EMBO J 30, 3368-3382 (2011).

29. Kantor, G.L., Van Herle, A.J. \& Barnett, E.V. Auto-antibodies of the IgD class. Clin Exp Immunol 6, 951-962 (1970).

30. Wu, Y., Chen, W., Chen, H., Zhang, L., Chang, Y., Yan, S., Dai, X., Ma, Y., Huang, Q. \& Wei, W. The elevated secreted immunoglobulin D enhanced the activation of peripheral blood mononuclear cells in rheumatoid arthritis. PLoS One 11, e0147788 (2016).

31. Drenth, J.P., Cuisset, L., Grateau, G., Vasseur, C., van de Velde-Visser, S.D., de Jong, J.G., Beckmann, J.S., van der Meer, J.W. \& Delpech, M. Mutations in the gene encoding mevalonate kinase cause hyper-IgD and periodic fever syndrome. International Hyper-IgD Study Group. Nat Genet 22, 178-181 (1999).

32. Hager, E.J., Tse, H.M., Piganelli, J.D., Gupta, M., Baetscher, M., Tse, T.E., Pappu, A.S., Steiner, R.D., Hoffmann, G.F. \& Gibson, K.M. Deletion of a single mevalonate kinase (Mvk) allele yields a murine model of hyper-IgD syndrome. $J$ Inherit Metab Dis 30, 888-895 (2007).

33. Ammouri, W., Cuisset, L., Rouaghe, S., Rolland, M.O., Delpech, M., Grateau, G. \& Ravet, N. Diagnostic value of serum immunoglobulinaemia D level in patients with a clinical suspicion of hyper $\operatorname{IgD}$ syndrome. Rheumatology (Oxford) 46, 1597-1600 (2007).

34. Govindaraj, G.M., Jain, A., Peethambaran, G., Bhoyar, R.C., Vellarikkal, S.K., Ganapati, A., Sandhya, P., Edavazhippurath, A., Dhanasooraj, D., Puthenpurayil, J.M., Chakkiyar, K., Mishra, A., Batra, A., Punnen, A., Kumar, S., Sivasubbu, S. \& Scaria, V. Spectrum of clinical features and genetic variants in mevalonate kinase (MVK) gene of South Indian families suffering from Hyperimmunoglobulin D Syndrome. PLoS One 15, e0237999 (2020).

35. Koelsch, K., Zheng, N.Y., Zhang, Q., Duty, A., Helms, C., Mathias, M.D., Jared, M., Smith, K., Capra, J.D. \& Wilson, P.C. Mature B cells class switched to IgD are autoreactive in healthy individuals. J Clin Invest 117, 1558-1565 (2007).

36. Rijkers, T., Van Den Ouweland, J., Morolli, B., Rolink, A.G., Baarends, W.M., Van Sloun, P.P., Lohman, P.H. \& Pastink, A. Targeted inactivation of mouse RAD52 reduces homologous recombination but not resistance to ionizing radiation. Mol Cell Biol 18, 6423-6429 (1998).

37. Sung, P. Function of yeast Rad52 protein as a mediator between replication protein A and the Rad51 recombinase. J Biol Chem 272, 28194-28197 (1997).

38. Symington, L.S., Rothstein, R. \& Lisby, M. Mechanisms and regulation of mitotic recombination in Saccharomyces cerevisiae. Genetics 198, 795-835 (2014).

39. Song, B. \& Sung, P. Functional interactions among yeast Rad51 recombinase, Rad52 mediator, and replication protein A in DNA strand exchange. J Biol Chem 275, 15895-15904 (2000).

40. Sung, P., Trujillo, K.M. \& Van Komen, S. Recombination factors of Saccharomyces cerevisiae. Mutat Res 451, 257-275 (2000).

41. Seong, C., Colavito, S., Kwon, Y., Sung, P. \& Krejci, L. Regulation of Rad51 recombinase presynaptic filament assembly via interactions with the Rad52 mediator and the Srs2 anti-recombinase. J Biol Chem 284, 24363-24371 (2009).

42. Wilson, P.F., Hinz, J.M., Urbin, S.S., Nham, P.B. \& Thompson, L.H. Influence of homologous recombinational repair on cell survival and chromosomal aberration induction during the cell cycle in gamma-irradiated CHO cells. DNA Repair 9, 737-744 (2010). 
43. Du, L.Q., Wang, Y., Wang, H., Cao, J., Liu, Q. \& Fan, F.Y. Knockdown of Rad51 expression induces radiation- and chemo-sensitivity in osteosarcoma cells. Med Oncol 28, 1481-1487 (2011).

44. Thorslund, T., McIlwraith, M.J., Compton, S.A., Lekomtsev, S., Petronczki, M., Griffith, J.D. \& West, S.C. The breast cancer tumor suppressor BRCA2 promotes the specific targeting of RAD51 to single-stranded DNA. Nat Struct Mol Biol 17, 1263-1265 (2010).

45. Kwon, Y. \& Sung, P. Rad52, maestro of inverse strand exchange. Mol Cell 67, 1-3 (2017).

46. Feng, Z., Scott, S.P., Bussen, W., Sharma, G.G., Guo, G., Pandita, T.K. \& Powell, S.N. Rad52 inactivation is synthetically lethal with BRCA2 deficiency. Proc Natl Acad Sci U S A 108, 686-691 (2011).

47. Ma, C.J., Kwon, Y., Sung, P. \& Greene, E.C. Human RAD52 interactions with replication protein A and the RAD51 presynaptic complex. J Biol Chem 292, 11702-11713 (2017).

48. Symington, L.S. Role of RAD52 epistasis group genes in homologous recombination and double-strand break repair. Microbiol Mol Biol Rev 66, 630-670 (2002).

49. Ciccia, A. \& Symington, L.S. Stressing Out About RAD52. Mol Cell 64, 1017-1019 (2016).

50. Truong, L.N., Li, Y., Shi, L.Z., Hwang, P.Y., He, J., Wang, H., Razavian, N., Berns, M.W. \& Wu, X. Microhomologymediated End Joining and Homologous Recombination share the initial end resection step to repair DNA double-strand breaks in mammalian cells. Proc Natl Acad Sci U S A 110, 7720-7725 (2013).

51. Abayasingam, A., Balachandran, H., Agapiou, D., Hammoud, M., Rodrigo, C., Keoshkerian, E., Li, H., Brasher, N.A., Christ, D., Rouet, R., Burnet, D., Grubor-Bauk, B., Rawlinson, W., Turville, S., Aggarwal, A., Stella, A.O., Fichter, C., Brilot, F., Mina, M., Post, J.J., Hudson, B., Gilroy, N., Dwyer, D., Sasson, S.C., Tea, F., Pilli, D., Kelleher, A., Tedla, N., Lloyd, A.R., Martinello, M., Bull, R.A. \& Group, C.S. Long-term persistence of RBD $(+)$ memory B cells encoding neutralizing antibodies in SARS-CoV-2 infection. Cell Rep Med 2, 100228 (2021).

52. Waters, L.R., Ahsan, F.M., Ten Hoeve, J., Hong, J.S., Kim, D.N.H., Minasyan, A., Braas, D., Graeber, T.G., Zangle, T.A. \& Teitell, M.A. Ampk regulates IgD expression but not energy stress with B cell activation. Sci Rep 9, 8176 (2019).

53. Sag, D., Carling, D., Stout, R.D. \& Suttles, J. Adenosine 5'-monophosphate-activated protein kinase promotes macrophage polarization to an anti-inflammatory functional phenotype. J Immunol 181, 8633-8641 (2008).

54. Moskophidis, D., Moskophidis, M. \& Lohler, J. Virus-specific IgD in acute viral infection of mice. J Immunol 158, 12541261 (1997).

55. Forsgren, A., Brant, M., Mollenkvist, A., Muyombwe, A., Janson, H., Woin, N. \& Riesbeck, K. Isolation and characterization of a novel IgD-binding protein from Moraxella catarrhalis. J Immunol 167, 2112-2120 (2001).

56. Min, J.Y., Nayak, J.V., Hulse, K.E., Stevens, W.W., Raju, P.A., Huang, J.H., Suh, L.A., Van Roey, G.A., Norton, J.E., Carter, R.G., Price, C.P.E., Weibman, A.R., Rashan, A.R., Ghosn, E.E., Patel, Z.M., Homma, T., Conley, D.B., Welch, K.C., Shintani-Smith, S., Peters, A.T., Grammer, L.C., 3rd, Harris, K.E., Kato, A., Hwang, P.H., Kern, R.C., Herzenberg, L.A., Schleimer, R.P. \& Tan, B.K. Evidence for altered levels of IgD in the nasal airway mucosa of patients with chronic rhinosinusitis. J Allergy Clin Immunol 140, 1562-1571 (2017).

57. Casali, P. \& Notkins, A.L. Probing the human B-cell repertoire with EBV: polyreactive antibodies and CD5+ B lymphocytes. Апnи Rev Immunol 7, 513-535 (1989).

58. Ikematsu, H., Kasaian, M.T., Schettino, E.W. \& Casali, P. Structural analysis of the VH-D-JH segments of human polyreactive IgG mAb. Evidence for somatic selection. J Immunol 151, 3604-3616 (1993).

59. Ichiyoshi, Y. \& Casali, P. Analysis of the structural correlates for antibody polyreactivity by multiple reassortments of chimeric human immunoglobulin heavy and light chain V segments. $J$ Exp Med 180, 885-895 (1994).

60. Casali, P. \& Schettino, E.W. Structure and function of natural antibodies. Curr Top Microbiol Immunol 210, 167-179 (1996).

61. Sabouri, Z., Perotti, S., Spierings, E., Humburg, P., Yabas, M., Bergmann, H., Horikawa, K., Roots, C., Lambe, S., Young, C., Andrews, T.D., Field, M., Enders, A., Reed, J.H. \& Goodnow, C.C. IgD attenuates the IgM-induced anergy response in transitional and mature B cells. Nat Commun 7, 13381 (2016).

62. Guo, L., Tian, J., Guo, Z., Zheng, B. \& Han, S. The absence of immunoglobulin D B cell receptor-mediated signals promotes the production of autoantibodies and exacerbates glomerulonephritis in murine lupus. Clin Exp Immunol 164, 227-235 (2011).

63. Houten, S.M., Kuis, W., Duran, M., de Koning, T.J., van Royen-Kerkhof, A., Romeijn, G.J., Frenkel, J., Dorland, L., de Barse, M.M., Huijbers, W.A., Rijkers, G.T., Waterham, H.R., Wanders, R.J. \& Poll-The, B.T. Mutations in MVK, encoding mevalonate kinase, cause hyperimmunoglobulinaemia D and periodic fever syndrome. Nat Genet 22, 175-177 (1999). 
bioRxiv preprint doi: https://doi.org/10.1101/2021.06.28.450246; this version posted July 14, 2021. The copyright holder for this preprint (which was not certified by peer review) is the author/funder. All rights reserved. No reuse allowed without permission.

Rad52 mediates CSR to IgD

64. Muramatsu, M., Kinoshita, K., Fagarasan, S., Yamada, S., Shinkai, Y. \& Honjo, T. Class switch recombination and hypermutation require activation-induced cytidine deaminase (AID), a potential RNA editing enzyme. Cell 102, 553563 (2000).

65. Park, S.-R., Zan, H., Zhang, J., Al-Qahtani, A., Pone, E.J., Xu, Z., Mai, T. \& Casali, P. HoxC4 binds to the promoter of the cytidine deaminase AID gene to induce AID expression, class-switch DNA recombination and somatic hypermutation. Nat Immunol 10, 540-550 (2009).

66. White, C.A., Pone, E.J., Lam, T., Tat, C., Hayama, K.L., Li, G., Zan, H. \& Casali, P. Histone deacetylase inhibitors upregulate B cell microRNAs that silence AID and Blimp-1 expression for epigenetic modulation of antibody and autoantibody responses. J Immunol 193, 5933-5950 (2014).

67. Zan, H., Zhang, J., Al-Qahtani, A., Pone, E.J., White, C.A., Lee, D., Yel, L., Mai, T. \& Casali, P. Endonuclease G plays a role in immunoglobulin class switch DNA recombination by introducing double-strand breaks in switch regions. Mol Immunol 48, 610-622 (2011).

68. Xu, Z., Fulop, Z., Wu, G., Pone, E.J., Zhang, J., Mai, T., Thomas, L.M., Al-Qahtani, A., White, C.A., Park, S.R., Steinacker, P., Li, Z., Yates, J., 3rd, Herron, B., Otto, M., Zan, H., Fu, H. \& Casali, P. 14-3-3 adaptor proteins recruit AID to 5'-AGCT-3'-rich switch regions for class switch recombination. Nat Struct Mol Biol 17, 1124-1135 (2010).

69. Zan, H., White, C.A., Thomas, L.M., Mai, T., Li, G., Xu, Z., Zhang, J. \& Casali, P. Rev1 recruits Ung to switch regions and enhances dU glycosylation for immunoglobulin class switch DNA recombination. Cell Rep 2, 1220-1232 (2012).

70. Li, G., White, C.A., Lam, T., Pone, E.J., Tran, D.C., Hayama, K.L., Zan, H., Xu, Z. \& Casali, P. Combinatorial H3K9acS10ph histone modification in IgH locus S regions targets 14-3-3 adaptors and AID to specify antibody classswitch DNA recombination. Cell Rep 5, 702-714 (2013). 
a Unswitched $/ g H$ locus

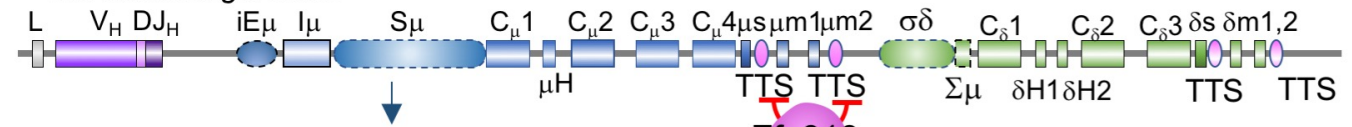

Primary transcripts in presence of ZFP318 Zfp318

Mature transcripts

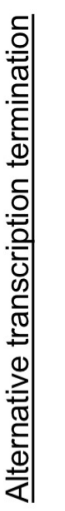

Prat

4

$\square$

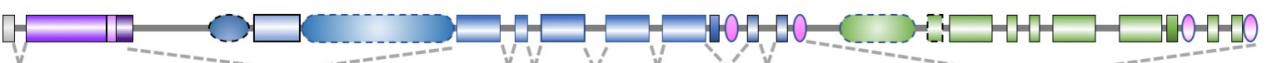

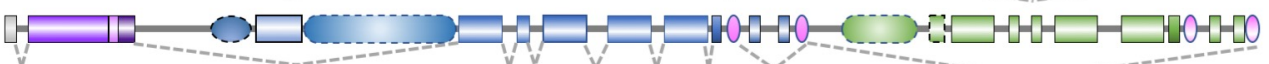

$\square(7,-70-70$

Primary transcripts in absence of Zfp318

प

(1)

$\square$

RNA splicing

b Unswitched $\lg H$ locus

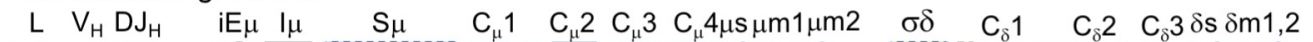
$\begin{array}{llll} & \end{array}$

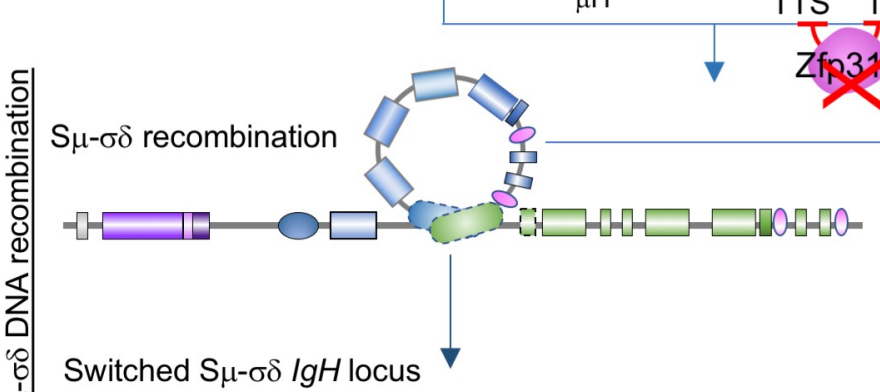

के $\square \square$

Primary transcripts

P

a

$\square \times-\ldots$

RNA splicing

$\longrightarrow 00 \mathrm{~V}_{\mathrm{H}} \mathrm{DJ} \mathrm{J}_{\mathrm{H}}-\mathrm{C} \delta \mathrm{m}$ Poly (A)

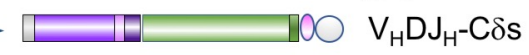

$\square+1 \mu-\mathrm{C} \delta$

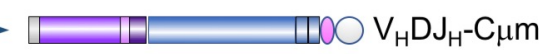

$\square$ VO $\mathrm{V}_{\mathrm{H}} \mathrm{DJ} \mathrm{H}^{-} \mathrm{C} \mu \mathrm{s}$

$\square \quad \square 00 \quad \mid \mu-C \mu$

$\square 00 \mathrm{~V}_{\mathrm{H}} \mathrm{D} \mathrm{J}_{\mathrm{H}}-\mathrm{C} \mu \mathrm{m}$

$-100 \mathrm{~V}_{\mathrm{H}} \mathrm{DJ} \mathrm{H}^{-} \mathrm{C} \mu \mathrm{s}$

$\square \quad \square 00 \quad \mid \mu-C_{\mu}$

Detection of recombined $S \mu-\sigma \delta$ DNA $\square \square \square$ $\mathrm{F} 1 \Rightarrow \quad \Leftrightarrow \mathrm{R} 1$

Nested PCR $\downarrow$

S $\mu$ probe $\sigma \delta$ probe Human B cells,

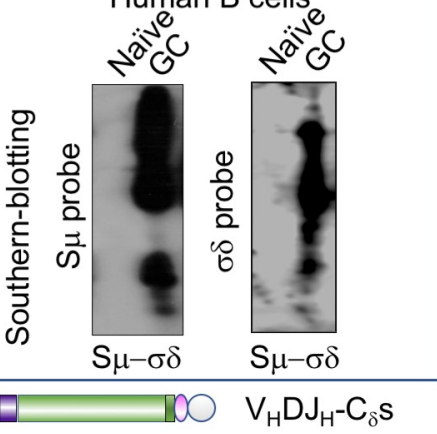

$\square \quad \mathrm{V}_{\mathrm{H}} \mathrm{DJ} \mathrm{J}_{\mathrm{H}}-\mathrm{C}_{\delta} \mathrm{s}$

$\square=0 \mathrm{~V}_{\mathrm{H}} \mathrm{DJ} \mathrm{J}_{\mathrm{H}}-\mathrm{C}_{\delta} \mathrm{m}$

$\square \quad 100 \quad 1 \mu-C_{\delta}$ 


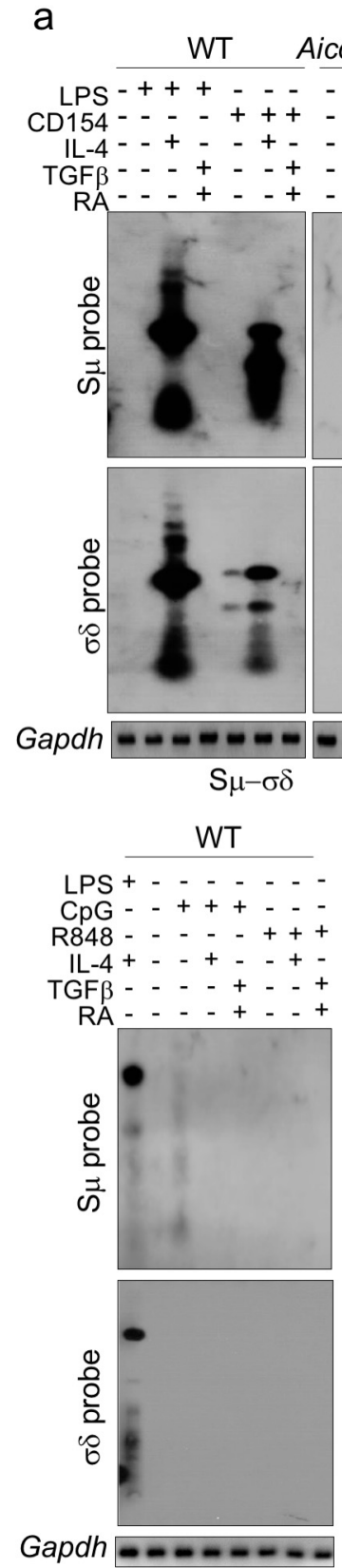

$\mathrm{S} \mu-\sigma \delta$
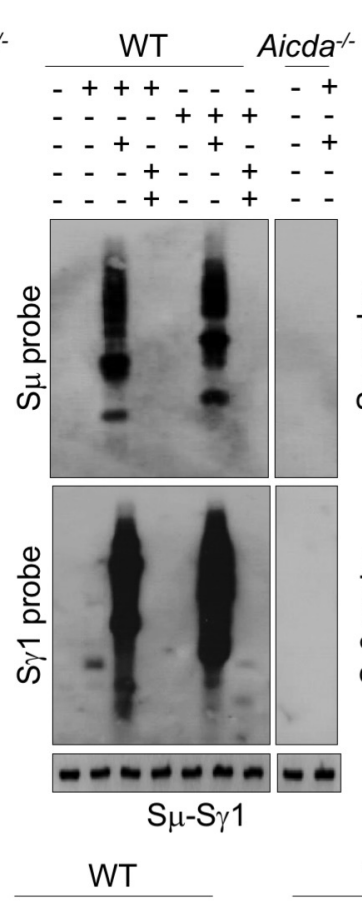

T- - - -
+-+++-

$-2-\ldots+++$

$+-+-\cdot+$
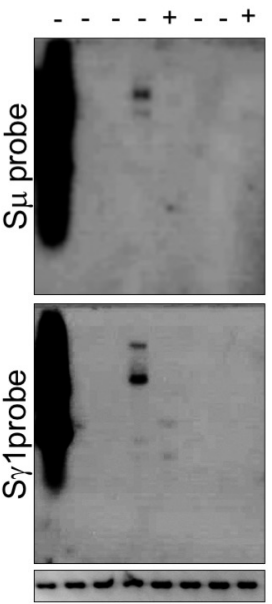

$\mathrm{S} \mu-\mathrm{S}_{\gamma} 1$
WT Aicda

WT Aicda--

WT Aicda ${ }^{-/}$

$-+\ldots+-+\ldots$

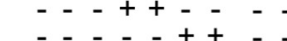

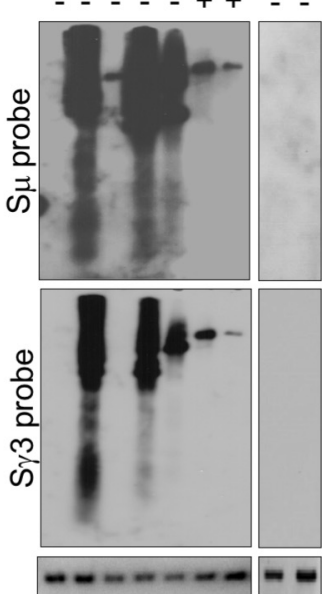

$\mathrm{S} \mu-\mathrm{S} \gamma 3$
-++++
--+-+

- - + + - -

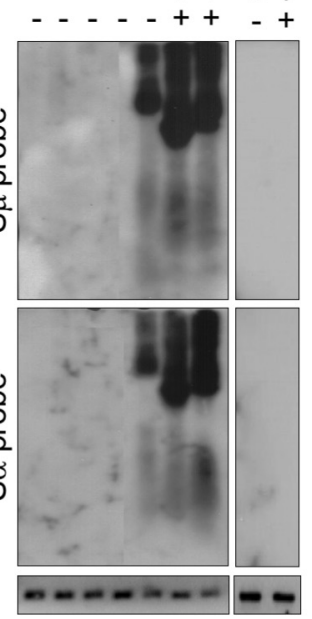

$\mathrm{S} \mu-\mathrm{S} \alpha$

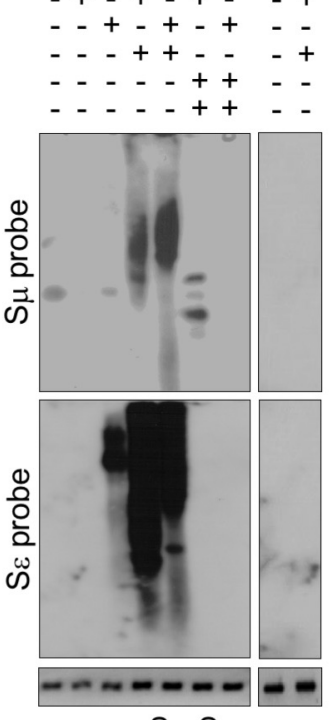

$\mathrm{S} \mu-\mathrm{S} \varepsilon$

Human B cells

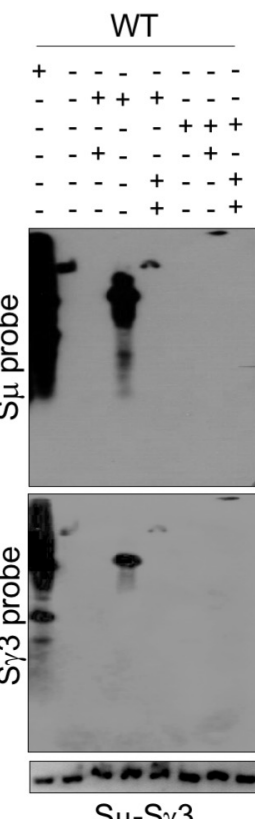
LPS + - - $\mathrm{CpG}-\cdot+++-$ R848- - - + + + + IL -4

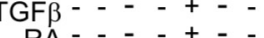

RA $--\bar{t}--+$
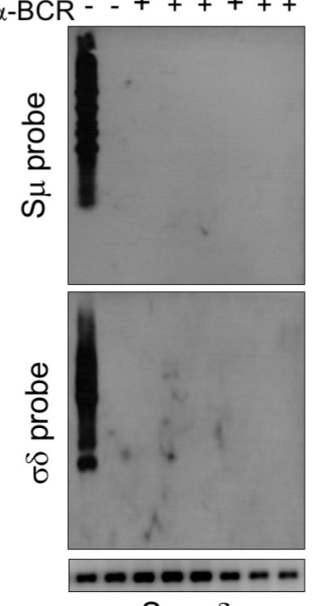

$\mathrm{S}_{\mu}-\mathrm{S} \gamma 3$

$\mathrm{S} \mu-\sigma \delta$

CD154+ + + . + + t ${ }^{+}$CpG - - - + + + + 은 $\mathrm{IL}-2-$

ठ $\overline{\bar{\Phi}} \mid \mathrm{L}-4+\ldots+\cdots+-$ m
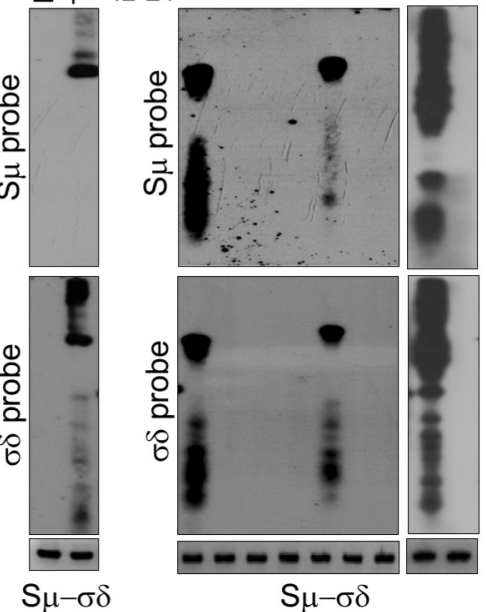

C $・ \mathrm{Nil}$

- LPS + IL-4

- LPS+TGF- $\beta+R A$
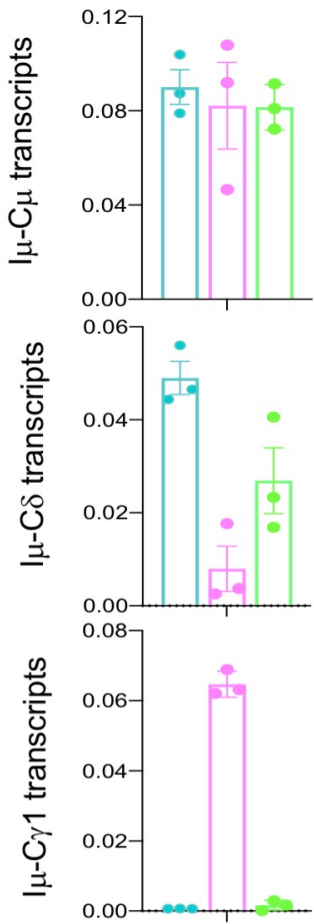
0.008

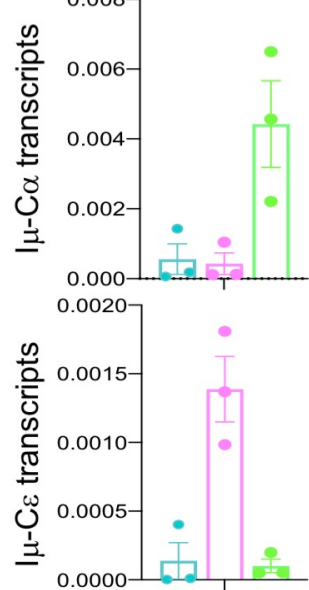

Xu et al., Figure 2 
a
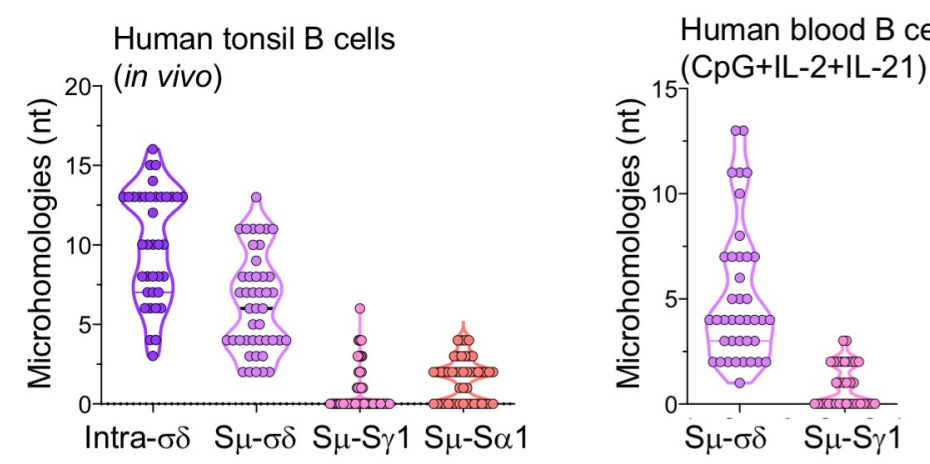

b

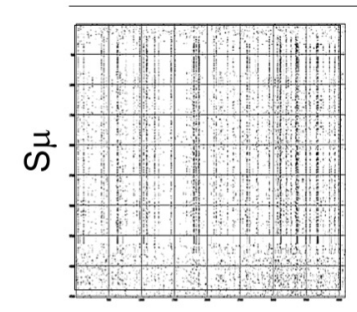

$\sigma \delta$

\section{Human}

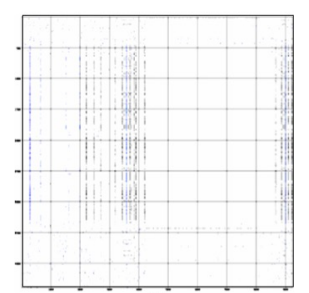

S $\gamma 1$

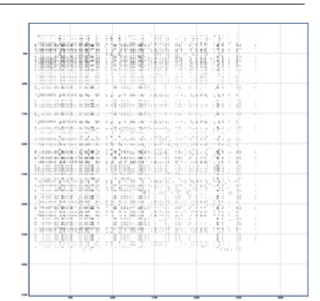

$\mathrm{S} \alpha 1$

C

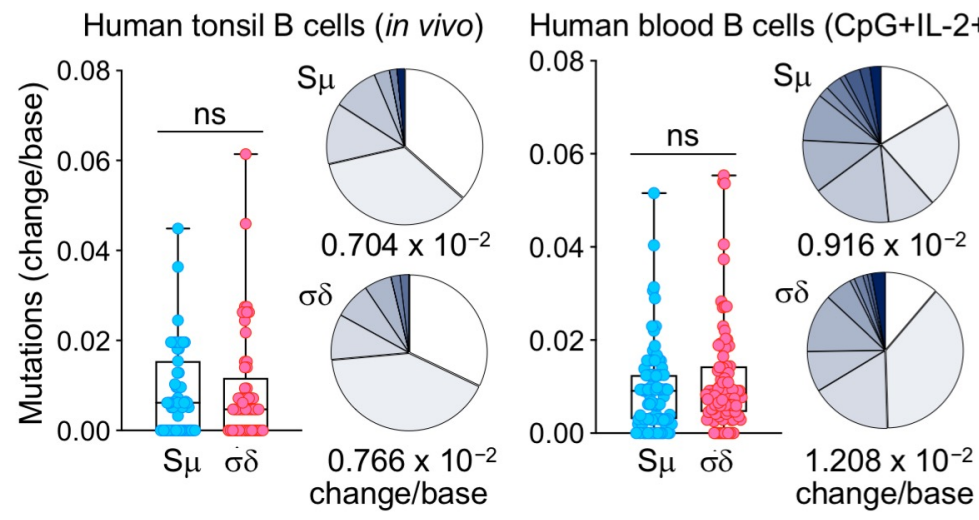

Mouse spleen B cells
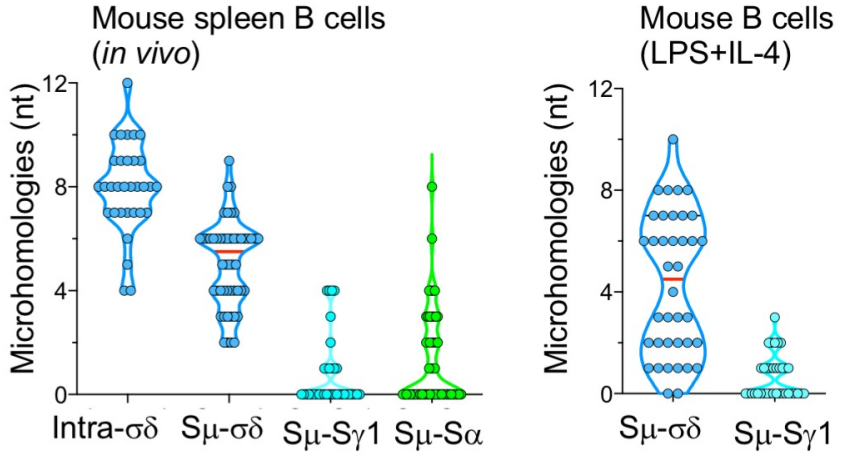

Mouse

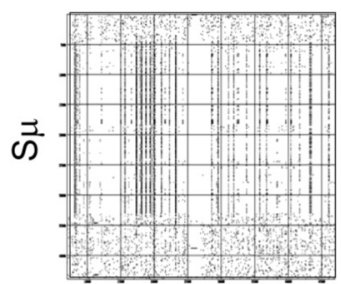

$\sigma \delta$

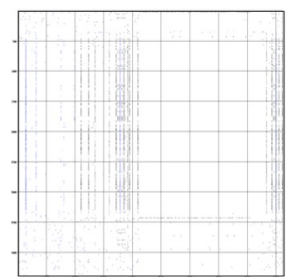

$\mathrm{S} \gamma 1$

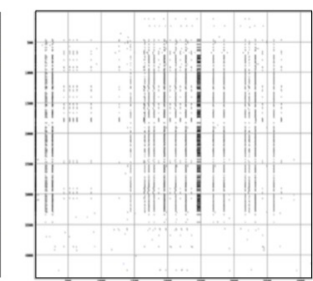

$\mathrm{S} \alpha$

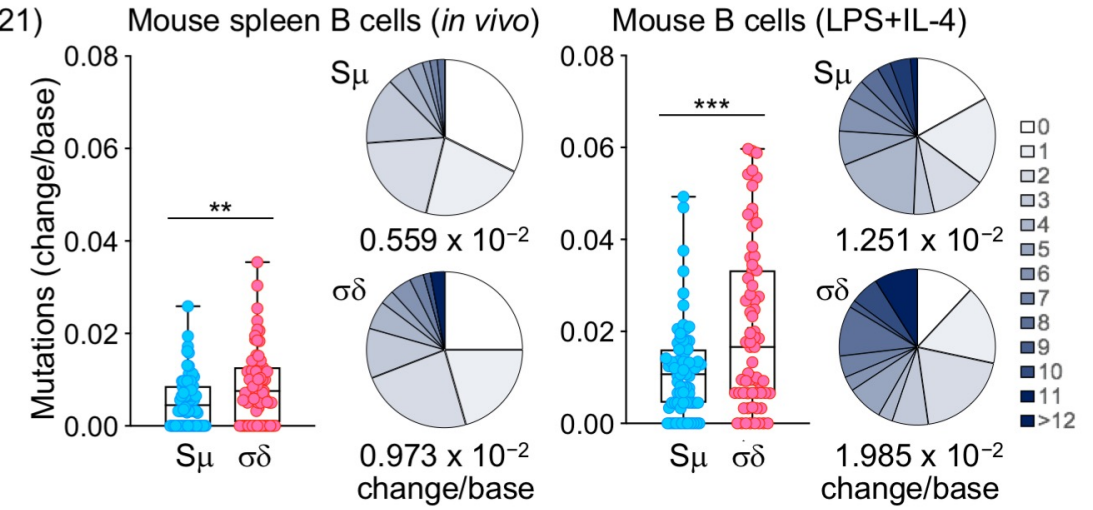

Xu et al., Figure 3 


\section{Human tonsil B cells (in vivo)}

Intra- $\sigma \delta$

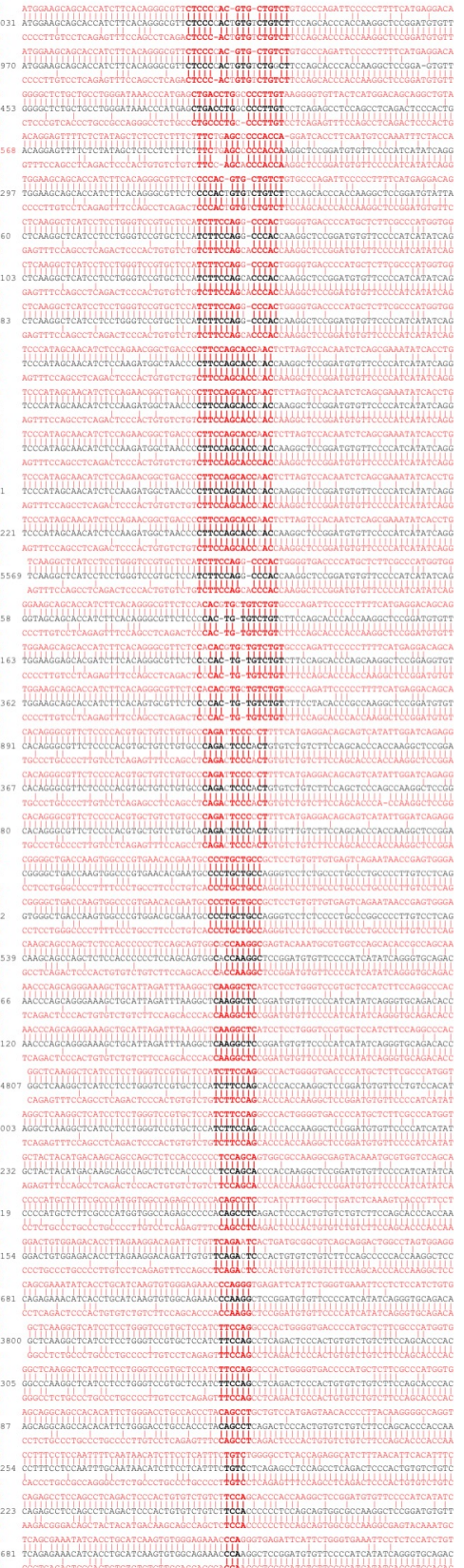

$\mathrm{S} \mu-\sigma \delta$

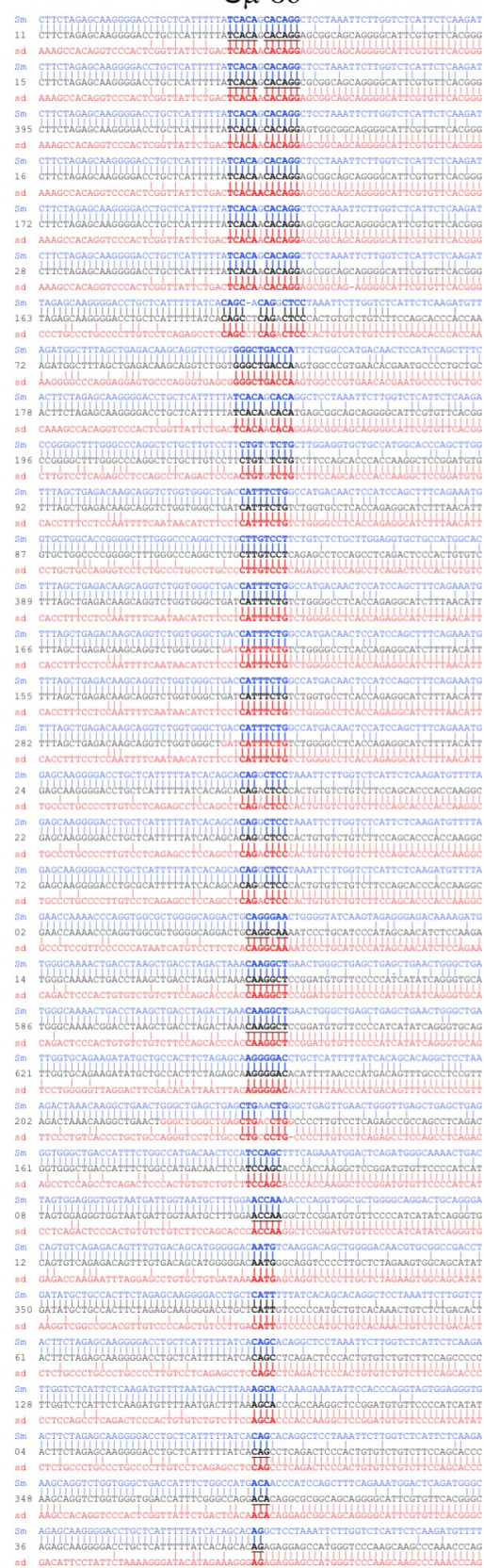

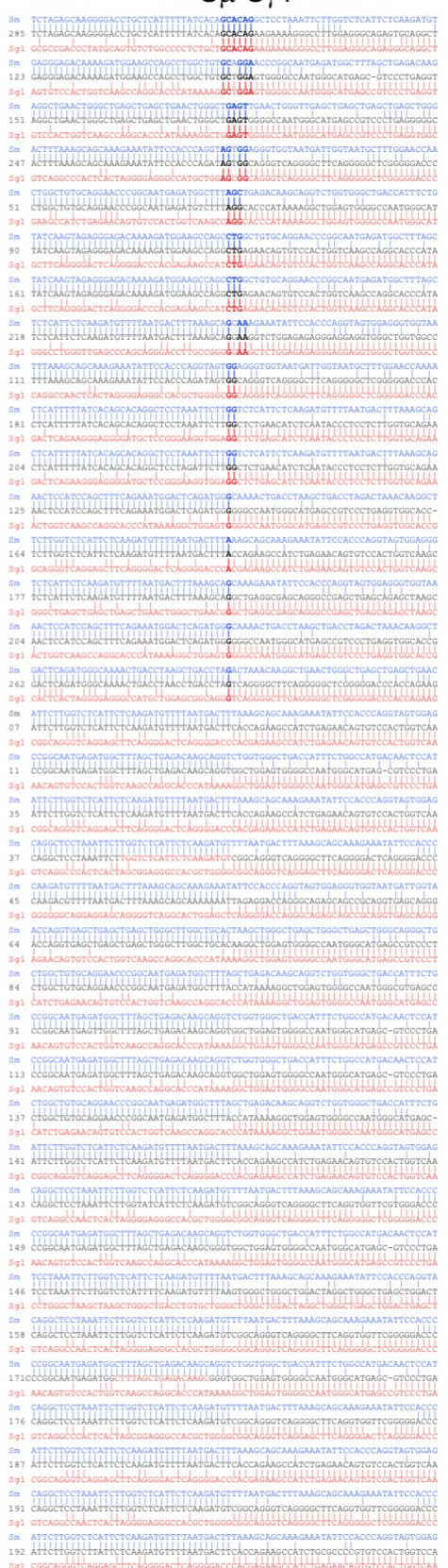

$\mathrm{S} \mu-\mathrm{S} \alpha 1$

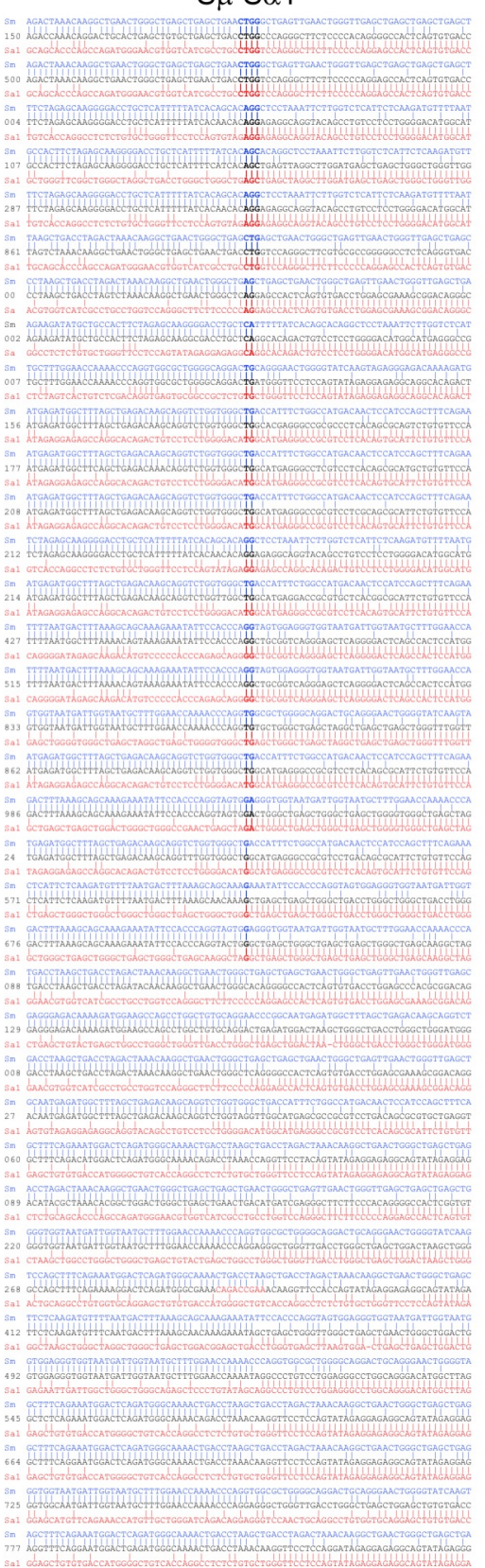

Xu et al., Figure 4 


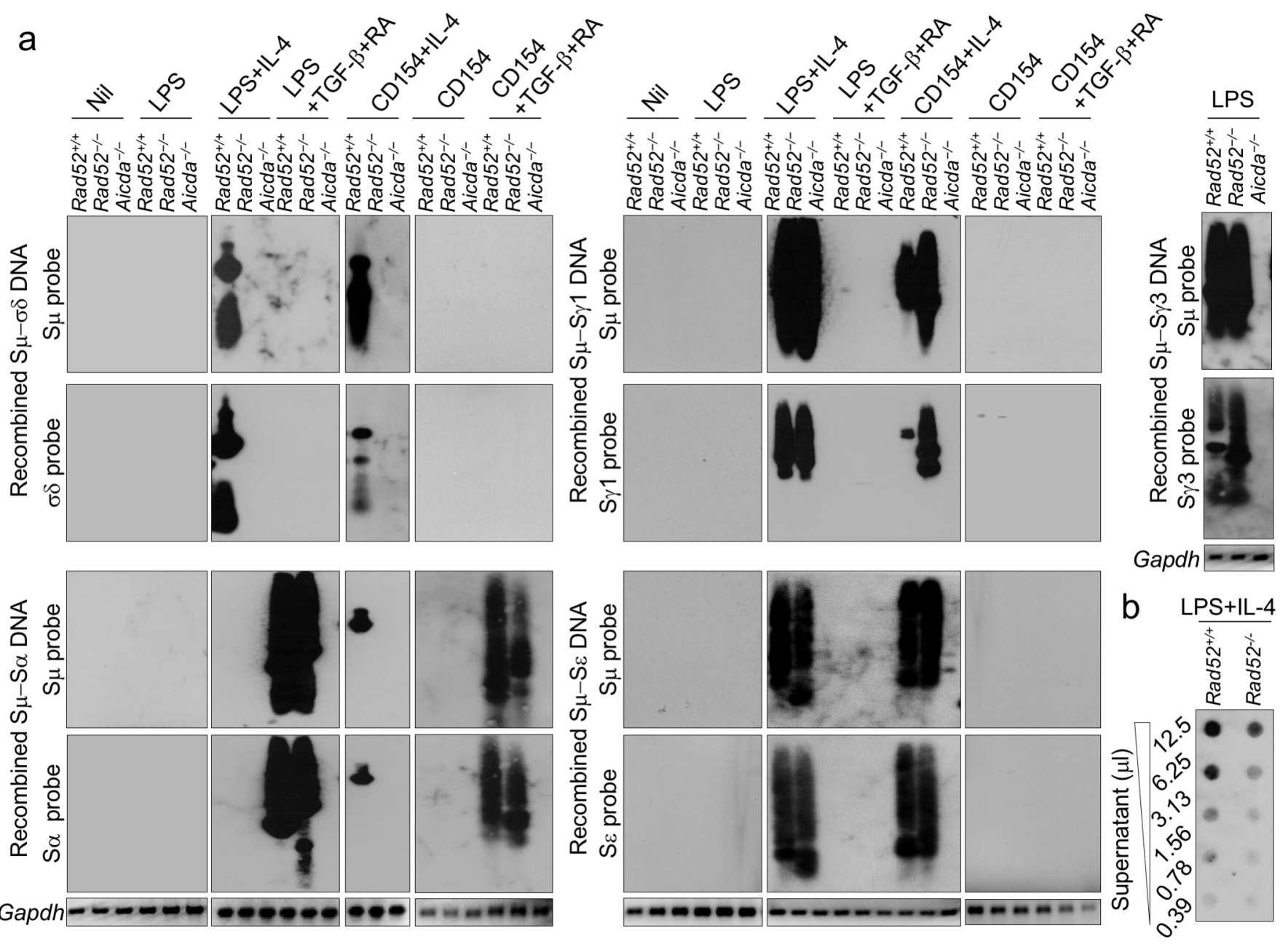


a $\quad \operatorname{Rad} 52^{+/+} \operatorname{Rad52^{--}}$
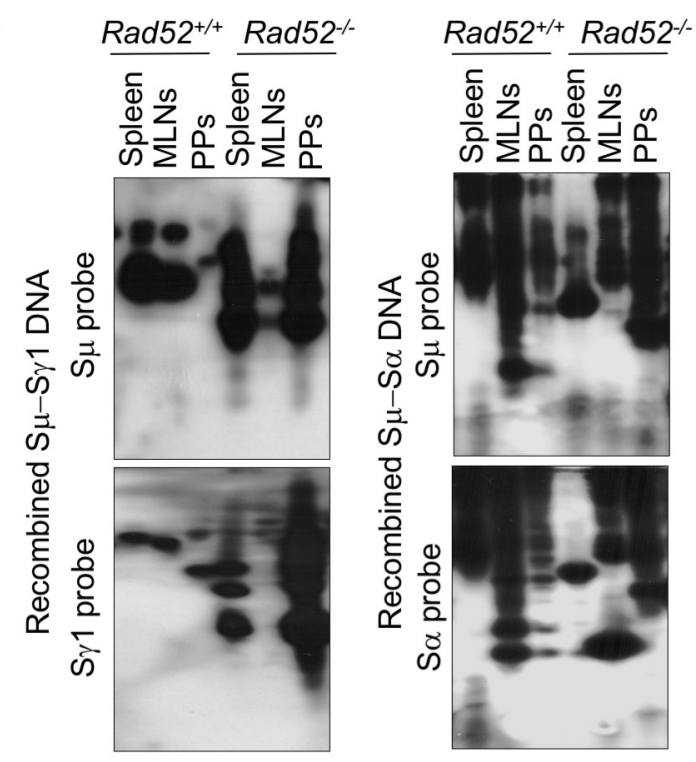

b
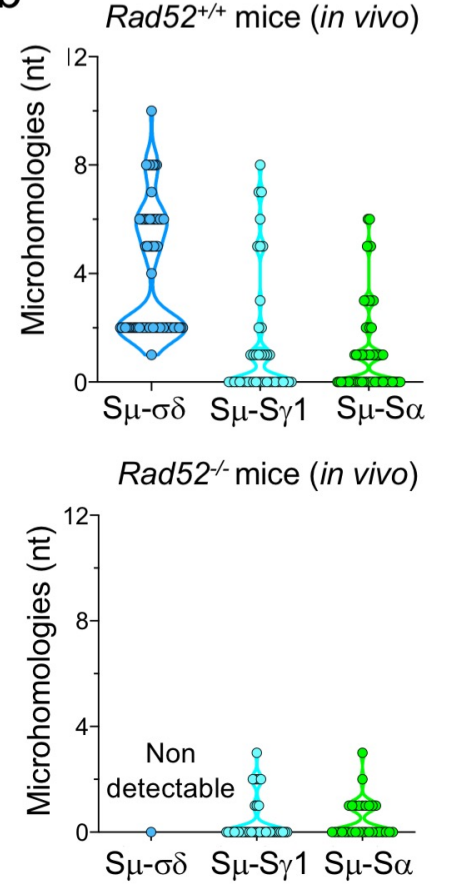

C Serum (total lg) $\bullet$ Rad52 $2^{+/+} \bullet$ Rad52-/-

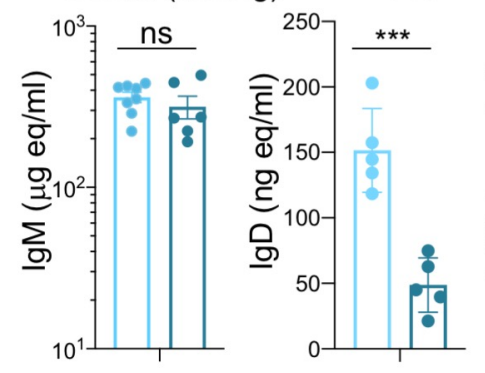

e Serum (OVA-binding Ab)

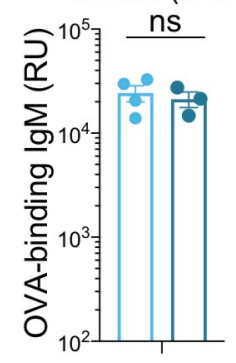

g

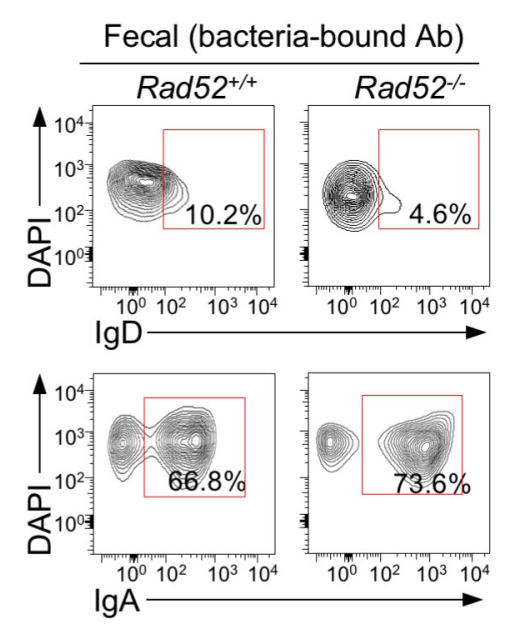

h

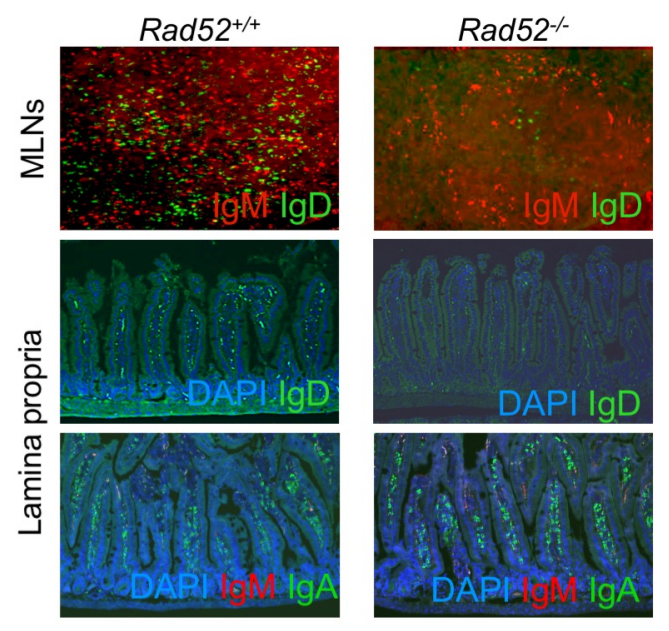

d
BALF (total lg)

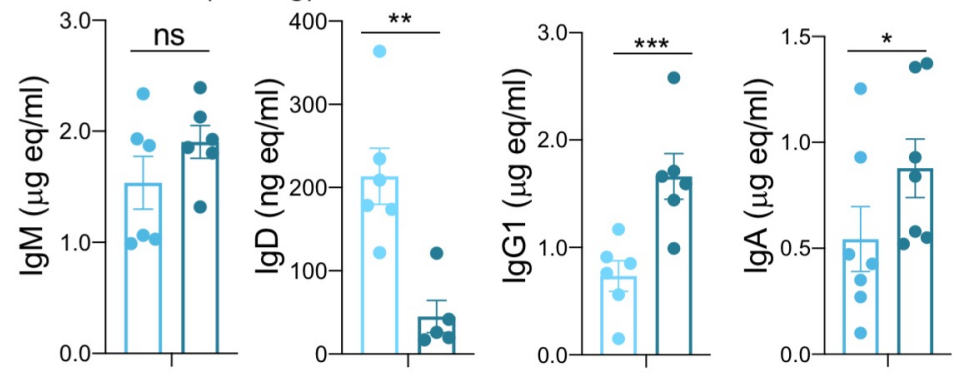

$\mathrm{f}$

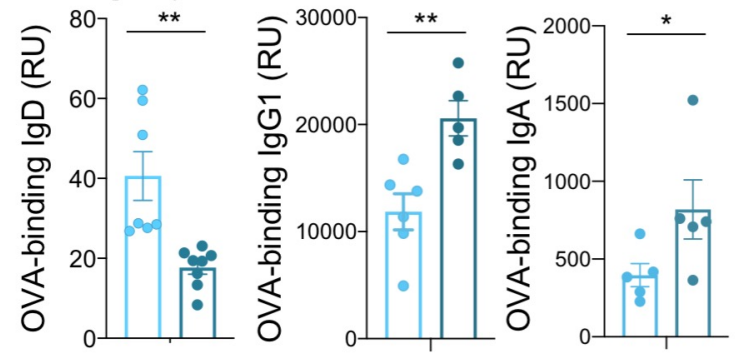

Fecal (total lg)

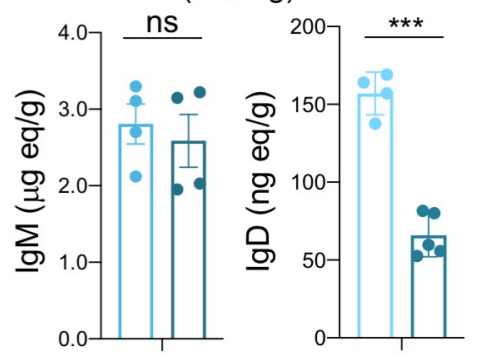

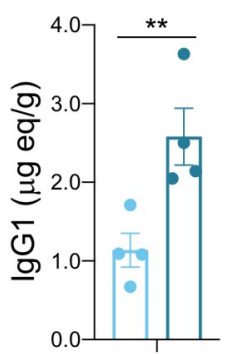


a

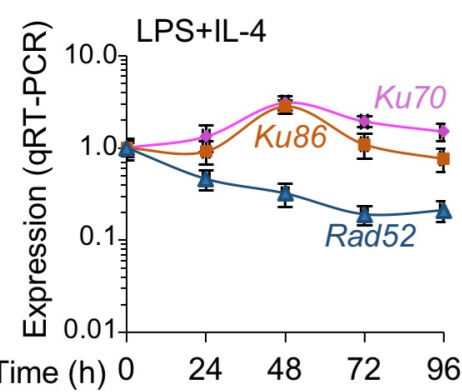

C

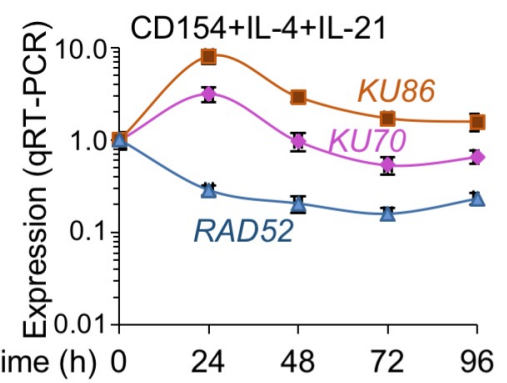

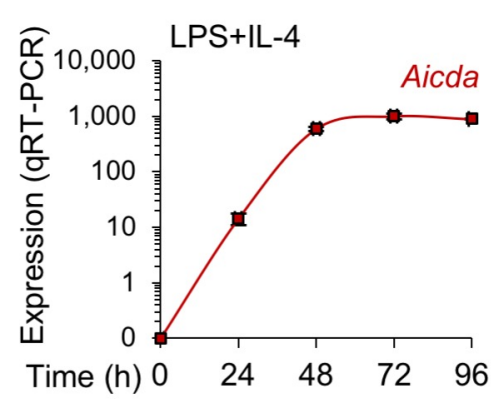

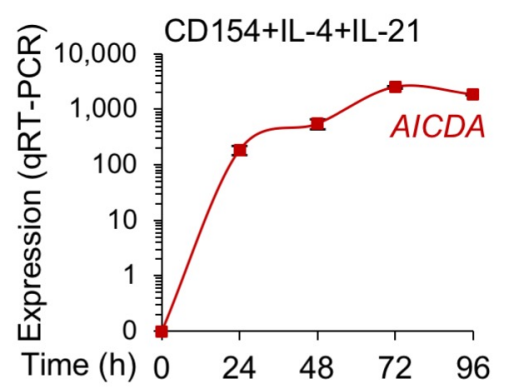

b

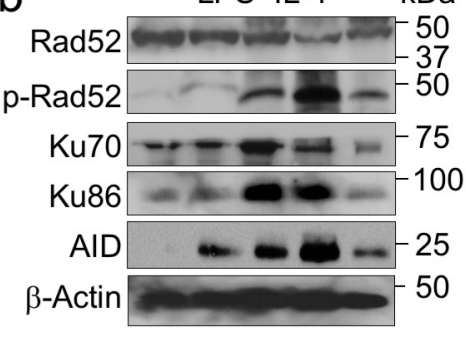

Time (h) $0 \quad 24 \quad 48 \quad 72 \quad 96$

d

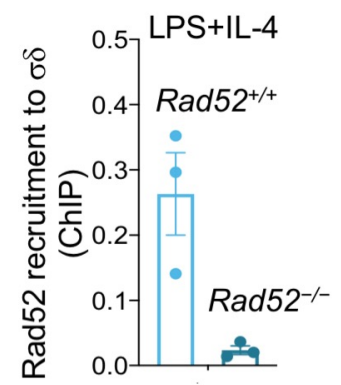

e

- Nil - LPS - LPS+IL- $4 \circ$ LPS+TGF- $\beta+R A$
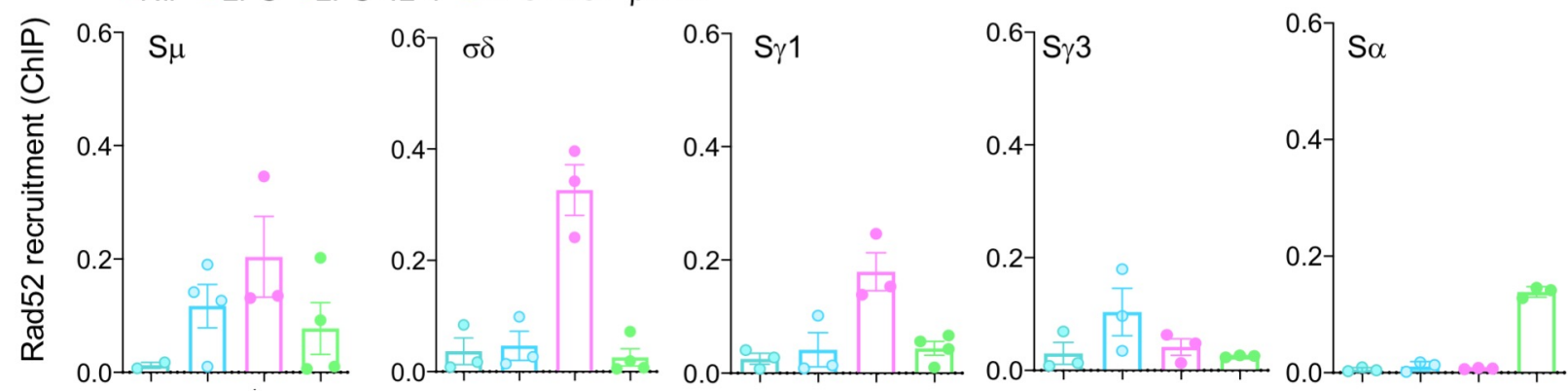

f

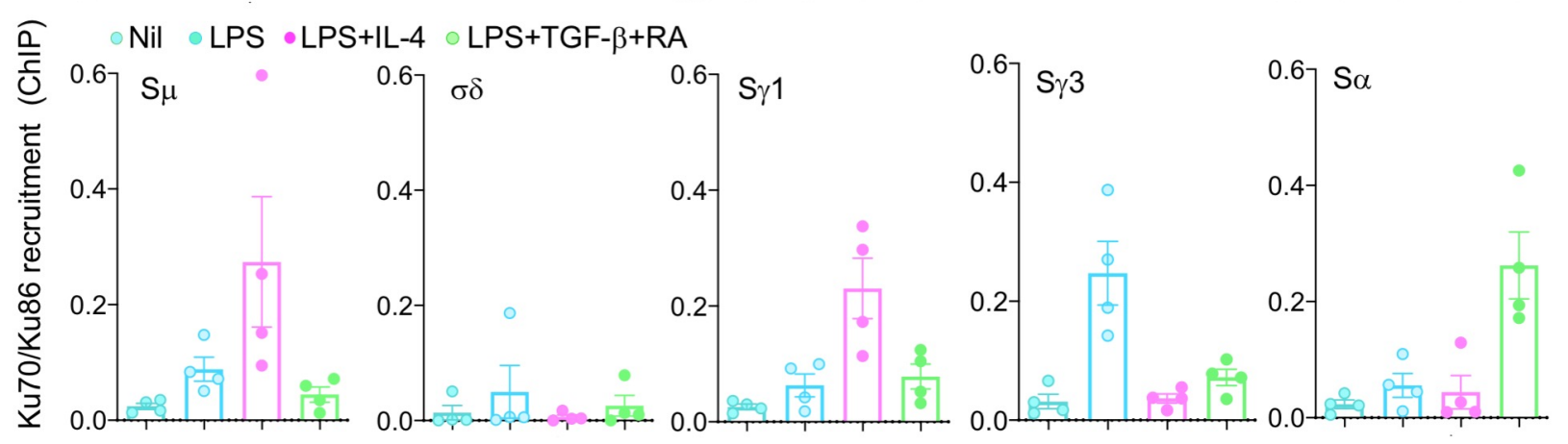




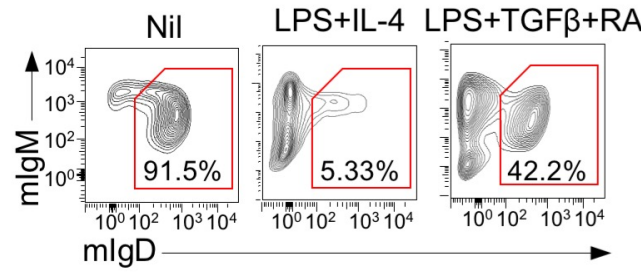

C

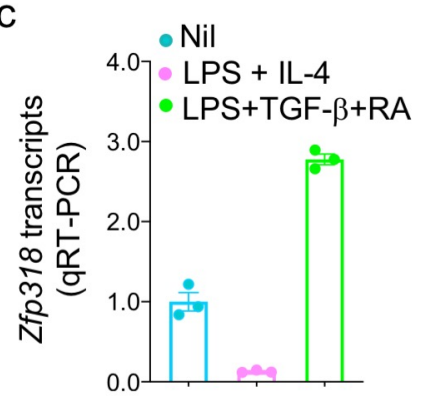

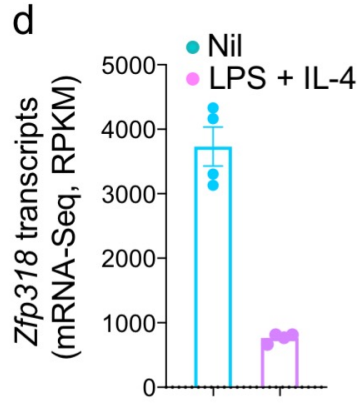

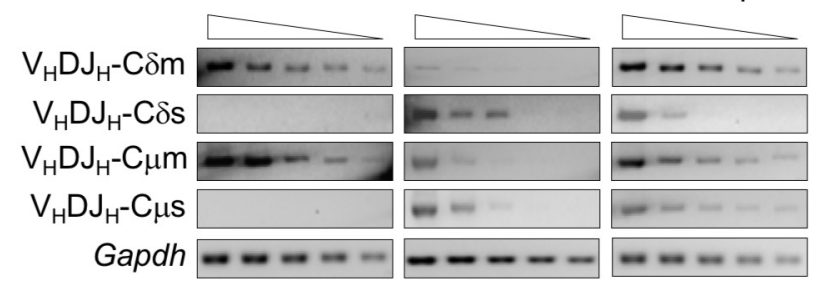

e

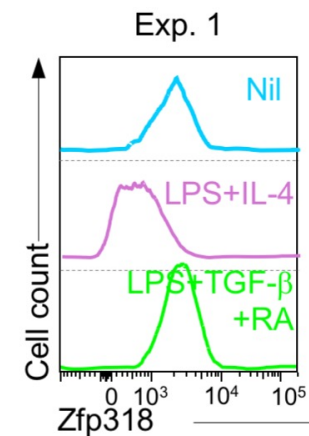

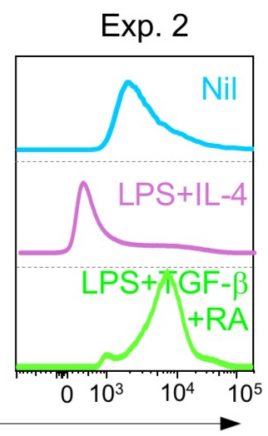

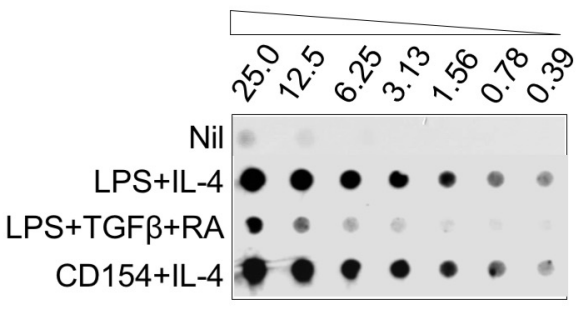

f

Human B cells (peripheral blood)
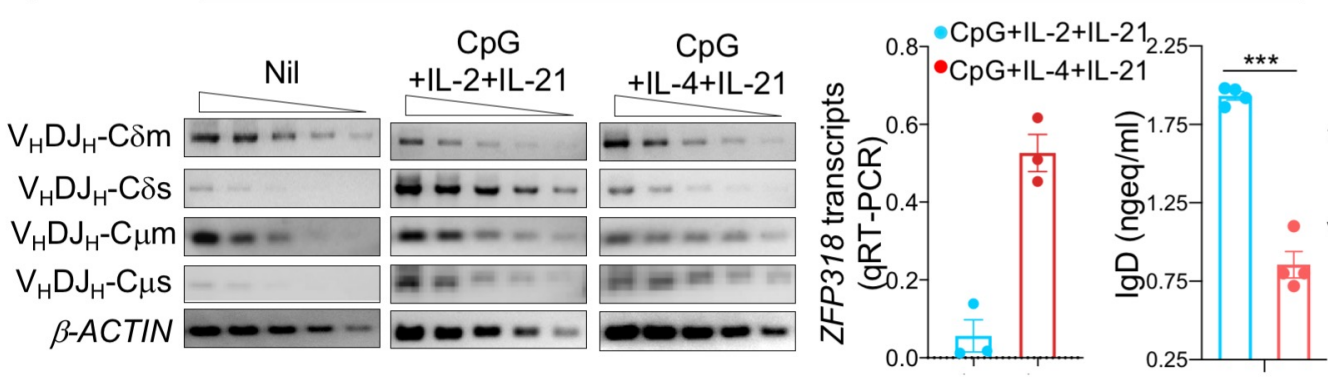

g

Human B cells (tonsils)
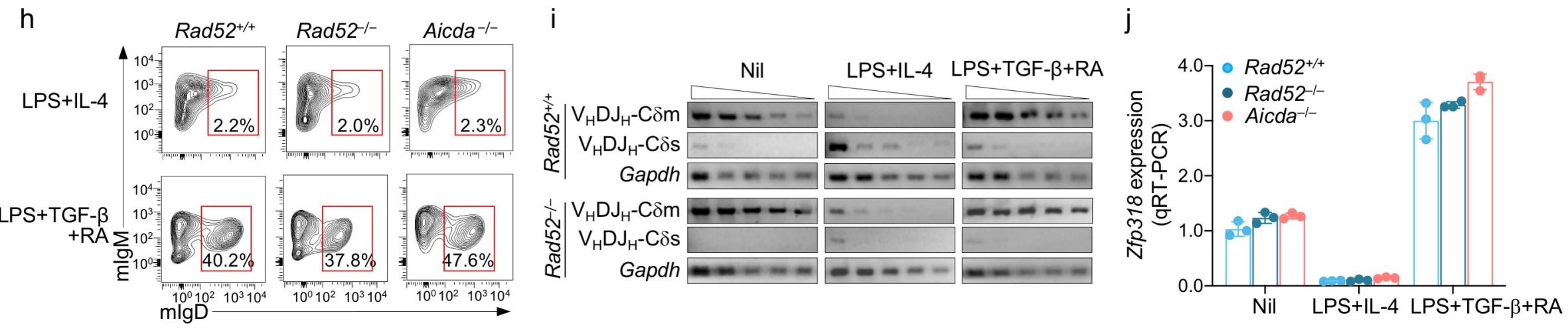

Xu et al., Figure 8 
a

Tonsil

B cells

产

喜总

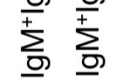

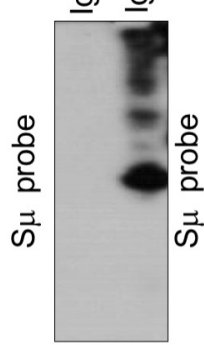

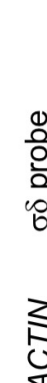

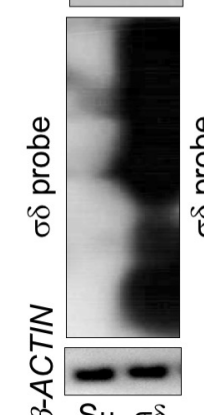

$S_{\mu-\sigma \delta}$
Blood B cells induced by CpG+IL-2+IL-21
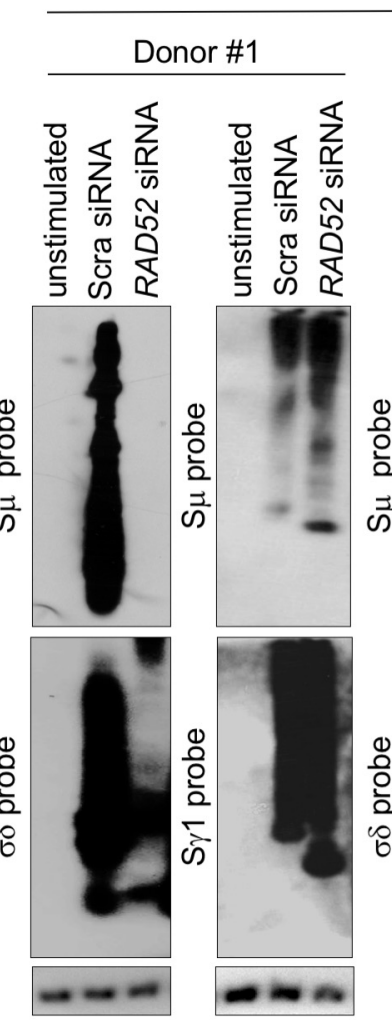

$\mathrm{S} \mu-\sigma \delta$
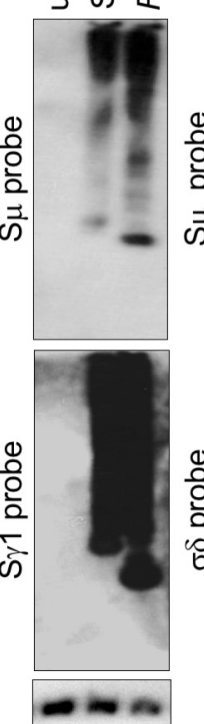

$\mathrm{S}_{\mu}-\mathrm{S}_{\gamma 1} 1$
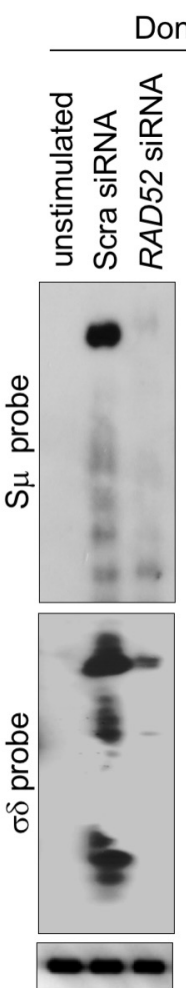

$\mathrm{S} \mu-\sigma \delta$
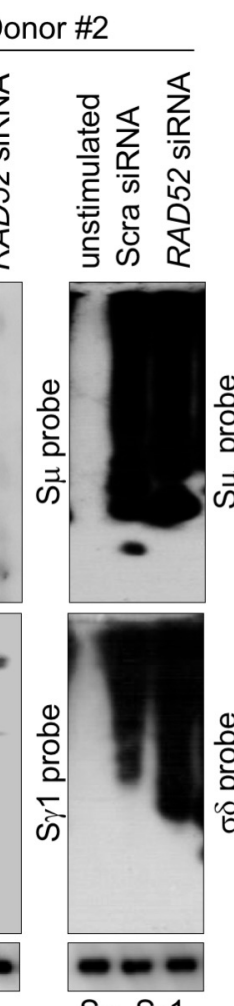

$\mathrm{S} \mu-\mathrm{S} \gamma 1$
Donor \#3
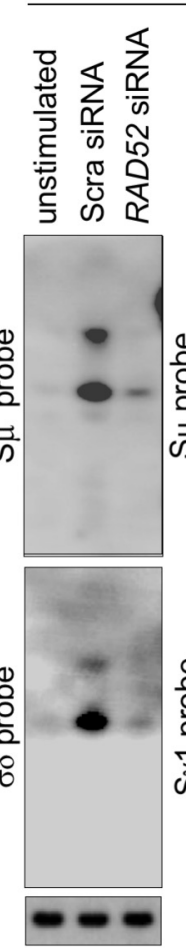

$\mathrm{S} \mu-\sigma \delta$ b

Blood $B$ cells induced by $\mathrm{CpG}+\mathrm{IL}-2+\mid \mathrm{L}-21$

$$
\text { - Scra siRNA }
$$

- RAD52 siRNA
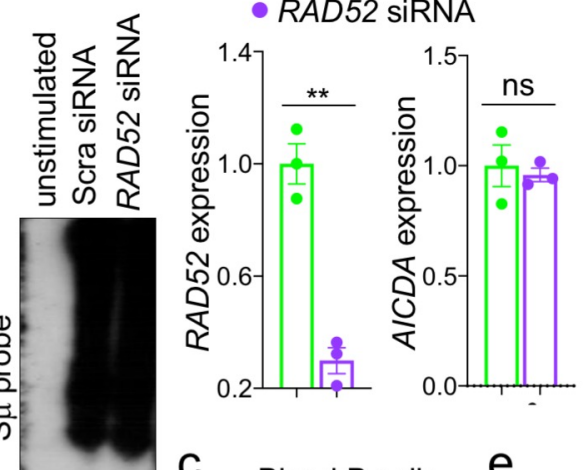

C

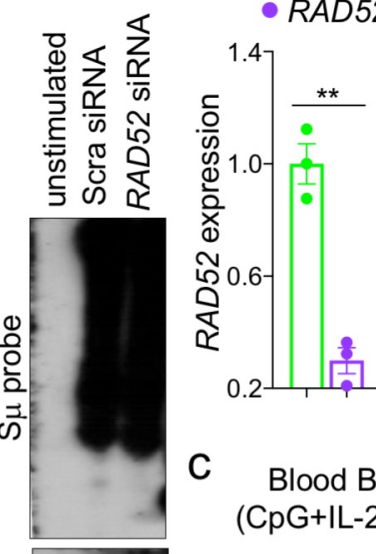

$\underset{(\mathrm{CpG}+\mathrm{IL}-2+\text { IL-21) }}{\operatorname{Blood} \mathrm{e} \text { cells }}$

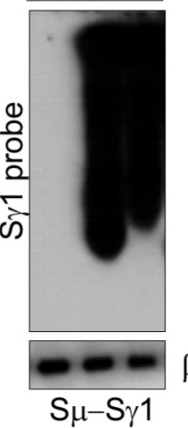

d

Blood B cells

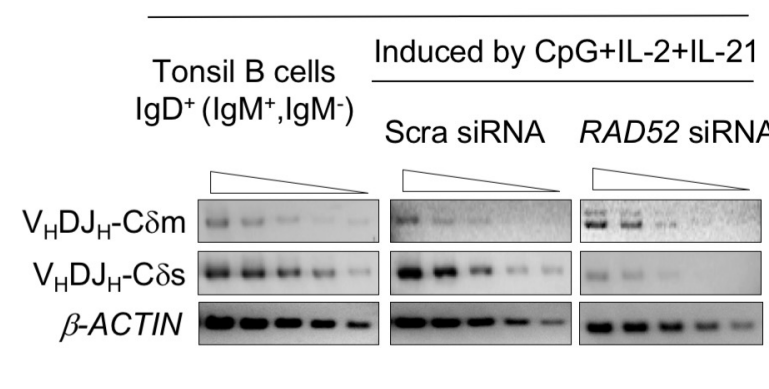

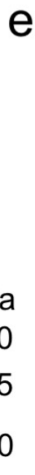
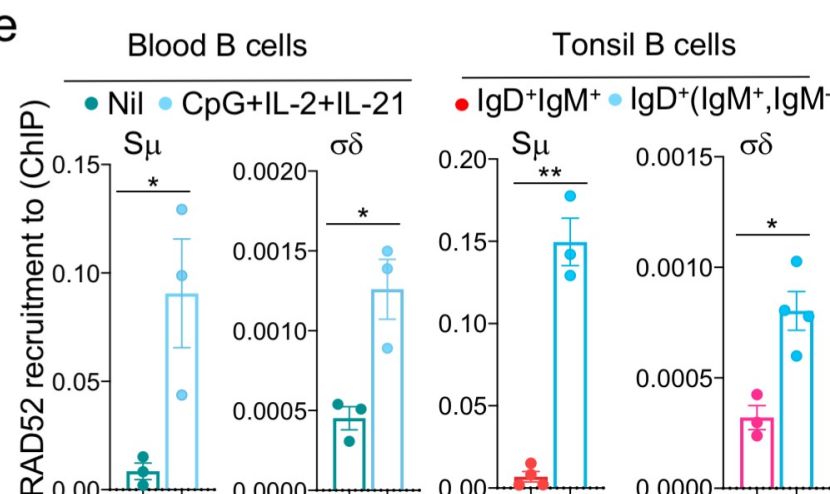
a Human B cells

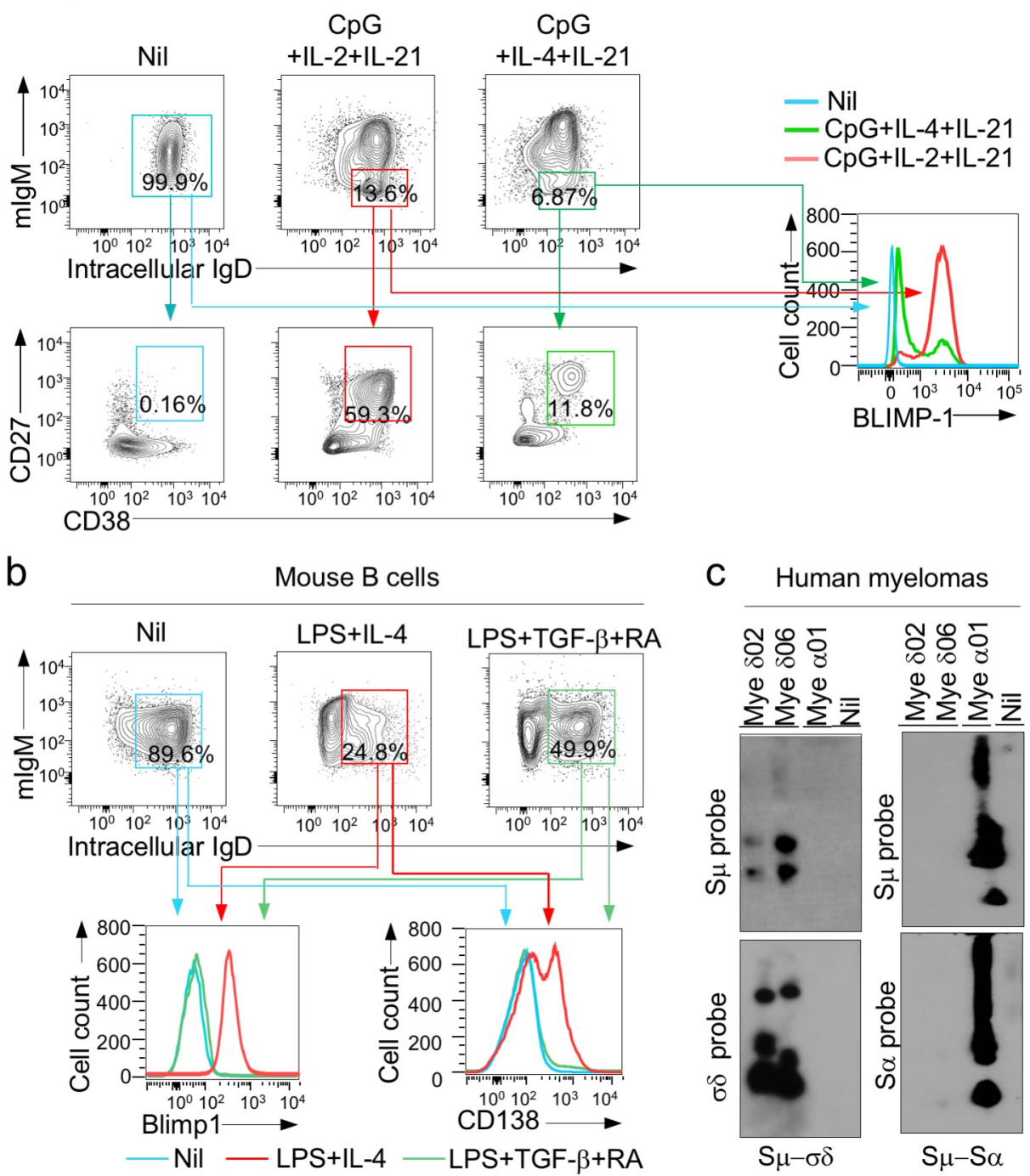


a $\circ$ Healthy Subjects SLE patients
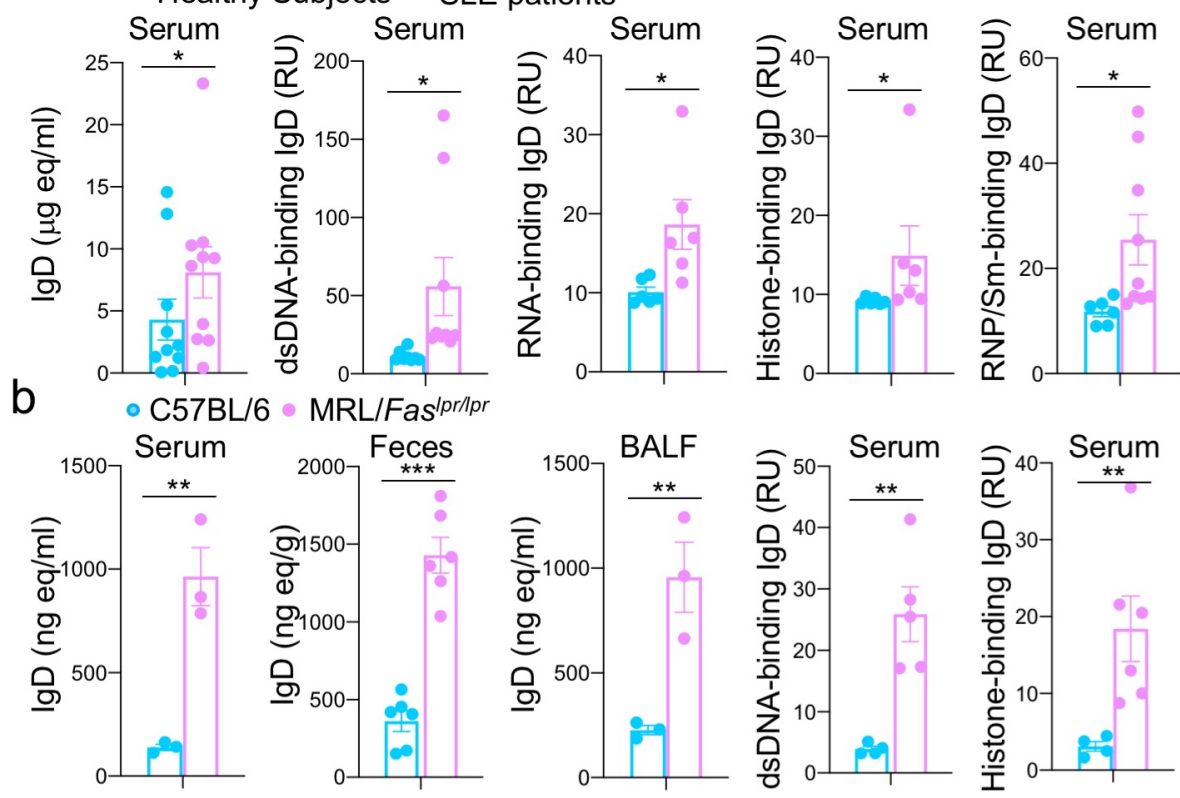

d

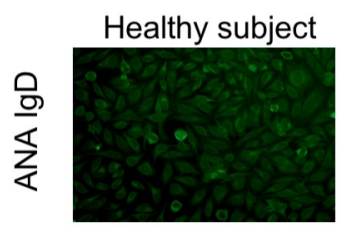

f
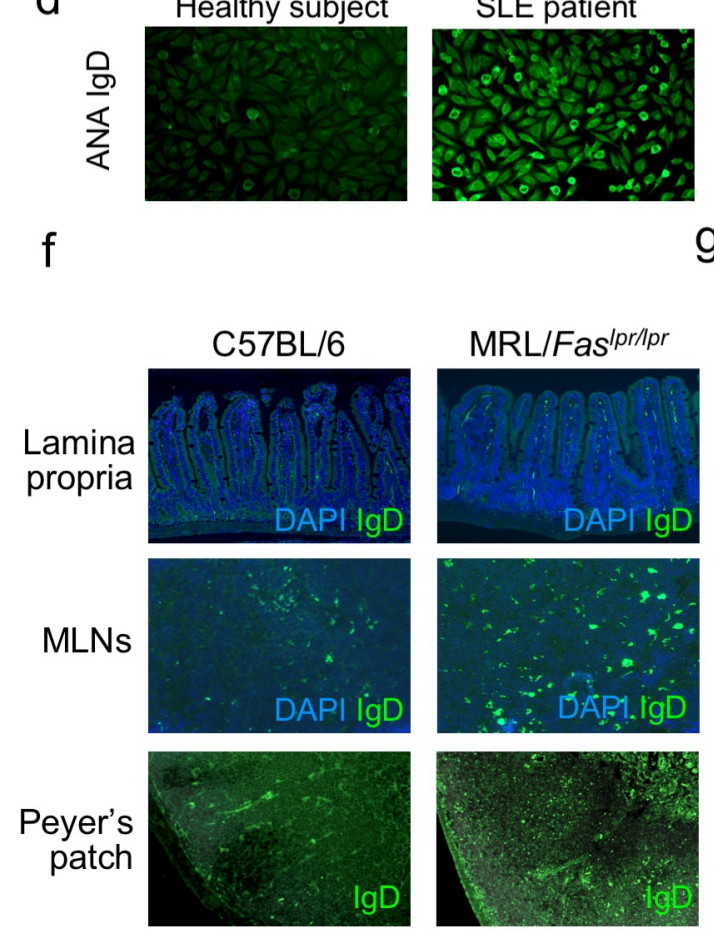

g C57BL/6 MRL//pr C57BL/6 MRL//prC57BL/6 MRL//pr

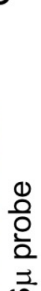

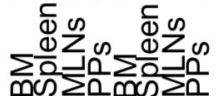
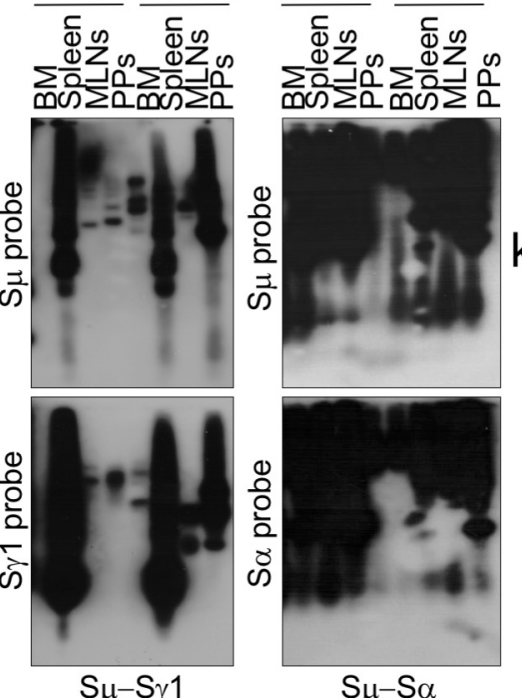

$S \mu-\sigma \delta$
C

Serum

Feces $(\mu \mathrm{g})$

$\operatorname{BALF}(\mu l)$

ำ $6030 \%$

C57BL/6 $\bullet \bullet \bullet \bullet$

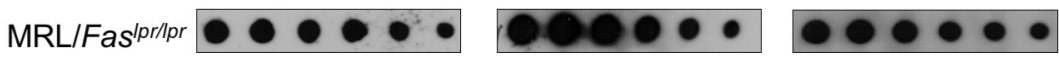

MLNs

C57BL/6

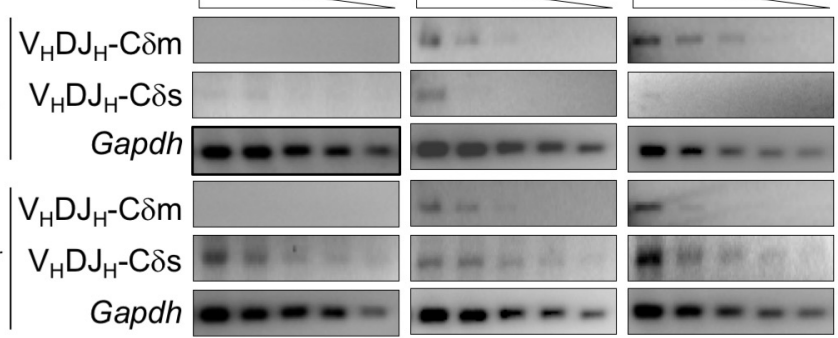

e
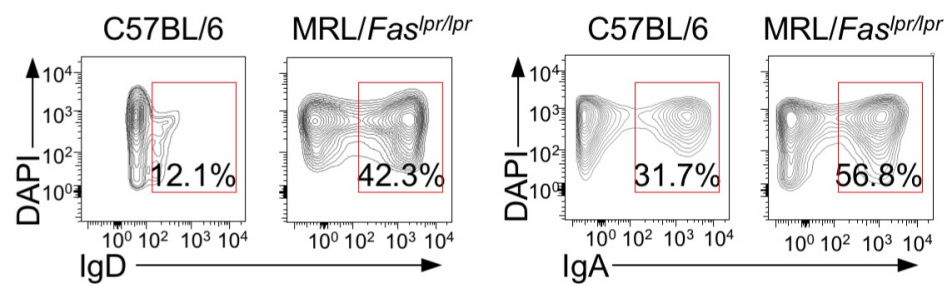

$\mathrm{h}$
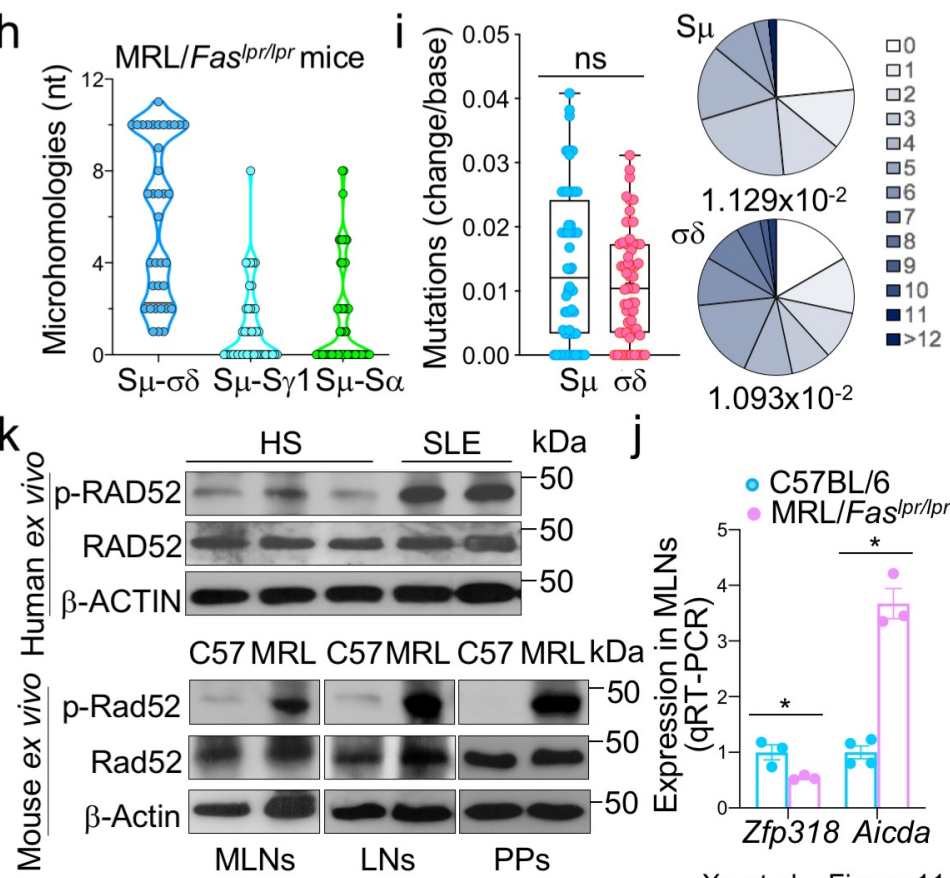

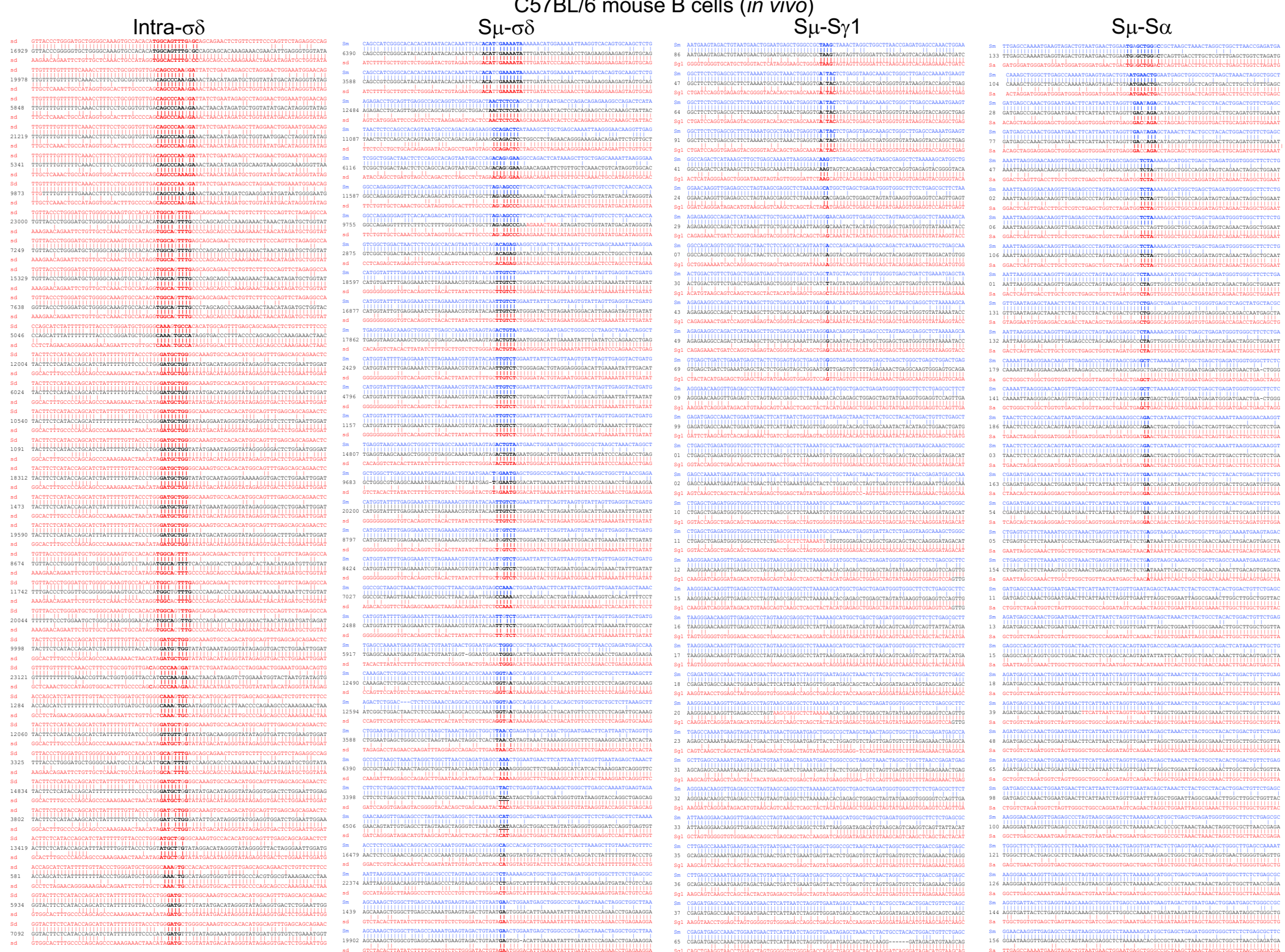

Extended Data Fig. 1 | $S \mu-\sigma \delta$ and intra- $\sigma \delta$ DNA recombination junctions in mouse spleen B cells contain high frequencies of microhomologies. The junctions of intra- $\sigma \delta, S \mu-\sigma \delta, S_{\mu}-S_{\gamma} 1$ and $S_{\mu}-S_{\alpha}$ recombinant DNAs from spleen B cells of an OVA-immunized C57BL/6 mouse were amplified and sequenced using MiSeq system. Thirty-two representative junction sequences from each group are shown. Each intra- $\sigma \delta$ recombinant DNA sequence (middle) is compared with the upstream (above) and the downstream (below) germline sd sequences. Each $S_{\mu}-\sigma \delta, S_{\mu}-S_{\gamma} 1$ and $S_{\mu-S} \alpha$ recombinant DNA sequence (middle) is compared with the germline $S \mu$ (above) and the $\sigma \delta, S \gamma 1$ or $S \alpha$ (below) sequence. Microhomologies (bold) were determined by identifying the longest regions at the junctions of perfect uninterrupted donor/acceptor identity or the longest overlap region at the S-S junction with no more than one mismatch on either side of the breakpoint. 


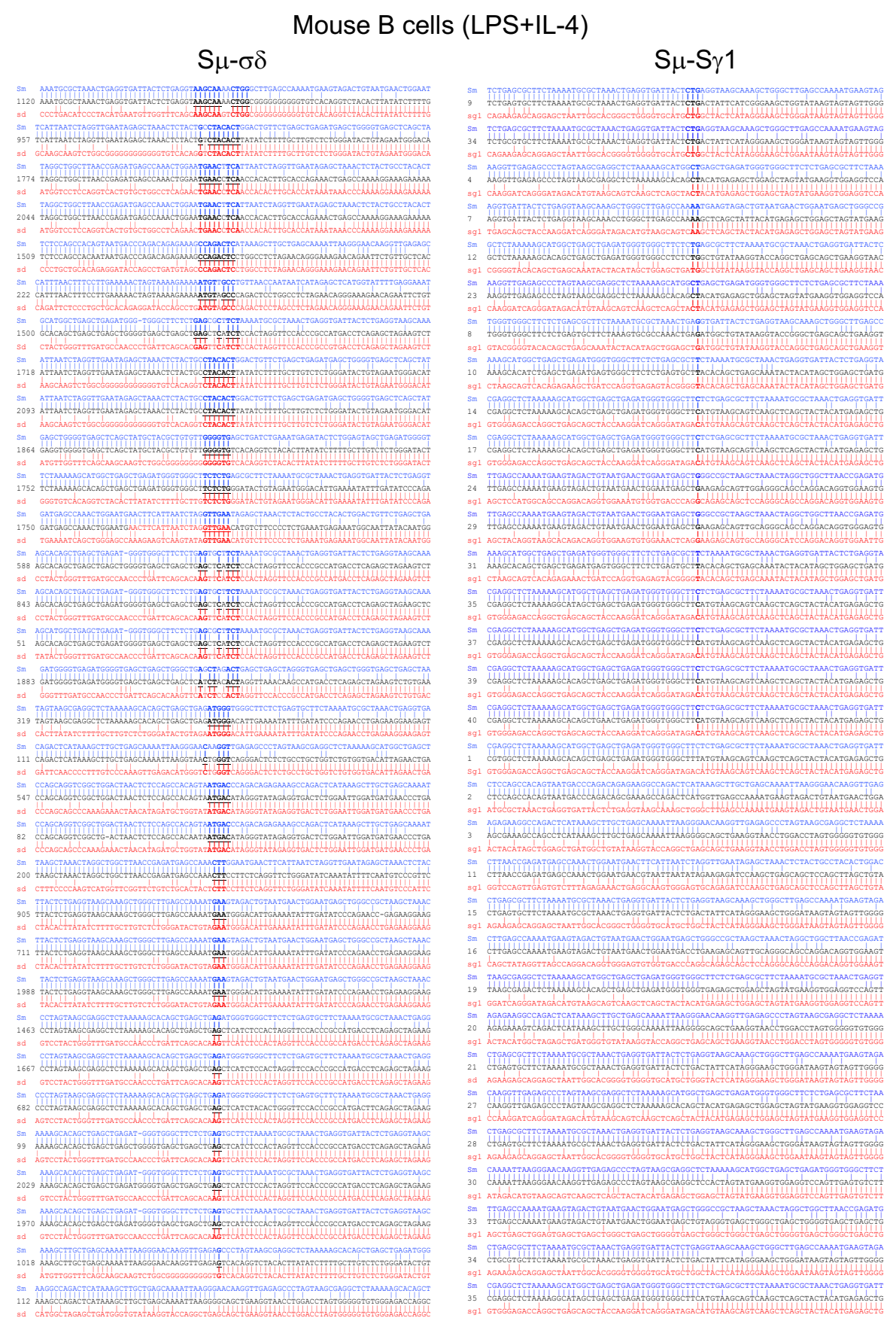

Extended Data Fig. 2 | Recombined $S \mu-\sigma \delta$ DNA junctions in mouse B cells stimulated in vitro to undergo IgD CSR contain high frequencies of microhomologies. C57BL/6 mouse B cells were stimulated with LPS plus IL-4 and cultured for $96 \mathrm{~h}$. The recombined $S \mu-\sigma \delta$ and $S \mu-S_{\gamma} 1$ DNA junctions were amplified and sequenced using MiSeq system. Thirty-two representative $S \mu-\sigma \delta$ and 32 representative $S \mu-S \gamma 1$ junction sequences are shown. Each recombinant DNA sequence (middle) is compared with the germline $S \mu$ (above, blue) and the $\sigma \delta$ or $S \gamma 1$ (below, red) sequence. Microhomologies (bold) were determined by identifying the longest region at the $S \mu-\sigma \delta$ or $S \mu-S \gamma 1$ junction of perfect uninterrupted donor/acceptor identity or the longest overlap region at the $\mathrm{S}-\mathrm{S}$ junction with no more than one mismatch on either side of the breakpoint. 


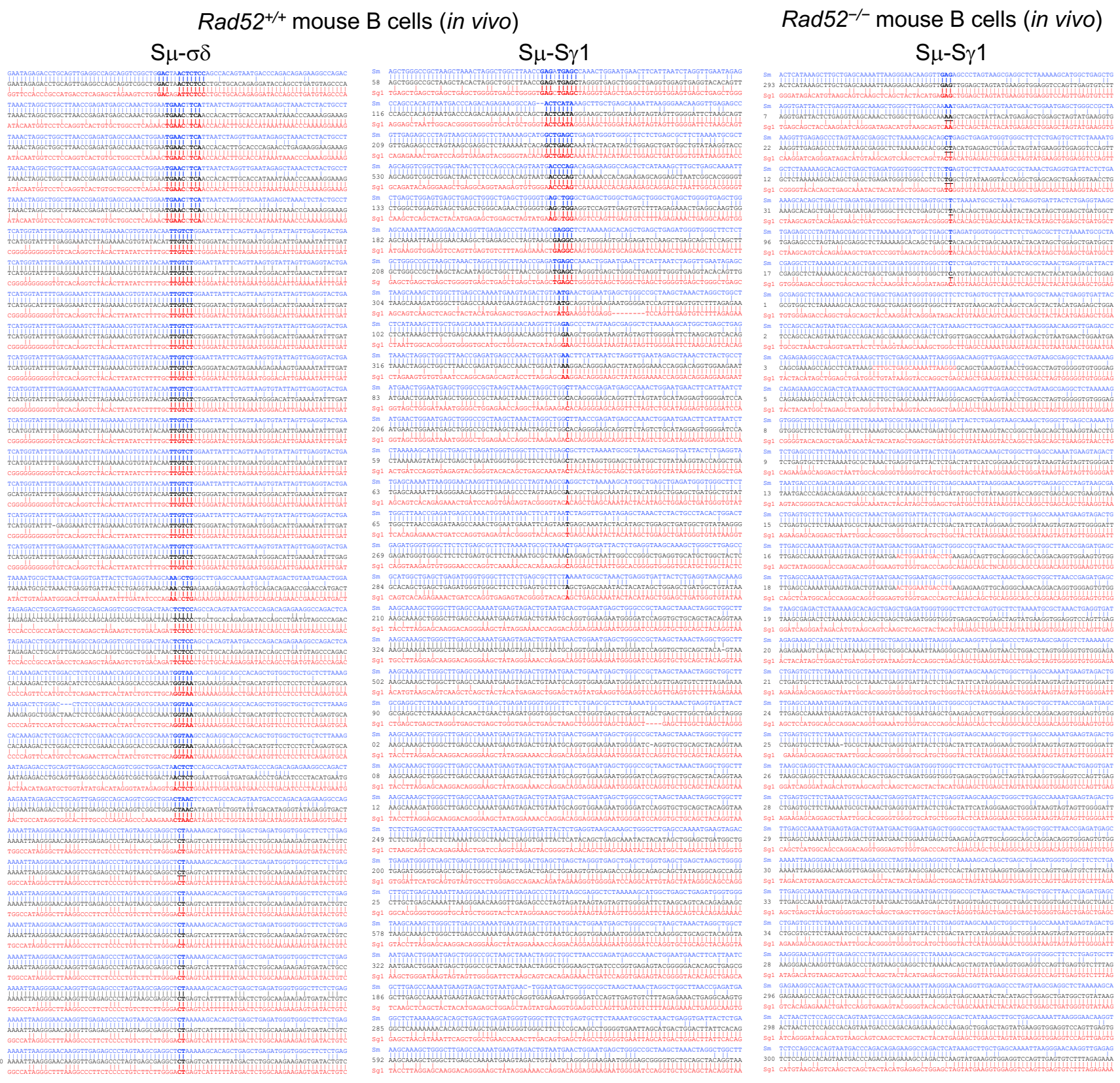

Extended Data Fig. $3 \mid$ Rad52 $2^{-\alpha}$ mice display no $S \mu-\sigma \delta$ recombination and even lower frequencies of microhomologies in $S_{\mu}$-S $\gamma 1$ junctions. The junctions of recombined $S_{\mu-\sigma \delta}$ and $S_{\mu}-S_{\gamma} 1$ DNAs from spleen B cells of OVA-immunized $\mathrm{Rad}_{52^{+/+}}$and $\mathrm{Rad} 52^{-/}$mice were amplified and sequenced using MiSeq system. No

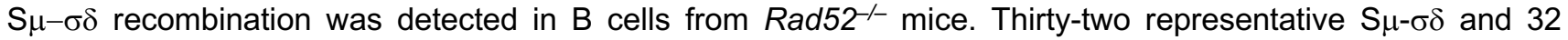
representative $S \mu-S \gamma 1$ junction sequences are shown. Each recombinant DNA sequence (middle) is compared with germline $S \mu$ (above, blue) and $\sigma \delta$ or $S_{\gamma} 1$ (below, red) sequences. Microhomologies (bold) were determined by identifying the longest region at the $S_{\mu-\sigma \delta}$ or $S_{\mu-S \gamma 1}$ junction of perfect uninterrupted donor/acceptor identity or the longest overlap region at the S-S junction with no more than one mismatch on either side of the breakpoint. 
Rad52 $^{+/+}$mouse B cells (in vivo)

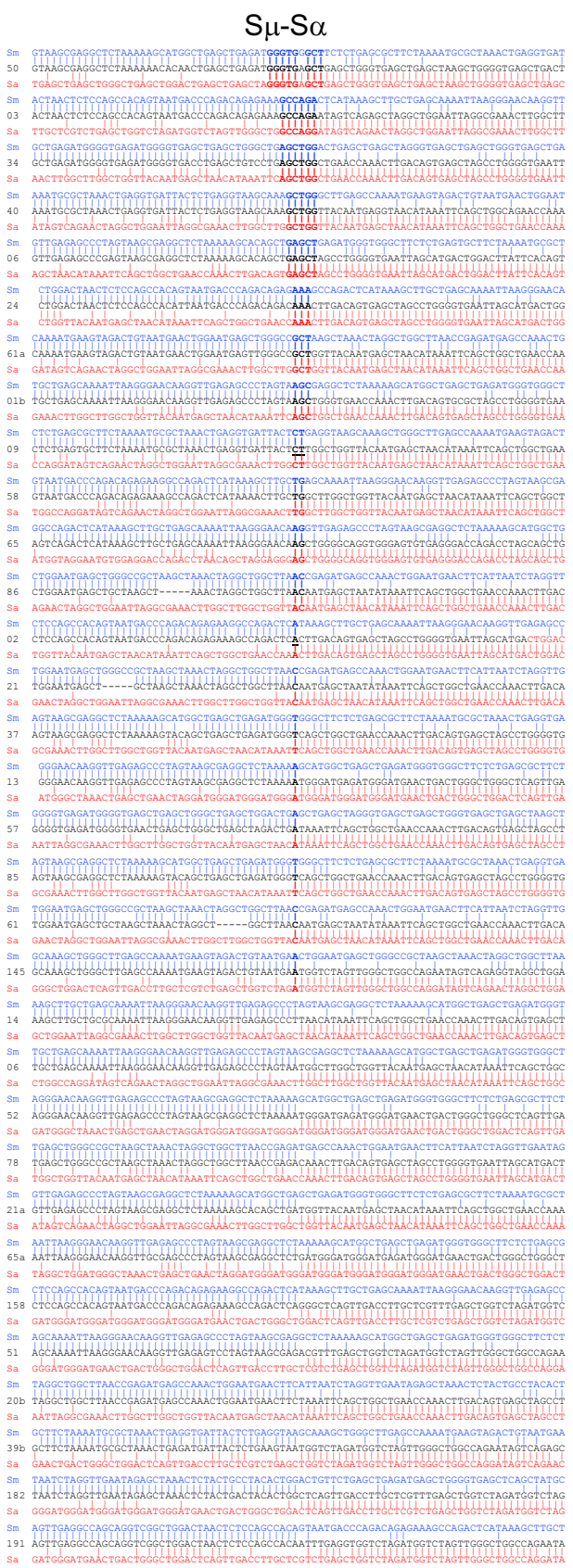

Rad52 ${ }^{-/-}$mouse B cells (in vivo)

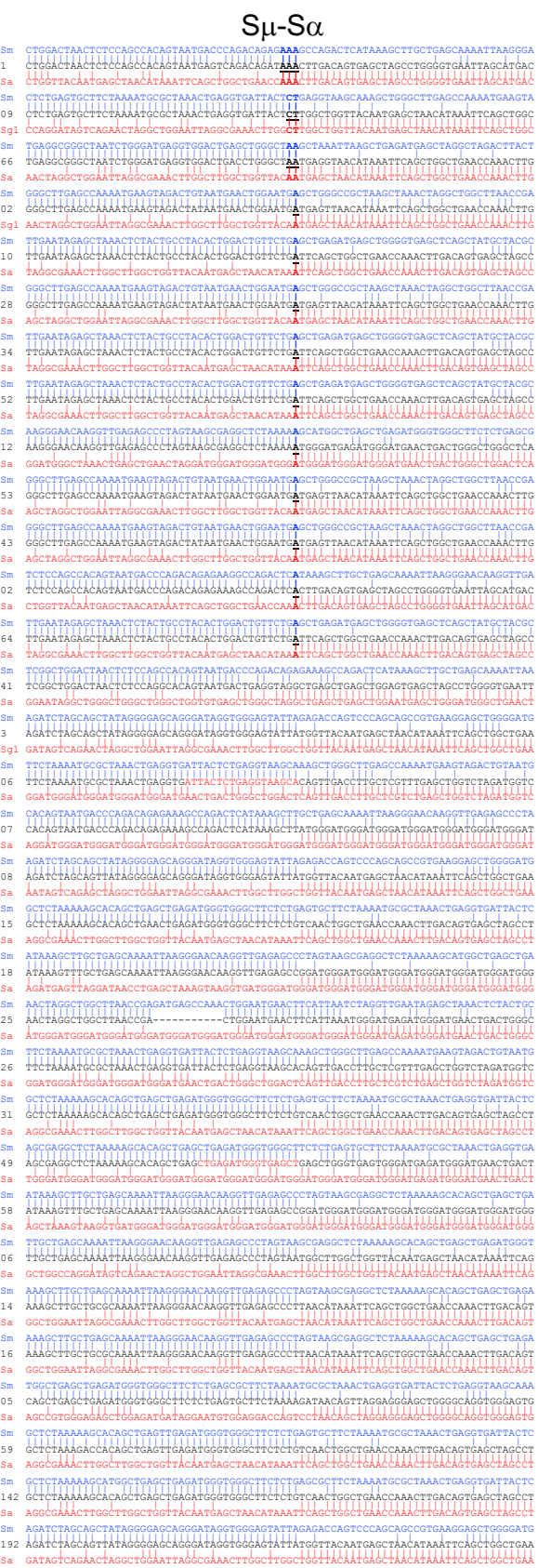

Extended Data Fig. 4 | Rad52 ${ }^{--}$mice display lower frequencies of microhomologies in B cell $\mathbf{S} \mu$-S $\alpha$ junctions. The junctions of recombined $S \mu-S \alpha$ DNAs from spleen B cells of OVA-immunized $R a d 52^{+/+}$and Rad52 $2^{-}$mice were amplified and sequenced using MiSeq system. Thirty-two representative junction

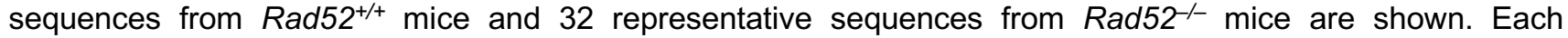
recombinant DNA sequence (middle) is compared with germline $S_{\mu}$ (above, blue) and $S \alpha$ (below, red) sequences. Microhomologies (bold) were determined by identifying the longest region at the $\mathrm{S} \mu$-S $\alpha$ junction of perfect uninterrupted donor/acceptor identity or the longest overlap region at the S-S junction with no more than one mismatch on either side of the breakpoint. 
Human blood B cells (in vitro, CpG+IL-2+IL-21)
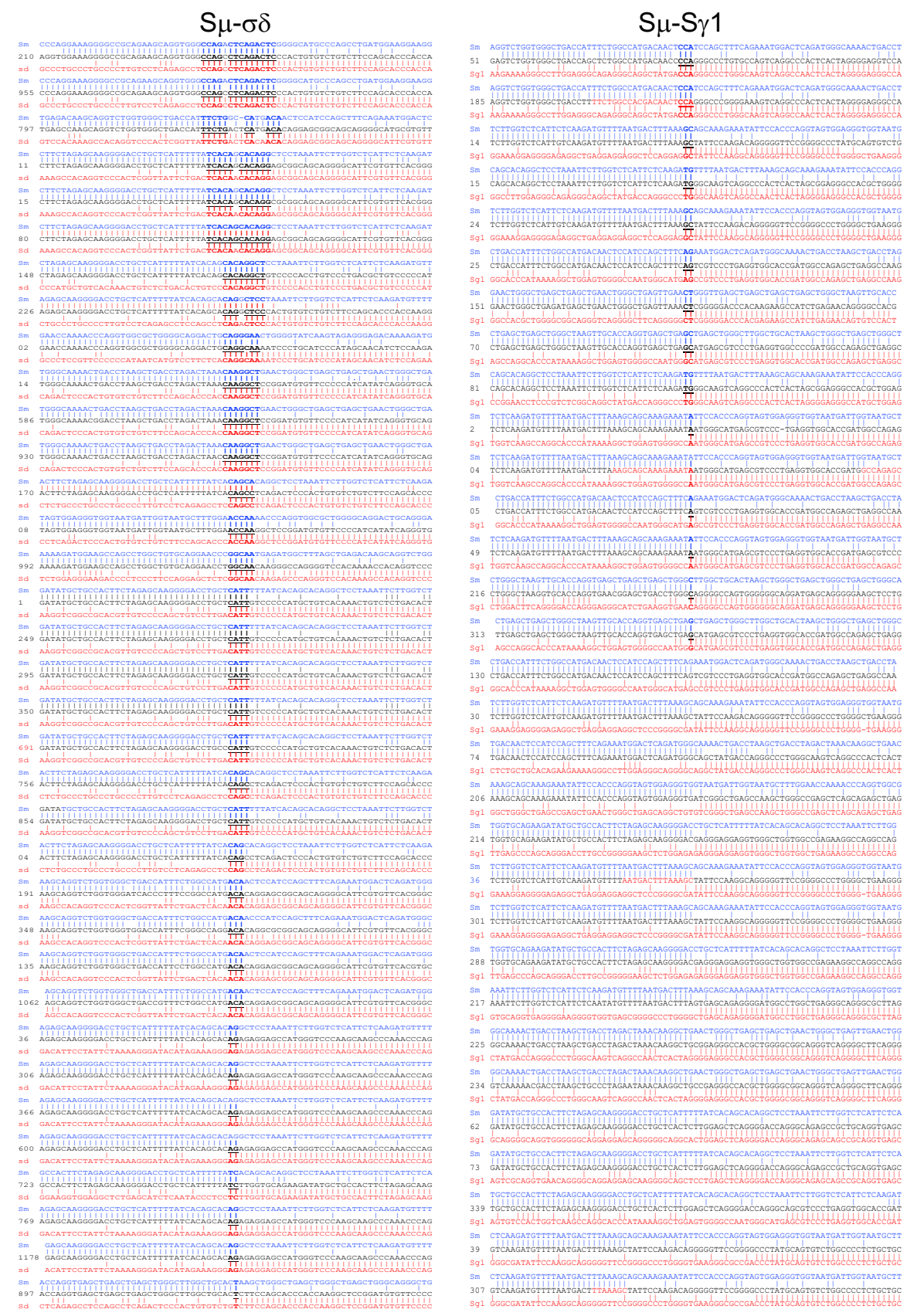

Extended Data Fig. 5 | Human B cells stimulated to undergo CSR to IgD and IgG1 in vitro display a higher frequency of microhomologies in $S \mu-\sigma \delta$ DNA junctions. Human naïve $B$ cells were stimulated with CpG plus IL-2 and IL-21 and cultured for $120 \mathrm{~h}$. The junctions of recombined $\mathrm{S} \mu-\sigma \delta$ and $S \mu-S \gamma 1$ DNAs were amplified and sequenced using MiSeq system. Thirty-two representative sequences from $S_{\mu-\sigma \delta}$ and $S_{\mu-S} 1$ junctions are shown. Each recombinant DNA sequence (middle) is compared with germline $S \mu$ (above, blue) and $\sigma \delta$ or $S \gamma 1$ (below, red) sequences. Microhomologies (bold) were determined by identifying the longest region at the $S \mu-\sigma \delta$ or $S \mu-S \gamma 1$ junction of perfect uninterrupted donor/acceptor identity or the longest overlap region at the S-S junction with no more than one mismatch on either side of the breakpoint. 
MRL/Fas ${ }^{\text {pr/lpr }}$ mouse B cells (in vivo)
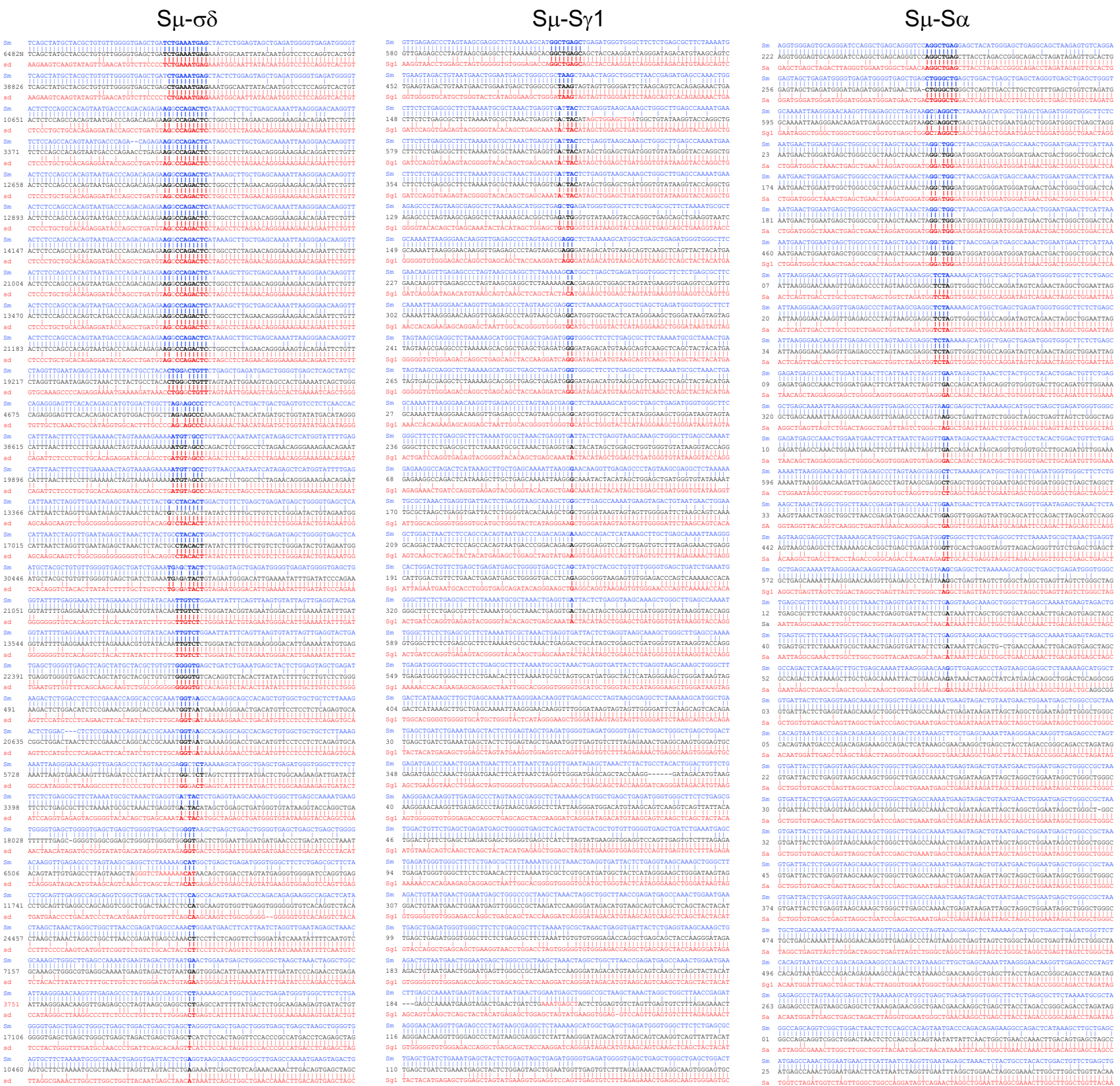

Extended Data Fig. 6 | Increased CSR to IgD associates with high frequency of microhomologies in recombined $S \mu-\sigma \delta, S \mu-S \gamma 1$ and $S \mu-S \alpha$ DNA junctions in autoimmune mice. The junctions of $S \mu-\sigma \delta, S \mu-$ $S \gamma 1$ and $S \mu-S \alpha$ recombinant DNAs from spleen B cells of MRL/Fas/pr/pr mice were amplified and sequenced by MiSeq. Thirty-two representative sequences from $S \mu-\sigma \delta, S \mu-S \gamma 1$ and $S \mu-S \alpha$ junctions are shown. Each recombinant DNA sequence (middle) is compared with the germline $S \mu$ (above, blue) and $\sigma \delta$, $S \gamma 1$ or $S \alpha$ (below, red) sequences. Microhomologies (bold) were determined by identifying the longest region at the $S \mu-$ $\sigma \delta, S_{\mu-S} 1$ or $S_{\mu-S \alpha}$ junction of perfect uninterrupted donor/acceptor identity or the longest overlap region at the S-S junction with no more than one mismatch on either side of the breakpoint. 
CSR to IgD or IgG3: DSBs resolved by Rad52 or KU70/Ku86 binding to DSB ends
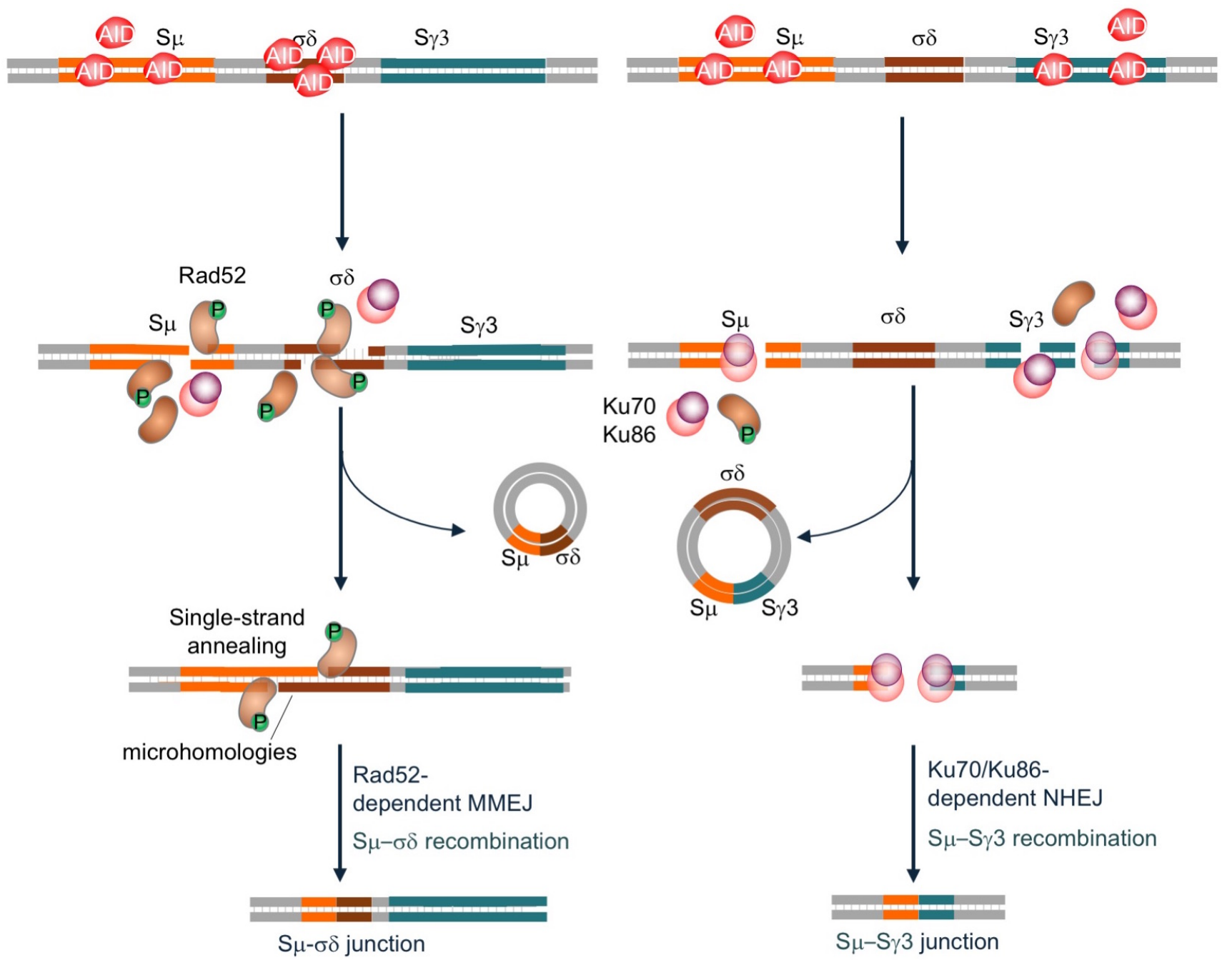

Extended Data Fig. 7 | Rad52 mediates $S \mu-\sigma \delta$ DNA recombination (CSR to IgD). CSR is initiated by AID-mediated generation of multiple DSBs in the targeted upstream $S \mu$ and downstream $S \gamma 3$ (shown here), $\mathrm{S} \alpha$ or $\mathrm{S} \varepsilon$ regions. Ku70/Ku86, a core NHEJ factor, binds to blunt DSB ends to synapse DSBs by NHEJ involving synapsis and long-range end-joining of $S$ region DSBs, leading to inter-S-S region recombination. This entails deletion of the intervening sequence between $S$ regions as an extrachromosomal circle and leads to CSR to IgG, IgA and IgE. Rad52, an HR element, which is phosphorylated upon CSR induction, binds preferentially to resected DSB single-strand overhangs and facilitates a (Ku70/Ku86-independent) microhomology-mediated A-EJ, which favors intra-S region recombination but can also mediate, particularly in the absence of the NHEJ pathway, inter-S-S CSR. In CSR to IgD, which involves short-range $S \mu-\sigma \delta$ recombination. B cells recruit the CSR machinery, including AID, to constitutively transcribed $S \mu$ and $\sigma \delta$ regions, and introduce DSBs into these regions. These DSB ends undergo abundant resection, yielding single-strand DNA overhangs. Upstream $S \mu$ and downstream $\sigma \delta$ DSB complementary overhangs are rejoined by Rad52 through MMEJ; Upstream $S_{\mu}$ and downstream $S_{\gamma 3}$ DSB blunt ends are rejoined by Ku70/Ku86 through NHEJ. 


\section{Supplemental Table 1. Primers used for this study.}

$$
\text { Forward primer }
$$

Human and mouse genes

\section{$\underline{\text { Human }}$}

ZFP318

5'-CCTGGGGAATCTGGGGGATA-3'

RAD52

5'-GTAGGGAGAGGCTCTGGACA-3'

KU70

KU86

5'-GAAGCAAAAGGCCCAAGGTG-3'

AICDA

5'-GCAGTGTCACCTCTGTTGGA-3'

$\beta$-ACTIN

5'-GTCACCTGGTTCACCTCCTG-3'

$\underline{\text { Mouse }}$

Zfp318

5'-AGAGCTACGAGCTGCCTGAC-3'

Rad52

5'-CGTAGTCGTCCCAATCTCCG-3'

Ku70

5'-CATTGGGACTCCCCAAACCA-3'

Ku 86

5'-CACCAAGCGGTCTCTGACTT-3'

Aicda

5'-AGGCCCAGGAAGCTCTATCA-3'

$\beta$-Actin

5'-AGAAAGTCACGCTGGAGACC-3'

Post-recombination transcripts

Mouse

$\mathrm{I} \mu-\mathrm{C} \mu$

5'-ACCTGGGAATGTATGGTTGTGGCTT-3'

$\mathrm{I} \mu-\mathrm{C} \delta$

5'-ACCTGGGAATGTATGGTTGTGGCTT-3'

$\mathrm{I} \mu-\mathrm{C} \gamma 1$

5'-ACCTGGGAATGTATGGTTGTGGCTT-3'

$\mathrm{I} \mu-\mathrm{C} \alpha$

5'-ACCTGGGAATGTATGGTTGTGGCTT-3'

$\mathrm{I} \mu-\mathrm{C} \varepsilon$

5'-ACCTGGGAATGTATGGTTGTGGCTT-3'

Secreted and transmembrane forms of $\operatorname{IgM}$ and $\operatorname{IgD}$

Human

$V_{H} D J_{H^{-}} C \mu m$

5'-GACACGGCYGTRTATTACTGTGCG-3'

$V_{H} D J_{H^{-}} C \mu s$

5'-GACACGGCYGTRTATTACTGTGCG-3'

$V_{H} D J_{H^{-}} C \delta m$

5'-GACACGGCYGTRTATTACTGTGCG-3'

$V_{H} D J_{H^{-}} C \delta s$

5'-GACACGGCYGTRTATTACTGTGCG-3'

$\underline{\text { Mouse }}$

$V_{H} D J_{H^{-}} C \mu m$

5'-GCCTGACATCTGAGGACTCTGC-3'

$V_{H} D J_{H^{-}} C \mu s$

$V_{H} D J_{H^{-}} C \delta m$

$V_{H} D J_{H^{-}} C \delta s$

5'-GCCTGACATCTGAGGACTCTGC-3'

5'-GCCTGACATCTGAGGACTCTGC-3'

5'-GCCTGACATCTGAGGACTCTGC-3'

$\underline{\mathrm{S}-\mathrm{S} \text { recombination }}$

$\underline{\text { Human }}$

$\mathrm{S} \mu-\sigma \delta$

First round

5'-TACCCTCCTCTTGGTGCAGA-3'

Second round

$\mathrm{S} \mu$ probe

$\sigma \delta$ probe

$\mathrm{S} \mu-\mathrm{S} \gamma 1$

First round

Second round

5'-TACCCTCCTCTTGGTGCAGA-3'
Reverse primer

5'-GCGGGATCGGAGGAATTACA-3'

5'-GCAGGTGCTTAGGACCAAGT-3'

5'-AGCAGCTCCTGCTTCTTCAG-3'

5'-GCTCGGATGCAGTCTATGCT-3'

5'-CTTGCGGTCCTCACAGAAGT-3'

5'-AGCACTGTGTTGGCGTACAG-3'

5'-TGGAATGGACACCCGAACAG-3'

5'-GCGAGTCTCCATCTGTTCCC-3'

5'-AGAGAGGGCCTCAGGTAGTG-3'

5'-GCACTCTTGGATTCCCCACA-3'

5'-CTCCTCTTCACCACGTAGCA-3'

5'-ACCAGAGGCATACAGGGACA-3'

5'-GAAATGGTGCTGGGCAGGAA-3'

5'-GCACTCTGAGAGGAGGAACA-3'

5'-ATGGAGTTAGTTTGGGCAGCA-3'

5'-TAATCGTGAATCAGGCAG-3'

5'-ACAGGGCTTCAAGGGGTAGA-3'

5'-AGAGGCTCAGGAGGAAGAGG-3'

5'-CTGTGTCGGACATGACCAGG-3'

5'-CCACAAACGTGGACAGGGT-3'

5'-CATGGGGCCATGGTCTGTTACA-3'

5'-GCCTTCCTCCTCAGCATTCACCTC-3'

5'-CATGATCAGGGAGACATTGTACAG-3'

5'-ACACGAGTGTTGGATGGTGTTGAC-3'

5'-GGGCAGGACCATCAGGTTT-3'

5'-CTGGCCAGCGGAAGATCTCCTTCTT-3'

5'-AGGGCTGTTATCCTTTGGGTG-3'

5'-CCAGTGGGGCTTGGTATGTT-3'

5'-AGGGCTGTTATCCTTTGGGTG-3'

5'-AGTCAGCACAGTCCAGTGTCTCTAG-3'

5'-CATCGGTGCCACCTCAGGGACGCT-3' 


$\begin{array}{ll}\text { S } \mu \text { probe } & \text { 5'-CCCCAGCCCTTGTTAATGGA-3' } \\ \text { S } \gamma 1 \text { probe } & \text { 5'-CACTGGGGCTAAGGGGAAAG-3' } \\ \text { S } \mu \text {-S } \alpha 1 & \\ \text { First round } & \text { 5'-TACCCTCCTCTTGGTGCAGA-3' } \\ \text { Second round } & \text { 5'-TGCTGCCACTTCTAGAGCAA-3' } \\ \text { S } \mu \text { probe } & \text { 5'-CCCCAGCCCTTGTTAATGGA-3' } \\ \text { S } \alpha 1 \text { probe } & \text { 5'-CTCTCTGTGCTGGGTTCCTC-3' } \\ \text { Mouse } & \end{array}$

$\mathrm{S} \mu-\sigma \delta$

\section{First round}

Second round

$\mathrm{S} \mu$ probe

$\sigma \delta$ probe

$\mathrm{S} \mu-\mathrm{S} \gamma 1$

First round

Second round

$\mathrm{S} \mu$ probe

$\mathrm{S} \gamma 1$ probe

$\mathrm{S} \mu-\mathrm{S} \gamma 3$

First round

Second round

$\mathrm{S} \mu$ probe

$\mathrm{S} \gamma 3$ probe

$\mathrm{S} \mu-\mathrm{S} \alpha$

First round

Second round

$\mathrm{S} \mu$ probe

S $\alpha$ probe

$\mathrm{S} \mu-\mathrm{S} \varepsilon$

First round

Second round

$\mathrm{S} \mu$ probe

$\mathrm{S} \varepsilon$ probe

ChIP Assays

Mouse $\mathrm{S} \mu$

Mouse $\sigma \delta$

Mouse $\mathrm{S} \gamma 1$

Mouse S $\gamma 3$

Mouse $\mathrm{S} \alpha$
5'-GGGCTTCTAAGCCAGTCCAC-3'

5'-CTCTGGCCCTGCTTATTGTTG-3'

5'-CTGGGAATGTATGGTTGTGGC-3'

5'-CCCAGAACCTGAGAAGGAAG-3'

5'-GGGCTTCTAAGCCAGTCCAC-3'

5'-CTCTGGCCCTGCTTATTGTTG-3'

5'-CTGGGAATGTATGGTTGTGGC-3'

5'-GTGCCGACTTCAATGTGCTT-3'

5'-GGGCTTCTAAGCCAGTCCAC-3'

5'-CTCTGGCCCTGCTTATTGTTG-3'

5'-CTGGGAATGTATGGTTGTGGC-3'

5'-AAGCACAGGTGCAAGAGACT-3'

5'-GGGCTTCTAAGCCAGTCCAC-3'

5'-CTCTGGCCCTGCTTATTGTTG-3'

5'-CTGGGAATGTATGGTTGTGGC-3'

5'-ACCCAGTGATAATCGGCTGC-3'

5'-GGGCTTCTAAGCCAGTCCAC-3'

5'-CTCTGGCCCTGCTTATTGTTG-3'

5'-CTGGGAATGTATGGTTGTGGC-3'

5'-GGTGGGGTTGAGCTGAATGA-3'

5'-ACCGCAAATGGTAAGCCAGA-3'

5'-ATGCCAACCCTGATTCAGCA-3'

5'-AACCACAGAAGAGCAGGAGC-3'

5'-AGGGGACCTGGATAAGCCAT-3'

5'-CTGGGCTGGACTCAGTTGAC-3'
5'-CCAGTGGGGCTTGGTATGTT-3'

5'-GCCCCACTCCAGCCTTTTAT-3'

5'-CTTTCGCTCCAGGTCACACT-3'

5'-TACTGGAGGAACCCAGCACA-3'

5'-CCAGTGGGGCTTGGTATGTT-3'

5'-TGTAGTGCTTCACGTGGCAT-3'

5'-CCAATTACTAAACAGCCCAGGT-3'

5'-CAGCCCAGGTTTATCTTTTCA-3'

5'-TGACCCAGACAACGGTACTC-3'

5'-CAGCCCAGGTTTATCTTTTCA-3'

5'-GGACAGGACAGGACCAAACC-3'

5'-TAGAAGGCCGCTCTTTTGCA-3'

5'-TGACCCAGACAACGGTACTC-3'

5'-CCCATGTCCCCGACTCTCTA-3'

5'-CTTTGACAAGGCATCCCAGTGT-3'

5'-ACCAAGGGATAGACAGATGGGG-3'

5'-TGACCCAGACAACGGTACTC-3'

5'-ACCAAGGGATAGACAGATGGGG-3'

5'-CATCCAATTCTTGGACGGCG-3'

5'-CGGCGTTAGAGTCATGTTGC-3'

5'-TGACCCAGACAACGGTACTC-3'

5'-CGGCGTTAGAGTCATGTTGC -3'

5'-TCCACATGCCCAGGACATTC-3'

5'-TTCTCCTGAGAGAGGGGCTC-3'

5'-TGACCCAGACAACGGTACTC-3'

5'-ATTCCTGCTAGGCCCGATTG-3'

5'-TGTGAGTGACCCAGACAACG-3'

5'-AGGCTAGGAGTCTGGGCTAC-3'

5'-TACCCCGTACTCTCACCTGG-3'

5'-CCCCACTATGGTTGCTTGGT-3'

5'-AGTCCAGTCATGCTAATTCACC-3' 